
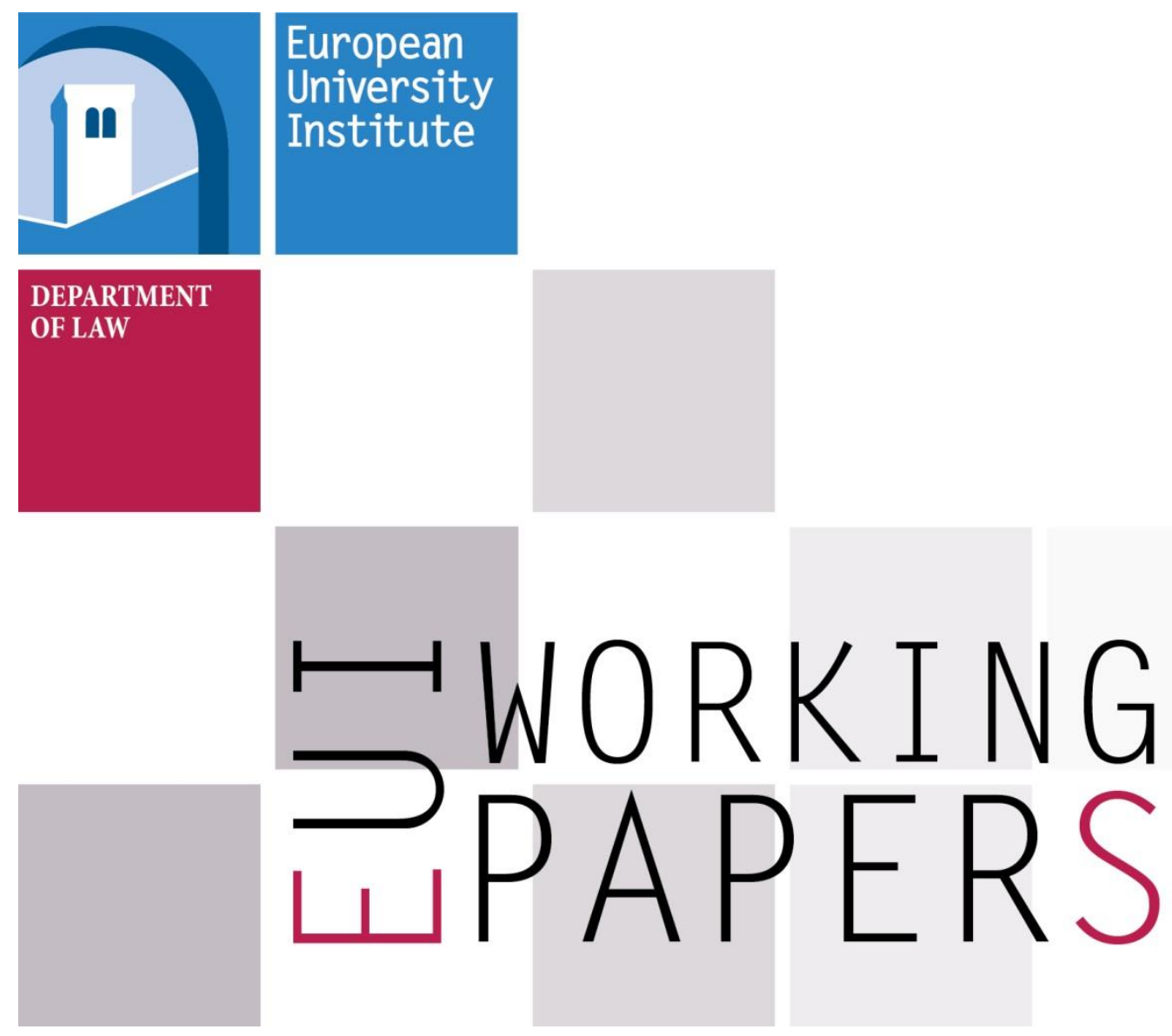

LAW 2020/17

Department of Law

\title{
COVID-19 and the social role of indicators: a preliminary assessment
}

David Nelken, Mathias Siems, Marta Infantino, Nathan Genicot, David Restrepo Amariles and John Harrington 
The Dickson Poon School of Law

Somerset House East Wing

Strand, London, WC2R 2LS

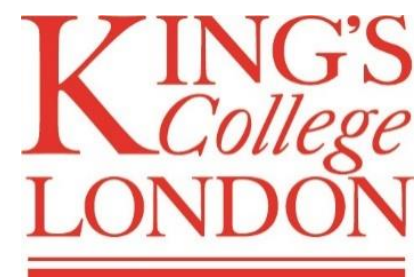

\title{
COVID-19 \\ and the social role of indicators: a preliminary assessment
}

\author{
David Nelken \\ Mathias Siems \\ Marta Infantino \\ Nathan Genicot \\ David Restrepo Amariles \\ John Harrington
}

King's College London Law School

Research Paper Forthcoming 
European University Institute

Department of Law

King's College London

Dickson Poon School of Law

COVID-19 AND THE SOCIAL ROLE OF INDICATORS: A PRELIMINARY ASSESSMENT

David Nelken, Mathias Siems, Marta Infantino, Nathan

Genicot, David Restrepo Amariles and John Harrington

EUI Working Paper LAW 2020/17

King's College London Law School Research Paper Forthcoming 
This text may be downloaded for personal research purposes only. Any additional reproduction for other purposes, whether in hard copy or electronically, requires the consent of the author(s), editor(s). If cited or quoted, reference should be made to the full name of the author(s), editor(s), the title, the working paper or other series, the year, and the publisher.

ISSN 1725-6739

(C) David Nelken, Mathias Siems, Marta Infantino, Nathan Genicot, David Restrepo Amariles and John Harrington 2020

Printed in Italy

European University Institute

Badia Fiesolana

I-50014 San Domenico di Fiesole (FI)

Italy

www.eui.eu

cadmus.eui.eu 


\begin{abstract}
Indicators play a key role in the COVID-19 crisis. Infection and casualty rates are used as proxies for the spread and effect of the virus. There are also indicators about health care capacities, government responses, as well as combined rankings. The six contributions of this working paper explore the social role of these indicators in the COVID-19 crisis from various perspectives. We asked the contributors to reflect on one or more of the following questions: how can these and other COVID-19-related indicators be classified (descriptive, explanatory, normative etc.)? What can the prior debates about the strengths and weaknesses of indicators add to the discussion and uses of indicators in the current pandemic? Conversely, what can the way these indicators were made and used add to the academic discussion on indicators? How far do these indicators compare things that are comparable, in particular in a crosscountry context? What are the advantages and dis-advantages (or uses and abuses) of these indicators? How far do (and should) these indicators guide social interventions and change behaviour? What is the role of law in terms of allowing, restricting or incorporating such indicators? What is the role of technology in this field? What are the relevant ethical considerations?
\end{abstract}

\title{
Keywords
}

COVID-19, COVID-19 infection rates, COVID-19 contact tracing apps, health data, governance indicators, global social indicators, global governance, sovereignty, comparative law 
Editor contact details:

David Nelken

Law Department

King's College London

david.nelken@kcl.ac.uk

\section{Mathias Siems}

Law Department

European University Institute

mathias.siems@eui.eu 


\section{Table of contents}

ABSTRACT.

KEYWORDS

TABLE OF CONTENTS

DAVID NELKEN AND MATHIAS SIEMS: INTRODUCTORY REMARKS

MARTA INFANTINO: GLOBAL NUMBERS IN THE PANDEMICS: THE SPREAD OF INDICATORS AND

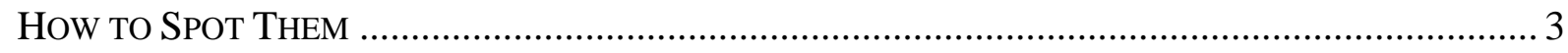

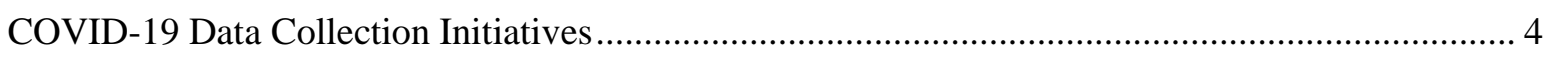

(i) The high level of simplification to which data are subject ................................................... 9

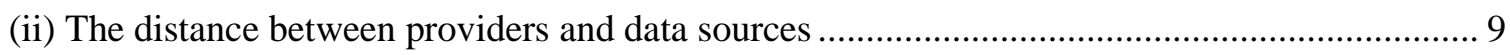

iii) The distance between the expertise of providers and what is measured................................... 9

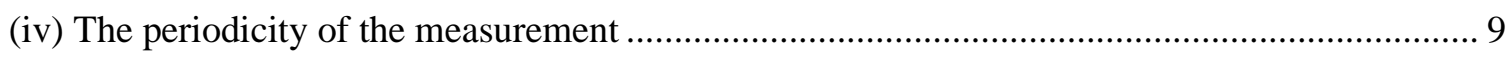

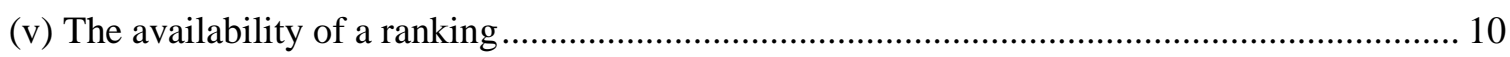

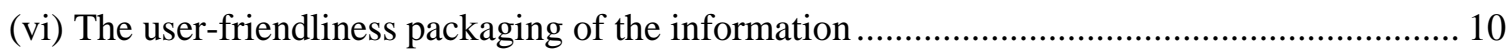

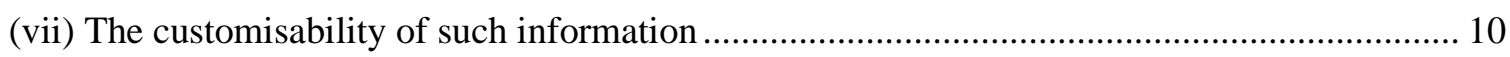

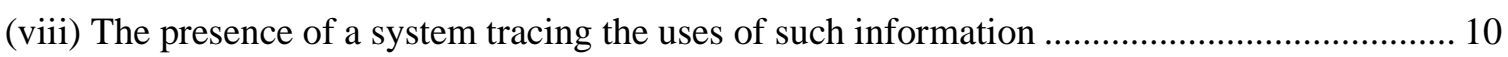

DAVID NELKEN: COVID RANKINGS: BETWEEN COMPARISON AND COMMENSURATION ........... 12

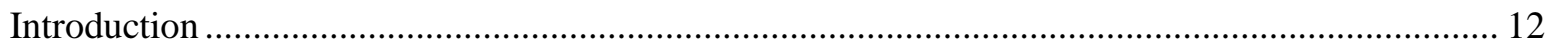

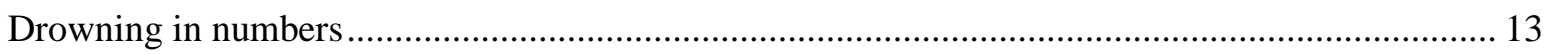

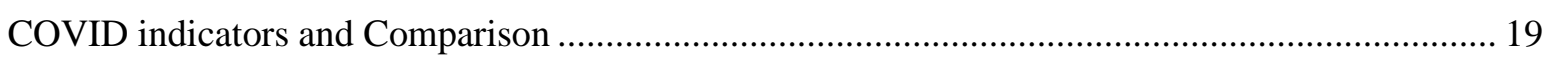

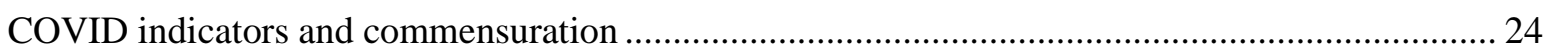

Nathan Genicot: Health Data For Global Monitoring of The COVID-19 PANDEMIC HISTORICAL BACKGROUND AND PRELIMINARY ANALYSIS ...................................................... 30

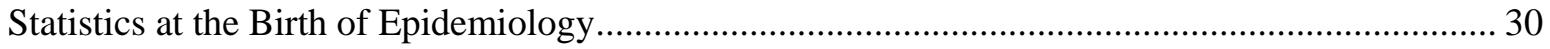

Data collection for audit and surveillance purposes ........................................................................ 32

The Global Management of Health Data during the COVID-19 Crisis ............................................. 34

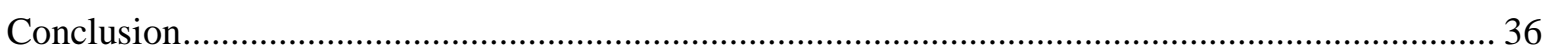


DAVID RESTREPO AMARILES: TOWARDS COMPUTATIONAL INDICATORS: INTERNET OF THINGS, DATA ANALYTICS AND ENCODING IN COVID-19 CONTACT TRACING APPS ........................... 37

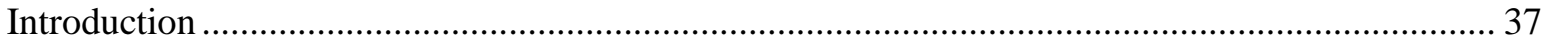

Section I: Technology-Charged Data in COVID-19 Contact Tracing Apps ..................................... 38

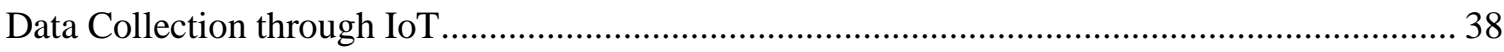

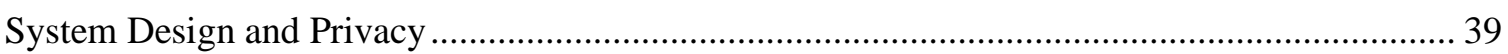

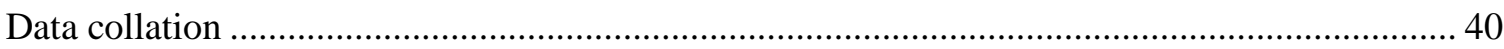

Section II: Computational indicators, Data Analysis and Social Graphs ........................................ 41

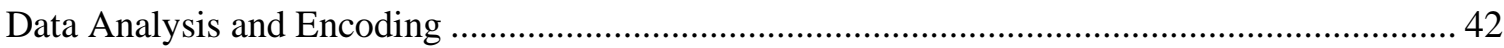

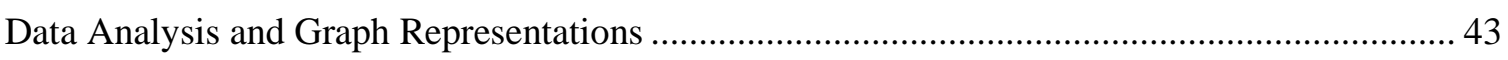

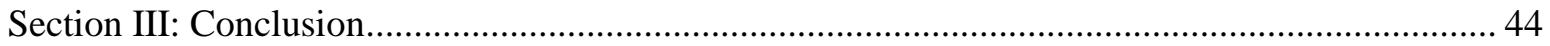

JOHN HARRINGTON: INDICATORS, SECURITY, AND SOVEREIGNTY - DURING COVID-19 IN THE

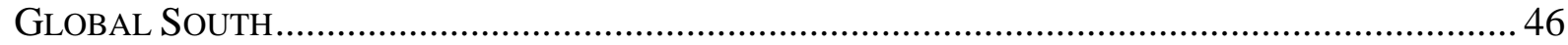

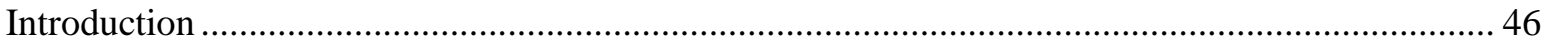

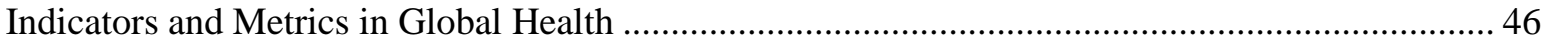

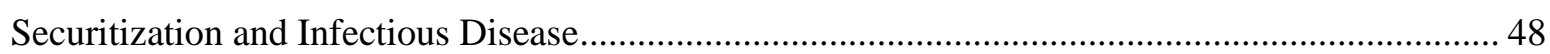

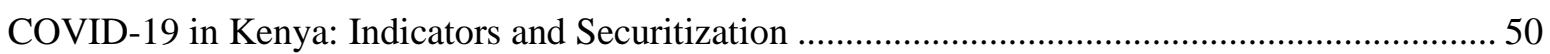

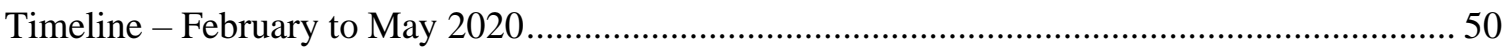

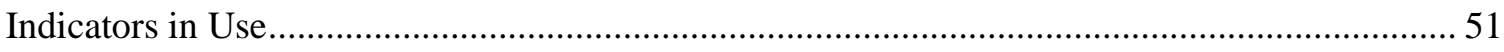

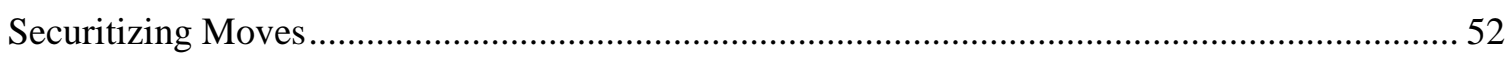

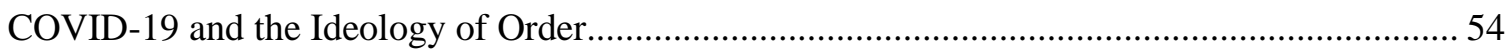

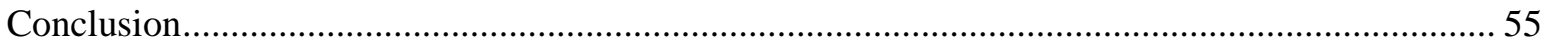

MATHIAS SIEMS: MAPPING THE CAUSAL RELATIONSHIPS BETWEen INDICATORS IN THE COVID-

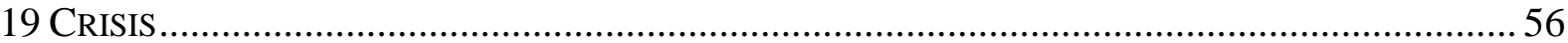

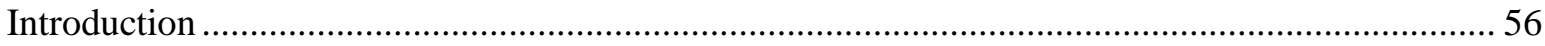

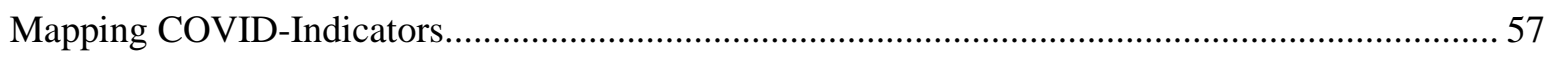

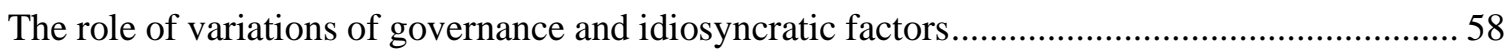

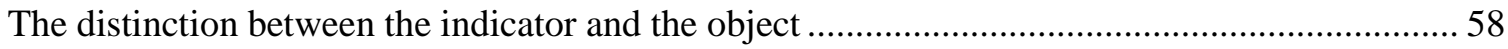

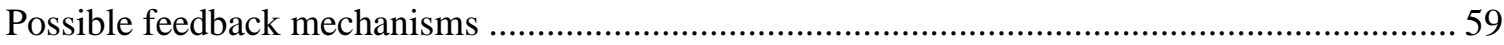

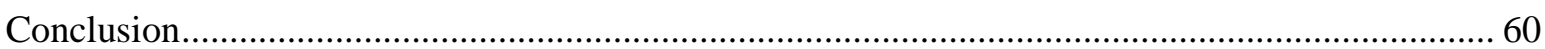




\section{Introductory Remarks}

\section{David Nelken* and Mathias Siems**}

Recent years have seen a large body of literature on topics such as 'The Power of Global Performance Indicators', 'The Quiet Power of Indicators', 'Indicators in Global Governance', 'Indicators as Political Spaces' and 'Global Law and Indicators'. 'This literature reflects the proliferation of indicators in many fields of life. Indicators also play a key role in the COVID-19 crisis. Infection and casualty rates are used as proxies for the spread and effect of the virus by governments and newspapers, but also the World Health Organisation (WHO). ${ }^{2}$ There are also indicators about the health care capacities of countries (including number of hospital beds), government responses (for example, a stringency index ${ }^{3}$ ), as well as combined ranked indicators (such as the Deep Knowledge Group's safety indicators ${ }^{4}$ ).

This working paper aims to fill a gap in the literature by exploring the social role of these indicators in the COVID-19 crisis. We asked the contributors to this working paper to reflect on one or more of the following questions:

1. How can these and other COVID-19-related indicators be classified (descriptive, explanatory, normative etc.)?

2. What can the prior debates about the strengths and weaknesses of indicators add to the discussion and uses of indicators in the COVID-19-pandemic? Conversely, what can the way these indicators were made and used add to the academic discussion on indicators?

3. How far do these indicators compare things that are comparable, in particular in a cross-country context?

4. What are the advantages and disadvantages (or uses and abuses) of these indicators?

5. How far do (and should) these indicators guide social interventions and change behaviour?

6. What is the role of law in terms of allowing, restricting or incorporating such indicators?

7. What is the role of technology in this field?

8. What are the relevant ethical considerations?

\footnotetext{
* David Nelken, King’s College London (david.nelken@kcl.ac.uk).

** Mathias Siems, European University Institute (mathias.siems@eui.eu).

${ }^{1}$ Judith G. Kelley and Beth A. Simmons eds., The Power of Global Performance Indicators (Cambridge: Cambridge University Press, 2020); Sally Engle Merry, Kevin E. Davis \& Benedict Kingsbury (eds.), The Quiet Power of Indicators: Measuring Governance, Corruption, and Rule of Law (Cambridge University Press 2015); Debora Valentina Malito, Gaby Umbach, and Nehal Bhuta eds., The Palgrave Handbook of Indicators in Global Governance (Basingstoke: Palgrave, 2018); 'Indicators as Political Spaces' Special Issue of International Organization Law Review (vol. 12, issue 1, 2015), 'Global Law and Indicators', special issue of The Journal of Legal Pluralism and Unofficial Law (vol. 47, issue 1, 2015). We also contributed to this debate: 'Global Social Indicators: Constructing Transnational Legitimacy', special issue of International Journal of Law in Context (vol. 13, issue 4, 2017).

2 'WHO Coronavirus Disease (COVID-19) Dashboard' (WHO) <https://covid19.who.int/>.

3 'Coronavirus Government Response Tracker' (University of Oxford) <https://www.bsg.ox.ac.uk/research/researchprojects/coronavirus-government-response-tracker>.

4 ‘COVID-19 Regional Safety Assessment' (Deep Knowledge Group) <https://www.dkv.global/covid-safety-assessment200-regions>.
} 
The subsequent contributions of this working paper can be divided under two broad categories:

Three of them present conceptual and/or historical perspectives: (i) Marta Infantino, University of Trieste: 'Global Numbers in the Pandemics: The Spread of Indicators and How to Spot Them'; (ii) David Nelken, King's College London: 'COVID Rankings: Between Comparison and Commensuration'; (iii) Nathan Genicot, Université Libre de Bruxelles: 'Health Data for Global Monitoring of the COVID-19 Pandemic - Historical Background and Preliminary Analysis'

The other three concern applied and/or empirical perspectives: (iv) David Restrepo Amariles, HEC: 'Towards Computational Indicators: IoT, Data Analytics and Encoding in COVID-19 Contact Tracing Apps'; (v) John Harrington, Cardiff University: 'Indicators, Security, and Sovereignty During COVID19 in the Global South'; (vi) Mathias Siems, EUI and Durham University: 'Mapping the Causal Relationships Between Indicators in the COVID-19 Crisis'

We hope that these contributions will stimulate the debate about COVID-19 and the social role of indicators. In this respect, we also want to note the preliminary nature of this working paper given the ongoing nature of the pandemic and the ongoing use of the indicators discussed here. ${ }^{5}$ Therefore, any comments to this working paper are also very welcome!

\footnotetext{
${ }^{5}$ The authors of this working paper will elaborate on the ideas expressed here in a more extensive manner in a special issue of the International Journal of Law in Context 2021.
} 


\section{Global Numbers in the Pandemics: The Spread of Indicators and How to Spot Them}

\section{Marta Infantino*}

The COVID-19 pandemic has dramatically shaken a great deal of our assumptions and beliefs. Yet it has also confirmed, in no less dramatic terms, many trends that have long pre-existed. Among these is the fact that we are living in an increasingly globalized and data-driven society, yet we lack reliable global data on a variety of issues. Instead, we have a wide array of national information providers collecting local data with different means and purposes, and a few concerned actors gathering such information and repackaging it into numerical representations of the globe (with varying degrees of accuracy, objectivity and transparency). This global knowledge is questionable, insofar as it suffers from a number of weaknesses surrounding the collection, interpretation, and treatment of masses of largely inhomogeneous data. This being said, some information is less suitable to provide a basis for decisionmaking than others.

This is typically the case for indicators. According to the standard definition, indicators are collections of 'rank-ordered data that purport [...] to represent the past or projected performance of different units'. ${ }^{1}$ The data are 'generated through a process that simplifies raw data about a complex social phenomenon'.2 Consequently, the data, 'in this simplified and processed form, are capable of being used to compare particular units of analysis (such as countries or institutions or corporations), synchronically or over time, and to evaluate their performance by reference to one or more standards' ${ }^{3}$ All numerical representations of the world provide contestable forms of knowledge, insofar as they stem from and reproduce specific ideologies and beliefs about the social worlds they refer. However, global indicators are more prone than other artefacts to suffer from problems of lacking expertise, legitimacy, impartiality or transparency. Therefore, identifying which global numbers are indicators and assessing their deficiencies is crucial in a pandemic as always.

This contribution focuses on ten initiatives producing global data about either the health situation or the reactions of the world's countries vis-à-vis the pandemic. ${ }^{4}$ It analyses who is making each initiative, the data collected and on the basis of what sources, the methodologies, format and design adopted, and the uses they serve.

Some of these initiatives are more health-focused. This is namely the case for:

- the World Health Organisation (WHO)'s 'COVID-2019 situation reports';

- the European Centre for Disease Prevention and Control (ECDC)'s 'COVID-19 situation update worldwide';

- the Johns Hopkins University (JHU)'s 'COVID-19 Dashboard';

- Worldometer (WoM)'s statistics on the 'Coronavirus Pandemic';

\footnotetext{
* Marta Infantino, University of Trieste (minfantino@units.it).

${ }^{1}$ Sally Engle Merry, Kevin Davis, Benedict Kingsbury, 'Introduction', in Kevin Davis et al. (eds.), Governance by Indicators. Global Power through Quantification and Rankings (Oxford University Press, 2012) 3, 6.

2 ibid.

${ }^{3}$ Merry et al (n 1).

${ }^{4}$ Such initiatives are only a few of the many COVID-19-related measurement initiatives that have multiplied since the January 2020. The present contribution deals exclusively with a selection of English-speaking enterprises ongoing in mid-July 2020 and that aim to either collect or produce quantitative worldwide data about the health situation and/or the related legal and policy measures relating to COVID-19. It does not consider numerical initiatives on issues other than health and policy measures and leaves out non-quantitative datasets and policy tracking tools.
} 
- Our-World-in-Data (OWiD)'s statistics on the 'Coronavirus Pandemic' and

- the Institute for Health Metrics and Evaluation (IHME)'s 'COVID-19 Projections'.

Law- and policy-oriented initiatives form the remainder of the analysis. More specifically, this is the case for:

- the Oxford University's 'COVID-19 Government Response Tracker' (Ox-CGRT);

- the Deep Knowledge Group (DKG)'s 'COVID-19 Rankings and Analytics';

- the Centre for Civil and Political Rights (CCPR)'s 'State of Emergency Data'; and

- Simon Porcher's 'Rigidity of Governments' Responses to COVID-19' dataset and index.

It might be tempting to assume that there is a neat divide between health-focused initiatives and lawand policy-oriented ones. However, comparative analysis of the aforementioned programs will show that boundaries between descriptive numerical representations and indicators are unclear. Reviewing these initiatives will also be useful in identifying and testing existing criteria from the literature that establish whether a numerical representation of the world can be considered an indicator. Moreover, this analysis will help to assess whether there are reasons to doubt the initiatives' utility as a basis for understanding and action-taking in the context of the COVID-19 crisis.

\section{COVID-19 Data Collection Initiatives}

The aforementioned data collection initiatives are led by different actors and provide different data in different forms. Since the end of January 2020, the WHO has daily published a worldwide report (in a PDF file) collecting data about confirmed cases of COVID-19 and deaths caused by it as received by the WHO from national authorities. ${ }^{5}$ Around the same time, the ECDC's Epidemic Intelligence team started producing daily tables and maps about confirmed cases and deaths on the basis of information gathered by the WHO, EU/EEA countries and by national authorities from other countries. ${ }^{6}$ These are then made available on its website. ${ }^{7}$ Both the WHO and the ECDC collect data in a very simple and non-stylised format (although the ECDC later added an interactive dashboard). The data provided are not easily comparable and reworkable. To do so, the data have to be extracted manually from the reports. Neither the WHO nor the ECDC track the use of their data by third parties. Nonetheless, in fact, their numbers are relied upon by a number of other global data providers.

On January 22, 2020, Lauren Gardner, a civil and systems engineering professor at JHU, launched the Johns Hopkins Coronavirus Resource Center and its COVID-19 Dashboard. ${ }^{8}$ The dashboard offers realtime information, complemented with user-friendly and interactive maps, reporting confirmed cases and deaths worldwide. Its data sources include reports from the WHO, the ECDC and local media. Users

\footnotetext{
${ }^{5}$ See 'Coronavirus disease (COVID-19) Weekly Epidemiologival Update and Weekly Operational Updated (WHO) <https://www.who.int/emergencies/diseases/novel-coronavirus-2019/situation-reports>.

${ }^{6}$ Cf. 'How ECDC collects and processes COVID-19 data' $(E C D C)<$ https://www.ecdc.europa.eu/en/geographicaldistribution-2019-ncov-cases; https://www.ecdc.europa.eu/en/COVID-19/data-collection>.

${ }^{7}$ ibid.

${ }^{8}$ See 'Covid-19 Dashboard by the Center for Systems Science and Engineering (CSSE)' (Johns Hopkins University) $<$ https://coronavirus.jhu.edu/map.html>. See also Ensheng Dong et al., 'An interactive web-based dashboard to track COVID-19 in real time' (2020) 20(5) Lancet Infectious Disease.
} 
can interact with the data and create their own maps and rankings. The JHU website keeps track of the number of visits and of media uses of the data. ${ }^{9}$

WoM is a website owned by Dadax, a digital media company also based in the United States. ${ }^{10}$ Since January 30 2020, WoM's team of developers has screened reports from national authorities and media news to update an online table with confirmed cases, deaths, recovered cases, tests performed, and cases/deaths/tests per 1 million population. The table looks quite simple, and all its columns can be easily re-ordered from the highest to the lowest value. Similar to the feature in JHU's dashboard, WoM's website keeps track of policy, scientific and media uses of its data. ${ }^{11}$.

Both the OWiD and the Ox-CGRT are Oxford-based. OWiD is a non-profit initiative led since 2011 by Max Roser, an economics researcher at the University of Oxford. ${ }^{12}$ In mid-February 2020, OWiD built a freely available and downloadable dataset on COVID-19 related confirmed cases, deaths, tests and mortality risk, integrated with customizable graphs and maps. The dataset is compiled on the basis of the WHO's data (initially) and (now) ECDC's data. ${ }^{13}$ OWiD keeps track of academic and media references to its data ${ }^{14}$. It also features a section on policy responses, which is actually sourced from the Ox-CGRT. The latter, launched in March 2020, consists of a set of individual countries' trackers and heat maps. Ox-CGRT has put together seventeen indicators of government responses to the pandemic (covering containment and closure policies, economic policies and health system policies). From the eight indicators on containment and closure policies, the Ox-CGRT team extracts its Stringency Index. ${ }^{15}$ To build its indicators and index, the results of which are customizable by users, the team, led by Thomas Hale (Professor of Public Policy at the Oxford University's Blavatnik School of Government ${ }^{16}$ ), relies on news articles and press releases governments. The website also offers a list of media and scientific citations of the project. ${ }^{17}$

On March 26 2020, the Institute for Health Metrics and Evaluation (IHME), a global health research centre at the University of Washington, launched its set of COVID-19 projections. ${ }^{18}$ A team lead by Christopher Murray, a Professor in Health Metrics, aggregates worldwide data from national authorities, the WHO, the JHU, the OWiD and other sources on deaths, confirmed and estimated cases, tests, social distancing and hospital resource use. The aim of this exercise is to describe national and sub-national

${ }^{9}$ Cf. 'COVID-19 Map FAQs (Johns Hopkins University) <https://systems.jhu.edu/research/public-health/2019-ncov-mapfaqs/> and 'News \& Resources: Coronavirus Resource Center' (Johns Hopkins University) <https://coronavirus.jhu.edu/news>.

10 'About' (Worldometer) <https://www.worldometers.info/about/>.

11 'Worldometer COVID-19 Data' (Worldometer) <https://www.worldometers.info/coronavirus/about/>.

12 'Our Team' (Our World in Data) <https://ourworldindata.org/team>.

${ }^{13}$ See 'Statistics and Research: Coronavirus Pandemic (COVID-19)' (Our World in Data) $<$ https://ourworldindata.org/coronavirus> and Hannah Ritchie, 'Coronavirus Source Data' (Our World in Data) $<$ https://ourworldindata.org/coronavirus-source-data>.

${ }^{14}$ Hannah Ritchie, 'Where our work on the Coronavirus pandemic is used in media and research' (Our World in Data) <https://ourworldindata.org/covid-media-coverage>.

${ }^{15}$ Cf. 'Coronavirus Government Response Tracker' (University of Oxford) <https://www.bsg.ox.ac.uk/research/researchprojects/coronavirus-government-response-tracker> and Anna Petherick et al., 'Variation in Government Responses to COVID-19' (2020) 29, Blavatnik School Working Paper < https://www.bsg.ox.ac.uk/sites/default/files/2020-05/BSGWP-2020-032-v5.00.pdf> 4, 5.

16 'Faculty and Researchers: Thomas Hale' (University of Oxford) <https://www.bsg.ox.ac.uk/people/thomas-hale>.

${ }^{17}$ See <https://www.bsg.ox.ac.uk/research/research-projects/coronavirus-government-response-tracker>, at the end of the page.

18 'History' $(I H M E)<$ http://www.healthdata.org/about/history>. Projections available at 'Covid-19 Projections: United States of America' $(I H M E)<$ https://covid19.healthdata.org/united-states-of-america>. 
trends and to formulate projections. Data are displayed through interactive and customisable graphs and maps. The IHME's website collects a list of references for its projections in the news. ${ }^{19}$

At the end of March 2020, DKG published its COVID-19 rankings and analytics. This included a collection of rankings focusing on countries' (and their regions') safety, risk, treatment efficiency, and governments' response. There are other rankings currently in preparation. ${ }^{20} \mathrm{DKG}$, a Hong-Kong based consortium of high-tech commercial and non-profit organisations, collects data from WHO, ECDC, JHU and WoM. It treats them with proprietary sources and techniques to produce its top-10s (the results of which are not re-workable by users). ${ }^{21}$ The DKG website also keeps track of the rankings' media uses. ${ }^{22}$

On April 1 2020, the CCPR (a human rights NGO based in Geneva ${ }^{23}$ ), released its 'State of Emergency' dataset. ${ }^{24}$ The dataset relies upon information on governments' acts and policies directly gathered by the CCPR team (mostly comprising lawyers) from national authorities and media. The dataset then classifies the world's countries according to eight variables (such as whether a country has declared a state of emergency, closed places of worship and suspended asylum claims). The variables are combined to produce the 'State of Emergency Index' which are displayed on a non-interactive coloured map. The CCPR does not keep track of third parties' uses of its dataset and map.

On May 7, 2020, Simon Porcher, a Professor of Public Management at the IAE Paris-Sorbonne Business School, published two papers presenting his freely-available dataset on government responses to the pandemic and the related 'Rigidity of Governments' Responses to COVID-19' index. ${ }^{25}$ On the basis of cross-country information reported by international organisations, Porcher built a customisable table listing countries' actions with regards to ten health-related policies (such as school closures, postponement of elections, public testing and enhanced surveillance). Data are then reworked to produce the final index. The scores in the index results are displayed on coloured maps that are available in his papers only and not on the project's website. Porter does not list third-parties' uses of his data.

The following table summarises the above information.

${ }^{19}$ See 'COVID-19 model FAQs' (IHME) <http://www.healthdata.org/covid/faqs>; 'COVID-19 Projections in the news' $(I H M E)<\mathrm{http} / /$ www.healthdata.org/covid/media>, as well as Christopher Murray et al., 'Forecasting the impact of the first wave of the COVID-19 pandemic on hospital demand and deaths for the USA and European Economic Area countries' (2020) COVID-19 SARS-CoV-2 preprints from medRxiv and bioRxiv, <https://doi.org/10.1101/2020.04.21.20074732>.

20 'Covid-19 Regional Safety Assessment' $(D K G)<$ https://www.dkv.global/covid>.

${ }^{21}$ See 'Disclaimer' $(D K G)<$ https://www.dkv.global/disclaimer>; 'Deep Knowledge Group COVID-19 Countries Ranking Methodology' (DKG) <https://www.dkv.global/methodology>; and 'COVID-19 Ranking Framing Methodology' $(D K G)$ $<$ http://analytics.dkv.global/data/ranking-framework-and-methodology.pdf >.

${ }^{22}$ See'Media Digest: Deep Knowledge Group's COVID-19 Assessments in Press'(DKG) <https://www.dkv.global/medianews>.

23 'About the Centre' $(C C P R)<\mathrm{http} / / /$ ccprcentre.org/about-ccpr>.

${ }^{24}$ See 'States of Emergenices in Response to the COVID-19 Pandemic' (CCPR) $<$ https://datastudio.google.com/reporting/1sHT8quopdfavCvSDk7t-zvqKISOLjiu0/page/dHMKB> and 'Tracking tool Impacts of States of emergenices on civil and political rights' $(C C P R)<\mathrm{http} / / / \mathrm{ccp}$ rcentre.org/ccprpages/tracking-toolimpact-of-states-of-emergencies-on-civil-and-political-rights>.

${ }^{25}$ See Simon Porcher, “'Contagion”: The determinants of governments' public health responses to COVID-19 all around the world' (2020) <https://halshs.archives-ouvertes.fr/halshs-02567286>; Simon Porcher, 'A novel dataset of governments' responses to COVID-19 all around the world' (2020) <https://halshs.archives-ouvertes.fr/halshs-02567283/document>. The dataset is available under a MIT licence at <https://github.com/simonporcher/COVID-19-Governments-Responses>. 
Table 1. General Features

\begin{tabular}{|c|c|c|c|c|c|c|c|}
\hline Provider & $\begin{array}{l}\text { Identity of } \\
\text { the Provider }\end{array}$ & $\begin{array}{l}\text { Seat of the } \\
\text { Provider }\end{array}$ & $\begin{array}{l}\text { Expertise of } \\
\text { the Provider }\end{array}$ & Data Offered & $\begin{array}{l}\text { Source of } \\
\text { the Data }\end{array}$ & $\begin{array}{l}\text { Form of } \\
\text { the Data }\end{array}$ & $\begin{array}{c}\text { Uses by } \\
\text { Other } \\
\text { Providers } \\
\end{array}$ \\
\hline WHO & $\begin{array}{l}\text { international } \\
\text { organisation }\end{array}$ & $\begin{array}{c}\text { Geneva } \\
\text { (Switzerland) }\end{array}$ & health & $\begin{array}{c}\text { confirmed cases; } \\
\text { deaths }\end{array}$ & $\begin{array}{c}\text { national } \\
\text { authorities }\end{array}$ & $\begin{array}{l}\text { daily } \\
\text { tables, } \\
\text { graphs and } \\
\text { maps }\end{array}$ & $\begin{array}{c}\text { used by } \\
\text { ECDC; } \\
\text { JHU; } \\
\text { IHME; } \\
\text { (formerly) } \\
\text { OWiD; } \\
\text { DKG }\end{array}$ \\
\hline ECDC & $\begin{array}{c}\text { international } \\
\text { organisation }\end{array}$ & $\begin{array}{c}\text { Solna } \\
\text { (Sweden) }\end{array}$ & epidemiology & $\begin{array}{c}\text { confirmed cases; } \\
\text { deaths }\end{array}$ & $\begin{array}{l}\text { national } \\
\text { authorities; } \\
\text { WHO }\end{array}$ & $\begin{array}{l}\text { daily } \\
\text { tables and } \\
\text { maps }\end{array}$ & $\begin{array}{c}\text { used by } \\
\text { JHU; } \\
\text { (currently) } \\
\text { OWiD; } \\
\text { DKG } \\
\end{array}$ \\
\hline JHU & university & $\begin{array}{l}\text { Baltimore } \\
\text { (MD, USA) }\end{array}$ & engineering & $\begin{array}{c}\text { confirmed cases; } \\
\text { deaths }\end{array}$ & $\begin{array}{l}\text { WHO; } \\
\text { ECDC; } \\
\text { media }\end{array}$ & $\begin{array}{l}\text { dashboard } \\
\text { and maps }\end{array}$ & $\begin{array}{l}\text { used by } \\
\text { IHME and } \\
\text { DKG }\end{array}$ \\
\hline WoM & $\begin{array}{l}\text { private } \\
\text { company }\end{array}$ & $\begin{array}{l}\text { unclear } \\
\text { (USA) }\end{array}$ & data analytics & $\begin{array}{l}\text { confirmed cases; } \\
\text { deaths; people } \\
\text { recovered; tests; } \\
\text { cases/deaths/tests/per } \\
1 \mathrm{M} \text { people }\end{array}$ & $\begin{array}{l}\text { national } \\
\text { authorities; } \\
\text { media }\end{array}$ & $\begin{array}{l}\text { reworkable } \\
\text { table with } \\
\text { rankings }\end{array}$ & $\begin{array}{l}\text { used by } \\
\text { DKG }\end{array}$ \\
\hline OWiD & university & $\begin{array}{l}\text { Oxford } \\
\text { (UK) }\end{array}$ & economy & $\begin{array}{l}\text { confirmed cases; } \\
\text { deaths; tests; } \\
\text { mortality risk }\end{array}$ & $\begin{array}{l}\text { WHO; } \\
\text { ECDC }\end{array}$ & $\begin{array}{c}\text { reworkable } \\
\text { dataset, } \\
\text { graphs and } \\
\text { maps } \\
\end{array}$ & $\begin{array}{l}\text { used by } \\
\text { IHME }\end{array}$ \\
\hline $\begin{array}{l}\text { Ox- } \\
\text { CGRT }\end{array}$ & university & $\begin{array}{l}\text { Oxford } \\
\text { (UK) }\end{array}$ & $\begin{array}{l}\text { political } \\
\text { science }\end{array}$ & $\begin{array}{l}\text { governments' } \\
\text { responses to the } \\
\text { pandemic }\end{array}$ & media & $\begin{array}{l}\text { reworkable } \\
\text { trackers } \\
\text { and maps } \\
\end{array}$ & $\begin{array}{l}\text { used by } \\
\text { OWiD }\end{array}$ \\
\hline IHME & university & $\begin{array}{c}\text { Seattle } \\
\text { (WA, USA) }\end{array}$ & $\begin{array}{l}\text { health } \\
\text { metrics }\end{array}$ & $\begin{array}{c}\text { confirmed and } \\
\text { estimated cases; } \\
\text { deaths; tests; social } \\
\text { distancing; hospital } \\
\text { resources; } \\
\text { projections }\end{array}$ & $\begin{array}{c}\text { national } \\
\text { authorities; } \\
\text { WHO; JHU; } \\
\text { OWiD }\end{array}$ & $\begin{array}{l}\text { reworkable } \\
\text { graphs and } \\
\text { maps }\end{array}$ & none \\
\hline DKG & $\begin{array}{c}\text { venture } \\
\text { capital group }\end{array}$ & $\begin{array}{l}\text { Hong-Kong } \\
\text { (PRC) }\end{array}$ & $\begin{array}{l}\text { medicine } \\
\text { analytics }\end{array}$ & $\begin{array}{c}\text { safety, risk, } \\
\text { treatment efficiency } \\
\text { and supportive } \\
\text { government }\end{array}$ & $\begin{array}{c}\text { WHO; } \\
\text { ECDC, } \\
\text { WoM; JHU }\end{array}$ & ranking & none \\
\hline CCPR & $\begin{array}{c}\text { non- } \\
\text { governmental } \\
\text { organisation }\end{array}$ & $\begin{array}{c}\text { Geneva } \\
\text { (Switzerland) }\end{array}$ & law & $\begin{array}{c}\text { impact of } \\
\text { governments' } \\
\text { measures on civil } \\
\text { and political rights }\end{array}$ & $\begin{array}{l}\text { national } \\
\text { authorities; } \\
\text { media }\end{array}$ & $\begin{array}{l}\text { table and } \\
\text { map }\end{array}$ & none \\
\hline Porcher & university & $\begin{array}{c}\text { Paris } \\
\text { (France) }\end{array}$ & $\begin{array}{c}\text { public } \\
\text { management }\end{array}$ & $\begin{array}{c}\text { rigidity of } \\
\text { governments' public } \\
\text { health responses }\end{array}$ & $\begin{array}{l}\text { international } \\
\text { organisations }\end{array}$ & $\begin{array}{l}\text { dataset and } \\
\text { map }\end{array}$ & none \\
\hline
\end{tabular}

Thus, we can see that actors involved in global data making are comprised of international organisations with health-related competency, non-governmental organisations, private companies dealing with data analytics and scholars from various fields. The list confirms many points that are well known in the literature on global numbers, such as that global data-makers are mostly located in the Western side of the world, and that the entry into the market of global data is quite simple for a wide range of potential data providers, no matter how little expertise they possess on the substance of what is measured.

One of the reasons for the lack of substantial barriers to entry into the market of global data is the derivative nature of information characterising such initiatives. Once an entity starts publishing its own data, it is easy for others to step in and rework the original data in a new format. This is made clear by the fate of WHO's and ECDC's numbers. The WHO and ECDC (the latter relying upon the former) act 
as collectors of data provided by national authorities. Their data are, in turn, relied upon and repackaged by the projects led by JHU, OWiD, IHME and DKG.

Further, the type of data gathered is also varied, from information on cases and deaths (the WHO, ECDC and JHU) to progressively more layered judgments about countries' safety and governments' responses (the Ox-CGRT, DKG's rankings, CCPR's and Porcher's indexes). No matter which type of data are treated, a number of problems affect their accuracy and comparability. This includes deficiencies in the availability of local data, differences in their gathering practices and interpretation, issues of oversimplification and decontextualization of the original data at the global level, and data providers' discretionary methodological choices in the manner in which data are treated. It is not by chance that many of the initiatives surveyed accompany their data with caveats and disclaimers about their possible inaccuracy and misguided uses. ${ }^{26}$

Which of these initiatives can qualify as indicators, and which of them are problematic? As reported above, the standard definition describes an indicator as 'a named collection of rank-ordered data' that 'purports to represent the past or projected performance of different units [...], simplifies raw data about a complex social phenomenon' and is used 'to compare particular units of analysis [...] and to evaluate their performance by reference to one or more standards' ${ }^{27}$ The definition captures many typical features, strengths and weaknesses of global indicators, such as their ability to simplify complex information and to express value judgments with numbers, their emphasis on the comparability of the measured units through time or space, and their tendency to rank the performance of the measured units in light of a more or less explicit standard. Several other typical (yet not necessarily present) features, strengths and weaknesses might be added. For example, global indicators are often produced by teams whose expertise is not clearly related to the substance of what is measured and who have only indirect access to the contexts and phenomena that are measured. They are usually made freely available on the web, with a fancy, catchy and easy-to-use format (accessible even by laymen), such as scores and rankings. Indicators tend to repeat their measurements with a short-time periodicity and keep track of their achievements, since both temporal recursivity and evidence of success are keys to assert their legitimacy and unlock their potential of nudging change.

Many of the characteristics mentioned - such as the internal comparability of the results, the on-line free availability, and the temporal periodicity - are common with other contemporary forms of numerical representations of the world, such as global statistics. However, the more of such features an initiative presents, the more it should be treated with the greatest caution. Relying upon previous literature on indicators ${ }^{28}$, we suggest that the following elements raise a presumption that a certain initiative has indicator-like features and thus its findings be handled sceptically: (i) the high level of simplification to which data are subject, (ii) the distance between providers and data sources, (iii) the distance between the expertise of providers and what is measured, (iv) the periodicity of the measurement, (v) the availability of a ranking, (vi) the user-friendliness packaging of the information, (vii) the customisability of such information, and (viii) the presence of a system tracing the uses of such information. ${ }^{29}$

\footnotetext{
${ }^{26}$ Caveats and warnings are displayed by the WHO, the ECDC, the JHU, the Ox-CGRT, the DKG and the CCPR. The websites of the WoM, OWiD, IHME and Porcher's dataset, by contrast, do not contain any disclaimer.

${ }^{27}$ Merry et al, (n 1).

${ }^{28}$ See for example, Marta Infantino, Numera et impera. Il diritto comparato e gli indicatori giuridici globali (FrancoAngeli, 2019).

${ }^{29}$ One might be tempted to infer that the identity of the data makers also matters, in the sense that actors other than international organizations more often than not produce indicators. Yet, experience from outside the realm of pandemic-related data makes it clear that the data maker's identity is not conclusive about the kind of effort it might engage in.
} 
(i) The high level of simplification to which data are subject

The harder it is to quantify what is being measured, the less reliable the measure is. Counting confirmed cases and deaths is one thing; quite another is assessing the effectiveness of governments' responses to the pandemics. Although both measurements are open to substantial variability and interpretation, there is less discretion in aggregating national data about deaths than in assessing governments' measures. Of the programs herein analysed, the initiatives led by the WHO, the ECDC, the JHU, the WoM, the OWiD, and the IHME collect and repackage numbers gathered by others about cases, deaths and tests. By contrast, the Ox-CGRT, the DKG's rankings, the CCPR and Porcher's dataset more clearly depart from background data, to provide numerical assessment of harder-to-quantify notions, such as governments' responses and efficiency in treatment.

(ii) The distance between providers and data sources

All COVID-19 global data initiatives rely upon indirect sources, be they national authorities, news or other data providers. But data sourcing can be more or less direct and involve more or fewer steps. The less direct the data sourcing, the more likely it is that the data collected are not accurate. Of the initiatives herein surveyed, five rely upon second-hand data (the WHO and the ECDC gather data collected from national authorities; the WoM directly collects data form national authorities and media news; the OxCGRT and the CCPR teams extract them from the media). Five are based on third- or fourth-hand data, resting on the shoulders of other initiatives (the JHU, the OWiD and the DKG amalgamate the WHO's and the ECDC's data; the IHME puts together the JHU's and the OWiD's results; the DKG relies on the WoM's and the JHU's data while Porcher combines information from several international organisations).

(iii) The distance between the expertise of providers and what is measured

The further the expertise of data-producers from the field concerned, the more likely a misunderstanding of the field itself. Of the health-focused initiatives herein examined, the personnel of the WHO, the ECDC and the IHME are specifically trained to deal with health and epidemic data, while the expertise of other providers stem from fields as diverse as engineering (JHU), analytics development (WoM), and economics (OWiD). By contrast, the expertise of the providers of policy-focused global data aligns more closely to the fields surveyed, since the competency of their indicator makers stem from political science (Ox-CGRT), healthcare data analytics (DKG), law (CCPR) and public management (Porcher).

(iv) The availability of a ranking

Any numerical representation of the globe might be used for ranking purposes. Yet many initiatives present their data in ways that do not allow easy inferences to be drawn about which country is doing better and which one is doing worse. For instance, the WHO's and the ECDC's numerical data might be used for ranking purposes, but re-working their numbers requires skills in extracting, treating and displaying the data that go beyond the competence of average users. Indicators, by contrast, often have a tendency to rank their measured units to stimulate them to engage in a race to the top. The presence of a ranking, or, alternatively, the ease with which users can create one, expresses an indicator's potential for nudging behavioural change. Rankings might be explicit, such as in the case of the Ox-CGRT, DKG's rankings, the CCPR and Porcher's indices. They might also implicitly emerge from the ways in which results are or can be displayed, such as ordered tables and heat maps (JHU), re-workable tables (WoM) and interactive charts and maps (OWiD, IHME). 
(v) The user-friendliness packaging of the information

While the power of statistics is often linked to their author's expertise and authority, indicator-makers usually have to carve out their own prestige niche in the crowded market of global data. Like mating birds, one of the main methods adopted by indicator-makers to make their output visible and perform a nudging role is to create glamorous and easy-to-grasp formats devised to attract a broad range of users. Catchy formats include coloured maps (this is the case for the JHU's dashboard, the OWiD's dataset, the Ox-CGRT, IHME's projections, the CCPR's and Porcher's indices), interactive charts (the OWiD's dataset, the Ox-CGRT, IHME's projections), and top-10s (DKG's rankings). The more coloured and straightforward the layout is, the more likely the data collection is a nudging indicator. It is not by chance that both the WHO's and ECDC's numbers are presented in a very simple and unimaginative manner.

\section{(vi) The customisability of such information}

Another recurrent user-friendly feature of indicators is the customisability of data, allowing users to build their own data charts, graphs and maps. The more interactive and playable the data, the more likely the indicator will spread its power. While data collected by the WHO, the ECDC, the JHU, the DKG, the CCPR and Porcher cannot be customised, the visualisation of data offered by the WoM, the OWiD, the Ox-CGRT, and the IHME can be changed at the user's discretion.

(vii) The presence of a system tracing the uses of such information

As usability is crucial to the success of indicators, so is evidence of their use by third parties. Since indicator-makers often lack both the expertise and the authority to produce their data, confirmation by third parties allows indicator-makers to cement their influence. While the WHO, the ECDC, the CCPR and Porcher do not monitor how their data are used, the websites of the JHU, the WoM, the OWiD, the Ox-CGRT, the IHME and the DKG all keep track of their scientific and media uses.

(viii) The periodicity of the measurement

Much of the prescriptive/performative power of indicators come from the repetitiveness and periodicity of the measurements they provide. This is because repetition works as a carrot-and-stick incentive for those measured to improve their performances in every round. Data from the WHO, the ECDC, the JHU, the WoM, the OWiD and the IHME are updated with new entries daily. By contrast, the Ox-CGRT and initiatives from the DKG, the CCPR and Porcher are one-shot exercises focussing on a given timeperiod and providing no promise of repetition.

The following table summarises results for the initiatives herein surveyed. 
Table 2. Indicator-like Features

\begin{tabular}{|c|c|c|c|c|c|c|c|c|}
\hline & $\begin{array}{c}\text { (i) } \\
\text { Level of Data } \\
\text { Simplification } \\
\text { (low/high) }\end{array}$ & $\begin{array}{c}\text { (ii) } \\
\text { Distance } \\
\text { from } \\
\text { Sources } \\
\text { (far/close) }\end{array}$ & $\begin{array}{c}\text { (iii) } \\
\text { Expertise } \\
\text { Matching } \\
\text { (yes/no) }\end{array}$ & $\begin{array}{c}\text { (iv) } \\
\text { Ranking or } \\
\text { Rankability } \\
\text { (yes/no) }\end{array}$ & $\begin{array}{c}\text { (v) } \\
\text { Fancy } \\
\text { Format } \\
\text { (yes/no) }\end{array}$ & $\begin{array}{c}\text { Customizability } \\
\text { (yes/no) }\end{array}$ & $\begin{array}{c}\text { (vii) } \\
\text { Success } \\
\text { Tracking } \\
\text { (yes/no) }\end{array}$ & $\begin{array}{c}\text { (viii) } \\
\text { Repetitive- } \\
\text { ness } \\
\text { (yes/no) }\end{array}$ \\
\hline WHO & low & close & yes & No & no & no & no & yes \\
\hline ECDC & low & close & yes & No & no & no & no & yes \\
\hline JHU & low & far & no & Yes & yes & no & yes & yes \\
\hline WoM & low & close & no & Yes & yes & yes & yes & yes \\
\hline OWiD & low & far & no & Yes & yes & yes & yes & yes \\
\hline Ox- & high & close & yes & Yes & yes & yes & yes & no \\
\hline CGRT & low & far & yes & Yes & yes & yes & yes & yes \\
\hline DKG & high & far & yes & Yes & yes & no & yes & no \\
\hline CCPR & high & close & yes & Yes & yes & no & no & no \\
\hline Porcher & high & far & yes & Yes & yes & no & no & no \\
\hline
\end{tabular}

The criteria signalling indicator-like features that suggest taking the data provided by a given initiative with the greatest caution are the following: 'high' under 'Level of Data Simplification' (LDS); 'no' under 'Expertise Matching' (EM); 'far' under 'Distance from Sources' (DS); 'yes' under 'Ranking or Rankability' (RoR); 'yes' under 'Fancy Format' (FF); 'yes' under 'Customisability' (C); 'yes' under 'Success Tracking' (ST); 'yes' under 'Repetitiveness' (R). The final output is therefore the following:

Table 3. Caution Needed

\begin{tabular}{|c|c|c|c|c|c|c|c|c|c|}
\hline & LDS & DS & EM & RoR & FF & C & ST & R & Criteria \\
\hline WHO & & & & & & & & $\bullet$ & $1 / 8$ \\
\hline ECDC & & & & & & & & $\bullet$ & $1 / 8$ \\
\hline JHU & & $\bullet$ & $\bullet$ & $\bullet$ & $\bullet$ & & $\bullet$ & $\bullet$ & $6 / 8$ \\
\hline WoM & & & $\bullet$ & $\bullet$ & $\bullet$ & $\bullet$ & $\bullet$ & $\bullet$ & $6 / 8$ \\
\hline OwiD & & $\bullet$ & $\bullet$ & $\bullet$ & $\bullet$ & $\bullet$ & $\bullet$ & $\bullet$ & $7 / 8$ \\
\hline Ox-CGRT & $\bullet$ & & & $\bullet$ & $\bullet$ & $\bullet$ & $\bullet$ & & $4 / 8$ \\
\hline IHME & & $\bullet$ & & $\bullet$ & $\bullet$ & $\bullet$ & $\bullet$ & $\bullet$ & $6 / 8$ \\
\hline DKG & $\bullet$ & $\bullet$ & & $\bullet$ & $\bullet$ & & $\bullet$ & & $5 / 8$ \\
\hline CCPR & $\bullet$ & & & $\bullet$ & $\bullet$ & & & & $3 / 8$ \\
\hline Porcher & $\bullet$ & $\bullet$ & & $\bullet$ & $\bullet$ & & & & $4 / 8$ \\
\hline
\end{tabular}

As we expected, no initiative gets either 0 or 8 , but they are all located in a nuanced continuum from more to less virtuous exercises. The results obtained, however, are quite astonishing. One could have expected that health-focused initiatives were somewhat more objective than law- and policy-related initiatives. By contrast, as seen in Table 3, the initiatives for which more caution is suggested are exactly those providing apparently basic data about deaths, infections and tests - with the notable exception of the WHO's and the ECDC's data collection programs.

This, of course, might be interpreted as a signal that the above set of criteria should be improved or refined - which is obviously true. Be that as it may, the results nevertheless serves as a caveat that appearances are deceiving. Moreover, it acts as a reminder that, in the current emergency, it is fundamental to distinguish between different forms of global numerical representations. It is one thing to attempt to visualise situations and trends. However, it is quite another to direct efforts at orienting policy choices and nudging change - an aim that paradoxically makes these efforts less suitable as tools for decision-making. It is exactly because global quantitative measurements matter that it is even more important to properly measure their merit. 


\title{
COVID Rankings: Between Comparison and Commensuration
}

\author{
David Nelken*
}

Global social indicators, as a form of governance and soft regulation, can exert pressure for change and compliance through the way they compare and then rank the relative performance of states or other units. Is it reasonable to expect the comparisons they make in the process of carrying out such strategic exercises to be accurate and fair? In particular, how far can they, or should they, be required to be faithful to the requirement to 'compare like with like'. Using the role of indicators in documenting and responding to the Coronavirus epidemic as an example, we trace the way the hybrid and sometimes inconsistent commitment to both comparison and commensuration helps account for the difficulty they have had so far at establishing stable rankings of best practice.

\section{Introduction}

Sally Merry, with colleagues at New York University, was one of the leading authors who pioneered the study of what they called global social indicators. She made fundamental contributions to efforts to define and categorise such indicators, and she explored the way that they helped to construct what they claimed to measure and depoliticised the distributional decisions that they helped to justify. ${ }^{1}$ But, given that she was a committed qualitative anthropologist, it was never entirely clear how much her critique also reflected her more general suspicion of quantitative methodologies.

In her last book on the subject, The Seductions of Quantification, Merry expressly addressed this question and develops severe criticisms of the way these kind of indicators fail to attend to differences in context amongst the places or units they compare. ${ }^{2}$ For example, she pointed to subjective and cultural variation in the different ways persons experiences domestic violence and the way indicators of such behaviour fail to refer to kinship networks, gender norms, wider attitudes of violence, or the history of the relationship of a particular person. Likewise, she noted that the relevant indicators obscure the very different ways individuals experience sex trafficking on the ground. ${ }^{3}$ Merry conceded that to some degree it is 'essential to quantify social life', ${ }^{4}$ even as she proposes adding qualitative insights as a supplement. But the point of her critique is to warn against the seductive embrace of quantitatively sociological approaches. Even those writers who argue more strongly than her in favour of these kind of indicators, for example when used in the sphere of human rights, also admit that, 'it may be true that quantitative methods, in their very abstraction and stripping away of contextualizing information have particular -and especially high- risks for misuse by those with the power to mobilize them. ${ }^{5}$

But is it reasonable to criticise global social indicators for relying on and producing comparisons that strip away contextualizing information? Would global indicators be able to play their roles for which they are designed if, as Merry recommends, they had to be faithful to local contexts and give attention

\footnotetext{
* David Nelken, King’s College London (david.nelken@kcl.ac.uk).

${ }^{1}$ Sally Engle Merry, 'Measuring the World: Indicators, Human Rights, and Global Governance'(2011) 52 (3) Current Antropology. See, for example, Kevin Davis, Sally Engle Merry and Benedict Kingsbury (eds), Governance by Indicators. Global Power Through Quantification and Rankings (2012); Sally Engle Merry, Kevin Davis and Benedict Kingsbury (eds) The Quiet Power of Indicators (2015) Richard Rottenberg, Sally Engle Merry, Sung Joon Park and Johana Mugler (eds) The World of Indicators: The Making of Government Knowledge Through Quantification (2015).

${ }^{2}$ Sally Engle Merry, The Seductions of Quantification (2016).

3 ibid.

${ }^{4}$ Merry (n 2) at 212. It is also important not to confuse the question of measurement with that of quantification, see Alain Desrosières,'Retroaction: How Indicators Feed Back onto Quantified Actors' in Rottenberg et al (n 1) at 335.

${ }^{5}$ Ann Jannette Rosga and Margaret Satterthwaite, 'The trust in indicators: measuring human rights' (2009) 27 Berkeley Journal of International Law, 315.
} 
to qualitative differences? To answer these questions, we need to appreciate the differences between the practices of comparison (i.e. learning about similarities and differences) and commensuration (i.e. seeking to show equivalence and make matters come into line), and examine their interplay in the making, using and resisting of indicators. ${ }^{6}$ We suggest here that the hybrid commitment of trying both to provide good comparisons and, at the same time, compare only for the purpose of making similar, helps identify a basic tension in the making and using of indicators. In order to be accepted, global social indicators need to normalise the background contextual factors that are found in the societies or organizations that they rank higher so that these are seen as an inevitable part of their success. Conversely, the differences in context in less highly ranked and poorer performing units have to be understood not as vitiating the point of the comparison, but as helping make sense of why it is that some do less well. In order to achieve better rankings, it is they who have a responsibility to transform the wider social conditions that help explain their scores. A case study of COVID indicators can help us understand the difficulties that have been faced in establishing stable rankings of who has done best in responding to the pandemic. Moreover, it may also help us understand the conditions of success of indicators that are better established.

\section{Drowning in numbers}

Those living through the various waves of the COVID 19 pandemic (as of writing, 42 million infections, over 1 million deaths, and rising at a rate overall beyond its previous peak in March 2020), ${ }^{7}$ have also risked 'drowning' in a sea of numbers that purport to show the rise and fall of the disease over time and the relative success of attempts to govern it in different places. ${ }^{8}$ Such numbers are generated by national, international and transnational organisations, and illustrated in maps, graphs, tables and figures, as inputs of current data or as models to predict the future. They may be presented as 'snapshots', illustrating at any given date diachronic developments over time or synchronic differences between countries. Or they may be displayed on dashboards ${ }^{9}$ (some of which allow for interactive with the user), which focus on day by day bulletins, or even minute by minute changes, and offer the possibility of interrogating the data with respect to given localities and times.

In terms of the three different types of use that we have distinguished, these data

a) play a role in exercises seeking to explain different rates of infections and death,

b) may serve to document best practices and justify different policy choices,

c) or may be used to judge and rank performance.

${ }^{6}$ David Nelken, 'The Changing Roles of Social Indicators: From Explanation to Governance' in Valsamis Mitsilegas, Peter Alldridge \& Leonidas Cheliotis (eds), Globalisation, Criminal Law and Criminal Justice. Theoretical, Comparative and Transnational Perspectives (2015) 25; David Nelken, 'From pains-taking to pains-giving comparisons' (2016) 12 International Journal of Law in Context, 390-403; David Nelken, 'Whose Best Practices? The Significance of Context in and for Transnational Criminal Justice Indicators' (2019) 46 Journal of Law and Society S1, p S31, S50.

${ }^{7}$ https://www.bbc.com/news/live/world-54187391

${ }^{8}$ Ashley Kirk commented already in March 2020 that, 'More than any other time in my career as a data journalist, the general public is obsessed with numbers. The number of coronavirus cases, the number of coronavirus deaths, the number of tests administered - as well as any analysis that slices and dices these data, whether that's daily increases or per-person rates.' https://www.telegraph.co.uk/global-health/science-and-disease/everyone-wants-coronavirus-data-should-treat-numberscaution/. Warnings of the distorting effects of indicators on government policy making continued to be made well into the pandemic. See e.g. Hugh Pennington, 'Government policy, such as the introduction of a nightlife curfew yesterday, seems blind to this crucial difference. It concentrates simply on reducing the blanket figure, without making the vulnerable a priority. This approach lacks common sense and seems to be driven solely by a fear of red bars on graphs, a blind refusal to see sense': exasperated academic Hugh Pennington explains why he signed a stinging protest letter to Boris Johnson. Hugh Pennington For The Daily Mail September $22^{\text {nd }}$ 2020. https://www.dailymail.co.uk/debate/article8761609/Exasperated-professor-HUGH-PENNINGTON-signed-stinging-protest-letter-PM.html).

${ }^{9}$ See https://coronavirus.jhu.edu/map.html. See also Ensheng Dong et al., An interactive web-based dashboard to track COVID-19 in real time, LANCET INFECT DIS, February 19, 2020, https://doi.org/10.1016/S1473-3099(20)30120-1. 
Significantly, the same data can be used, and is often intended to be used, for more than one of these roles. Explanation provides a basis for policy- making, 10 and ranking requires knowledge of policies. ${ }^{11}$ Reported rates of testing, of infection (with and without symptoms) deaths, numbers in home isolation and hospitalised, those on ventilators, recovered, excess deaths as compared to previous years etc. can be represented both as dependent variables to be accounted for, or else as the outcomes of performances for which organisations can be held accountable. Our special concern here, however, will be with the way COVID indicators both seek to make comparisons (by understanding similarities and differences) and achieve commensuration (aiming to make policies globally align with supposed best practices). What we find (so far) is lots of comparison between places, intense but not always productive discussions of alternative policies, and only partially convincing efforts to find common standards for measuring the spread of COVID and government responses to it. If comparison for the purpose of explanation is often distorted by more practical aims of policy, efforts at commensuration have found it hard to institutionalise similarities in a world of difference.

Global indicators in the case of COVID ${ }^{12}$ are mainly concerned either with the progress of the epidemic ${ }^{13}$ or with the success of policies in dealing with it. ${ }^{14}$ Examples of the first:

- the World Health Organisation (WHO)'s 'COVID-2019 situation reports',

- the European Centre for Disease Prevention and Control (ECDC)'s 'COVID-19 situation update worldwide', 15

\footnotetext{
${ }^{10}$ The Johns Hopkins website explains, 'This website is a resource to help advance the understanding of the virus, inform the public, and brief policymakers in order to guide a response, improve care, and save lives.' https://coronavirus.jhu.edu/map.html.
}

${ }^{11}$ The DEEP KNOWLEDGE website tells us (under the heading Regional Top-30 Ranking) that,

'A comprehensive and quantitative analysis of the far-reaching global pandemic arising from the novel coronavirus is a critical challenge that must be carried out in order to plan the best strategic measures to reduce and neutralize negative repercussions of the outbreak until the final solution of a vaccine are within the reach of the scientific and medical community. With this in mind, Deep Knowledge Group's new COVID-19 special analytical case study is designed to classify, analyze and rank the economic, social and health stability achieved by each of the 30 regions included in its analysis, as well as the strengths, weaknesses, opportunities, and threats or risks that they present in the battle against the global health and economic crisis triggered by COVID-19. The pool of the 30 selected regions is made up of Switzerland, New Zealand, South Korea, Germany, Japan, China, Australia, Austria, Singapore, United Arab Emirates, Israel, Canada, Taiwan, Hong Kong, Norway, Saudi Arabia, Liechtenstein, Iceland, Monaco, Kuwait, Finland, Denmark, Bahrain, Luxembourg, Hungary, Cyprus, Netherlands, Qatar, Andorra, Oman, and more than 130 qualitative and quantitative parametric variables have been developed, tuned, and grouped into 6 broad and top-level categories capable of comprehensively describing the health and economic status of each region in terms of their absolute and relative stability and risks.'

${ }^{12}$ The following examples come mainly from the contribution by Marta Infantino (in this Working Paper).

${ }^{13}$ Johns Hopkins University has been amongst the leading collators of health data. See e.g. https://systems.jhu.edu/research/public-health/2019-ncov-map-faqs/ and https://coronavirus.jhu.edu/news. Other credible sources include https://www.worldometers.info/about/; https://www.worldometers.info/coronavirus/about/; https://ourworldindata.org/coronavirus and https://ourworldindata.org/coronavirus-source-data; https://ourworldindata.org/COVID-media-coverage. See also http://www.healthdata.org/about/history, https://COVID19.healthdata.org/united-states-of-america; http://www.healthdata.org/COVID/faqs, http://www.healthdata.org/COVID/media; https://www.dkv.global/COVID.

${ }^{14}$ Cf. https://www.bsg.ox.ac.uk/research/research-projects/coronavirus-government-response-tracker, and Anna Petherick et al., Variation in Government Responses to COVID-19, Blavatnik School Working Paper, 29 April 2020, https://www.bsg.ox.ac.uk/sites/default/files/2020-05/BSG-WP-2020-032-v5.0_0.pdf, 4-5; https://www.bsg.ox.ac.uk/people/thomas-hale; https://www.bsg.ox.ac.uk/research/research-projects/coronavirusgovernment-response-tracker.

${ }^{15}$ See also the USA CDC Global COVID-19 website at <https://www.cdc.gov/coronavirus/2019-ncov/global-COVID19/index.html>. 
- the Johns Hopkins University (JHU)'s 'COVID-19 Dashboard',

- Worldometer (WoM)'s Our-World-in-Data (OWiD)'s statistics on the 'Coronavirus Pandemic', and

- the Institute for Health Metrics and Evaluation (IHME)'s 'COVID-19 Projections'.

Examples of the second kind are:

- the Oxford University's 'COVID-19 Government Response Tracker' (Ox-CGRT),

- the Deep Knowledge Group (DKG)'s 'COVID-19 Rankings and Analytics',

- the Centre for Civil and Political Rights (CCPR)'s 'State of Emergency Data',

- and Simon Porcher's 'Rigidity of Governments' Responses to COVID-19' dataset and index.

Other indicators deal with other aspects of the pandemic such as its impact on the economy. ${ }^{16}$ The general public, however, tend to get their numbers indirectly, via the maps, tables and figures offered daily by different national newspapers and other media outlets that draw on and repackage data from these and other national and international sources. Efforts to show the progress of the disease over time also compare and contrast what is happening in different countries. Sometimes these reports leave it to the reader to work out who is doing better or worse, as in Figure 1.

\footnotetext{
${ }^{16}$ The World Bank indicator explains that 'This policy tracker summarizes the key economic responses governments are taking to limit the human and economic impact of the COVID-19 pandemic. The tracker includes 196 economies. See 'Policy Responses to Covid-19' (IMF) <https://www.imf.org/en/Topics/imf-and-covid19/Policy-Responses-to-COVID19>.
} 
Figure $1 \underline{\text { Neutral description }}^{17}$

\section{Europe watching for second rise in cases}
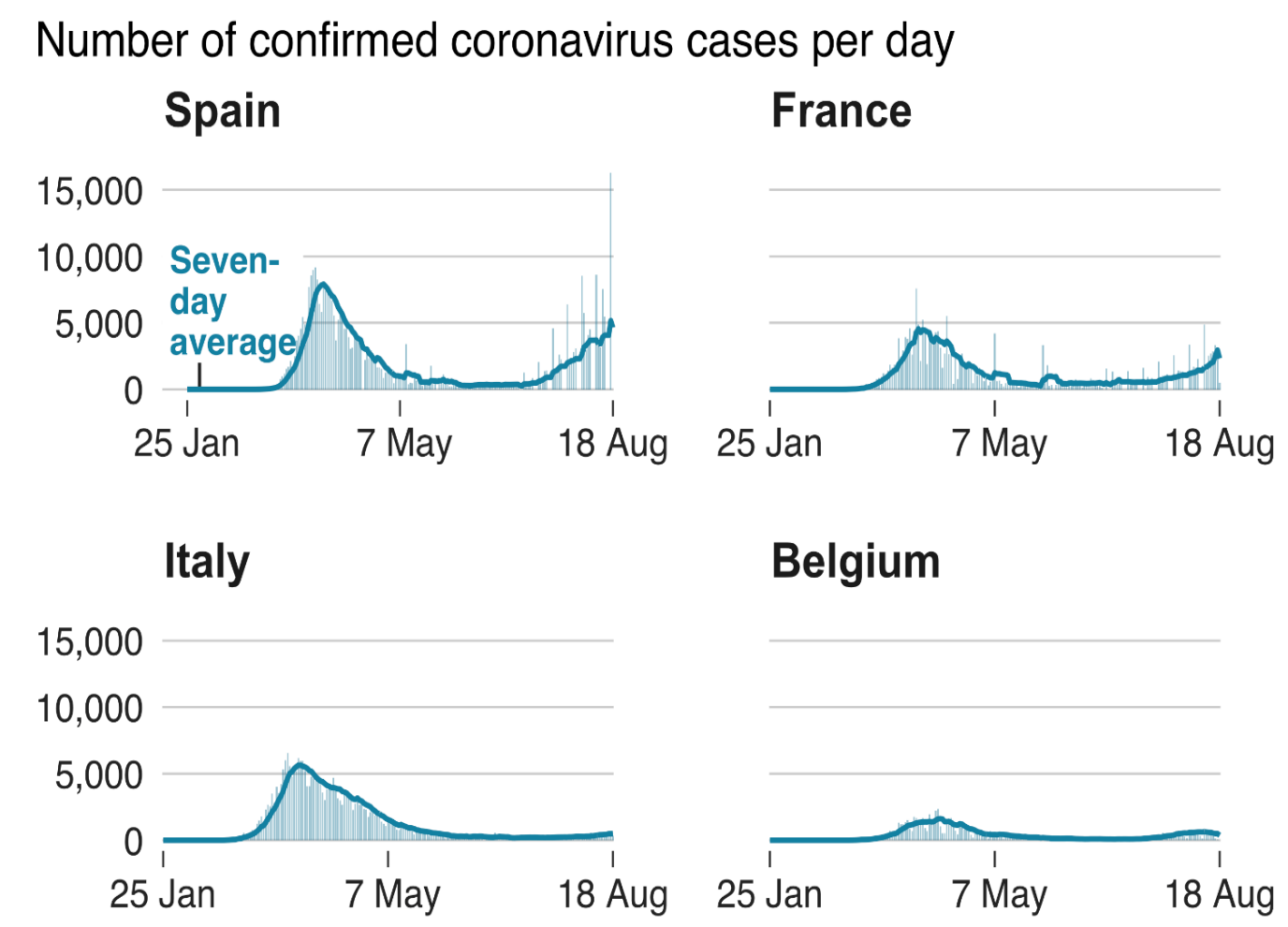

\section{Germany}

15,000

10,000

$$
5,000
$$

0

25 Jan

7 May

18 Aug 25 Jan

7 May

18 Aug

\section{Netherlands}

Source: ECDC, data to 18 August

18 Aug 25 Jan

7 May

18 Aug

More often, they will make some effort to underline the relative success of some countries in relation to others, as in Figure 2.

\footnotetext{
${ }^{17}$ https://www.bbc.com/news/world-europe-53832981
} 
Figure $2 \underline{\text { Pointed comparisons }}^{18}$

\section{Coronavirus cases increasing in European countries in recent weeks}

\section{Total cases per 100,000 people by week up to 20 September}

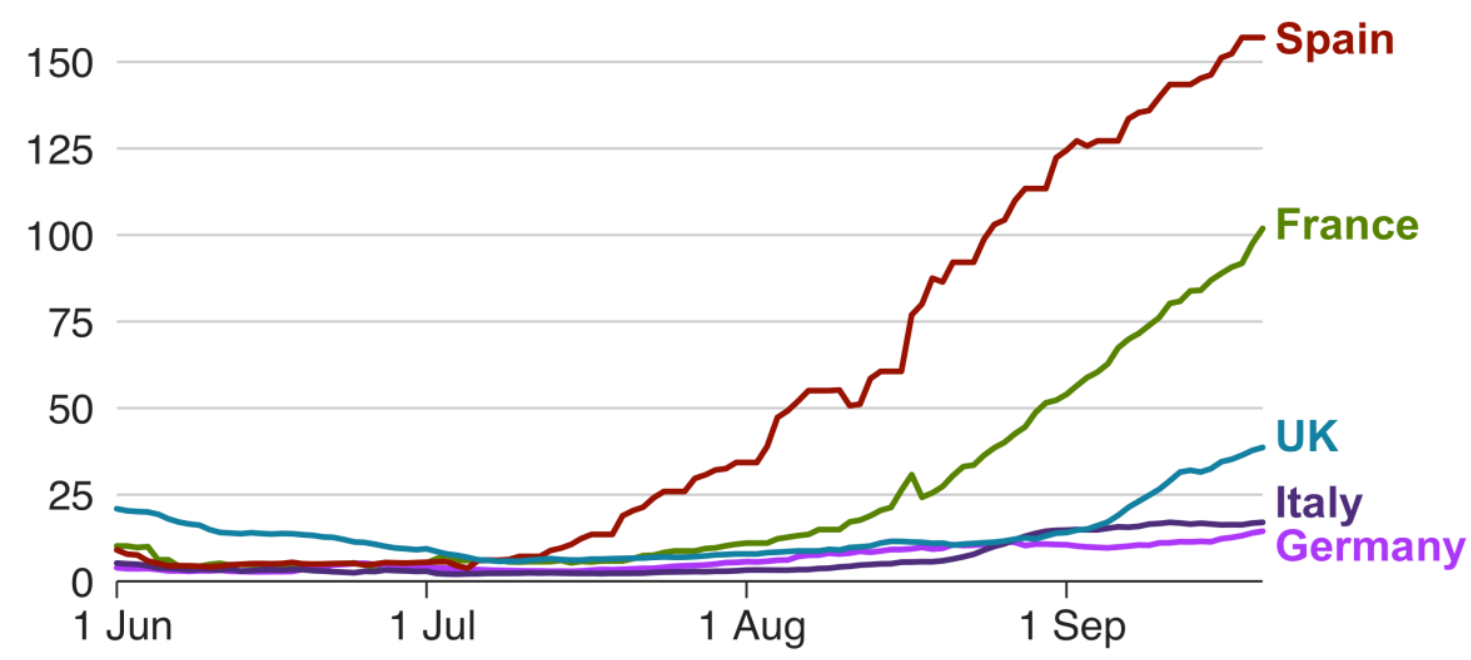

Note: Countries do not always release figures every day, which may explain some of the sharp changes in the trendlines

Source: ECDC, data to 20 Sep

BBC

Beyond simply monitoring the progress of the disease, COVID indicators are used by governments, administrators, and citizens for such aims as predicting, deciding, justifying and coordinating. As with other global social indicators, ranking what is happening in different countries can point users to which places are safer for investors, for workers and for travellers etc. They also form part of rituals that may create solidarity and reassurance, extend control or distract from other political issues. In addition, the ways indicators are used in practice may not always be the ones intended by those who sponsor or publicise them, ${ }^{19}$ and the use of the same indicators can also change over time. Like other indicators these too can be placed along a continuum of counter-factuality, and both intersect and interact with other forms of normative regulation (see Figure 3).

Like other global social indicators, these indicators too can be placed along a continuum of counterfactuality, and both intersect and interact with other forms of normative regulation (see Figure 3). COVID indicators were pressed into service by governments to justify rules requiring compliance by citizens (in association with both nudging ${ }^{20}$ or enforcement) and have helped justify legal crackdowns on those who fail to conform to health obligations. At the other end, they help prepare the way for the

\footnotetext{
${ }^{18}$ See https://www.bbc.com/news/world-europe-54839429

${ }^{19}$ Whatever effects their reports had on the circulation of the virus it certainly helped the circulation figures of the newspapers!

${ }^{20}$ A nudge alters the environment so that when a given decision is made, the resulting choice will be the most positive or desired outcome for those who have set it up.
} 
obligatory use of AI devices to measure one's own and other people's rates of infection in ways that leave little room for resistance.

Figure 3: A Continuum of Normative Regulation $^{21}$

\author{
Most counterfactual $\quad \leftrightarrow \quad$ Least counterfactual \\ Ethics, Law, Indicators, Benchmarks, Targets, Nudges, Algorithms, Architecture
}

At one end of the continuum, COVID indicators were pressed into service by governments to justify rules requiring compliance by citizens (in association with both nudging or enforcement) and have helped justify legal crackdowns on those who fail to conform to health obligations. At the other, more manipulative end, they help prepare the way for the obligatory use of AI devices to measure one's own and other people's rates of infection in ways that leave little room for resistance. What interests us here, however, is exploring the credibility problems that COVID indicators have faced in their efforts to compare and standardise criteria of successful performance. Have COVID indicators been successful in the purposes for which they have been used? What does (or should) success mean here? ${ }^{22}$ On the definition of success I shall be focusing on, success refers to take up and use, whether a given indicator has been adopted and given credibility at the expense of other ones. More broadly, success means wide acceptance and 'normalisation' of its underlying theory, the idea of what is being measured that a given indicator incorporates. Even if we are careful not to confuse the success of indicators with the outcomes of the policies they are being used to assess, ${ }^{23}$ establishing success is complicated by the many potentially conflicting aims of a given indicator. As noted, regular invocation of indicators may act as a ritual building social solidarity, or they may be used to justify actions taken in the name of COVID, when in fact aiming at other goals such as the curtailing of political protest. Of special relevance here, for all that management consultants tell us that we have to measure what we want to change, it has been argued that it is not possible simultaneously both to measure and change a phenomenon, ${ }^{24}$ especially where those being assessed are rewarded for given outcomes. As a variation on this theme, we will take COVID indicators to illustrate the difficulty of both comparing and commensurating. If the first, as we have argued, demands comparing like with like, the second presupposed not only that the units being compared are different, but that success consists exactly in evaluating and transforming such difference.

${ }^{21}$ See David Nelken, 'The Legitimacy of Global Social Indicators: Reconfiguring Authority, Accountability and Accuracy' (2018) 59 Les Cahiers de Droit 35.

${ }^{22}$ I set aside for the purpose of this essay the (all) important issue of who gains and loses even when an indicator is successful, including which groups in society are most exposed to COVID and why.

${ }^{23}$ A more demanding definition treats success as inseparable from what happens with the larger project for which indicators are being mobilised. Here this would be the effects of these indicators in reducing COVID through shaming governments into taking appropriate action or stimulating compliance by the public with rules intended to limit its spread. Yet it would often be a mistake to conflate the success of the indicator as such with the success of the policy it is being used to pursue. In the instant case, indicators may be providing a valuable service even when, and especially when, the project of controlling the disease is going badly.

${ }^{24}$ Charles A.E. Goodhart, Monetary Relationships: A View from Threadneedle Street. In Papers in Monetary Economics, vol. 1, Sydney: Reserve Bank of Australia (1975). 


\section{COVID indicators and Comparison}

Whatever else they were used for, as with other global social indicators, much effort was put into deploying these indicators in the familiar role of encouraging best practice by states and shaming those whose record seemed poorer. The means to achieving this involved providing ever updated information comparing the relative success of a given country in dealing with the virus over time. It was hard enough to be sure that comparing the same country over time made sense, given the changes in policies, testing and rules. Indeed the expression 'comparing apples and pears' was explicitly invoked. ${ }^{25}$ But quantitative comparisons on a global scale were bound to simplify and overlook differences in context. Explaining links between cause and effect were deliberately conflated with the search for 'best practices' and concomitant praise and blame for those whose practices are better or worse. ${ }^{26}$ This also allowed politicians to take advantage of the semantic ambiguity between being responsible for something in the sense of being part of 'the cause' and being responsible in the sense of 'to blame', for example when fingering young people and students (including those at schools and university) as those responsible for launching the second wave of the virus. ${ }^{27}$

The challenge raised by such comparisons was to identify what there was in common between the more successful countries such as Australia and New Zealand, Norway, Germany, Taiwan, Singapore, South Korea- and central European countries such as Hungary, as opposed to less successful ones, such as the USA, Brazil, Russia, Britain, Belgium, France, Spain, Peru, Mexico, Iran and India. As regards the less successful countries, commentators pointed to failures of leadership in the way the crisis was handled, under- preparation and slowness in reacting, ${ }^{28}$ and getting things wrong, including confusing COVID with influenza, using ventilators too soon, exposing old people in care homes to the disease, putting political logic before health, and not listening sufficiently to (the right) experts. Conversely, it was noted that some of the more successful countries, such as Taiwan, Singapore and South Korea, had experienced SARS and MERS epidemics (could we say that they had been 'vaccinated'?); South Korea, for example, had specifically learned from their mistakes last time round and had systems ready in place to deal with any new epidemic. ${ }^{29}$

More controversially, some argued that countries with more autocratic regimes, starting with China itself, were better able to respond quickly and decisively. Cepaluni, Dorsch and Branyiczki, for example, sought to understand "why countries with more democratic political institutions experienced deaths on a larger per capita scale and sooner than less democratic countries' ${ }^{30}$ They suggested that more democratic regimes face a dilemma if they are 'to respond quickly and more efficiently to future outbreaks of pandemics, or similar urgent crises. Successful strategies need to include expedited decision-making processes that place unpalatable restrictions on individual liberties. In our view, failure to deal effectively with pandemics poses a risk to the public's trust in democratic governance and could

\footnotetext{
${ }^{25}$ https://www.telegraph.co.uk/news/2020/10/12/apples-pears-rising-case-numbers-ignore-fact-had-no-ideatrue/?li_source=LI\&li_medium=liftigniter-onward-journey.

${ }^{26}$ See e.g. https://www.theguardian.com/world/2020/sep/20/global-preparation-how-different-countries-planned-for-thesecond-wave-of-COVID-19.

${ }^{27}$ See https://www.independent.co.uk/news/uk/home-news/coronavirus-young-people-students-blame-infectionsindependent-sage-b746383.html.

${ }^{28} \mathrm{https} / / /$ www.thetimes.co.uk/edition/news/government-underestimated-speed-of-surge-in-coronavirus-cases-0xzfkcvfh

${ }^{29}$ This explanation is also offered for Italy's relative success in (so far) avoiding a second wave https://www.theguardian.com/world/2020/sep/24/totally-awakened-how-tragedy-has-left-italians-alert-to-deadly-virus. Equally the 'wrong' lessons can be learned from the past; see https://www.thejc.com/news/uk/sir-lawrence-freedmanattacks-lacklustre-government-response-to-coronavirus-1.499670.

${ }^{30}$ Gabriel Cepaluni, Michael T. Dorsch, \& Réka Branyiczki 'Political Regimes and Deaths in the Early Stages of the COVID-19 Pandemic'. Working paper, Central European University. https://preprints.apsanet.org/engage/apigateway/apsa/assets/orp/resource/item/5ea7229e5d762d001217da9a/original/political-regimes-and-deaths-in-the-earlystages-of-the-COVID-19-pandemic.pdf.
} 
contribute to the democratic roll-back that is happening in some regions of the world. Giving up some liberties in the short- run within democratic institutions may be necessary to ensure liberties into the future with democratic institutions'. ${ }^{31}$ At the same time, however, it is in countries with 'illiberal populist' leaders where the virus has got most out of hand. ${ }^{32}$ Newspaper commentators were divided according to their usual ideological sympathies as to whether to blame social structural problems for the difficulty in making sound choices, ${ }^{33}$ or instead blaming individualistic and unruly populations. ${ }^{34}$

As in the general debate over global social indicators, some commentators from the social sciences object to such over simplified pictures and claim that it is only by introducing more contextual qualitative information that can we grasp the specific conditions and circumstances which explain why different countries performed as they did. ${ }^{35}$ Less successful outcomes of similar policies can be linked to the presence of major International airports, as in the Netherlands and the UK; unhealthy populations, as in the USA; built- up resistance to antibiotics, in the case of Italy, the distractions of Brexit, again in the UK; or tensions between the federal state and regional governments, for Spain. Outside of Europe the range of relevant factors increases. In Peru it is a challenge to enforce social distancing where so many live-in overcrowded homes, the lack of refrigerators means that people have to shop regularly and risk coming into contact with market vendors who may have the illness. The society relies on its informal economy and people have to use crowded public transport. It is difficult to deliver aid to those who need it when only $38 \%$ of the population have bank accounts. ${ }^{36}$ In India many people have a justified suspicion of top- down health interventions, as well as strong commitment to collective religious practices which can expose them to danger. Only careful empirical research in loco can hope to explain to understand the unexpectedly low rate of infections and deaths in most of Africa. Is this linked to their previous experience of dealing with pandemics, or more an artifact of their record keeping or other features of their health systems? ${ }^{37}$

How far do these differences matter? Are they exactly what we want to discover by engaging in comparison, or do they show that places are not really comparable $?^{38}$ If our goal is to discover and promote best practices (here in responding to COVID) why is it a problem that we are not comparing like with like? Other global social indicators, such as those that rank countries on business friendliness, respect for the rule of law or levels of corruption, certainly do not assume that, say, underlying circumstances and resources are the same in Somalia as they are in Sweden. Indeed, the fact that some countries face greater difficulties in achieving the designated goal helps make their poorer rankings

\footnotetext{
${ }^{31}$ Id. p. 25. On the other hand (also at 25), they do concede 'As the pandemic started in East Asia, the location of some of the best-managed autocracies, it may be that our sample disproportionately includes the autocratic governments with high state capacity. Therefore, it is an area for future research to see if our results hold when autocracies with lower state capacity are eventually included in the sample.'

${ }^{32}$ David Leonhardt and Lauren Leatherby, 'Where the Virus Is Growing Most: Countries With 'Illiberal Populist' Leaders Brazil, Russia, Britain and the U.S. have something in common.' NY times June 2, 2020.

${ }^{33} \mathrm{https}: / /$ www.theguardian.com/commentisfree/2020/aug/20/the-spread-of-coronavirus-is-not-the-fault-of-individuals-but-aresult-of-neoliberalism.

34 The answer of course can include both factors see https://www.marketwatch.com/story/why-do-so-many-americans-refuseto-wear-face-masks-it-may-have-nothing-to-do-with-politics-2020-06-16.

${ }^{35} \mathrm{https}$ ///www.bsg.ox.ac.uk/research/research-projects/coronavirus-government-response-tracker.

$36 \mathrm{https}: / /$ www.bbc.com/news/world-latin-america-5315080.

${ }^{37}$ https://www.bbc.com/news/world-africa-54248507; https://www.bbc.com/news/world-africa-54388340.

${ }^{38}$ COVID data can sometime be useful for confuting stereotypes. Surprisingly it seems that there is more regard for (these) rules in Italy than in the UK. See "COVID. Gli scienziati: la situazione nel nostro Paese non sarà come in Spagna e Francia. "Qui distanziamento e mascherine rispettati". https://www.quotidiano.net/cronaca/seconda-ondata-COVIDmette-in-crisi-1-europa-1-italia-resiste-seguiamo-le-regole-1.5530753.
} 
credible and persuasive. In any case, when trying to find ways of nudging places towards following the best practices of those countries that have had most successful outcomes in dealing with COVID, the reasons why some are doing better or worse might be considered of secondary importance to using the data to decide what action to advise about imposing lockdowns, in prohibiting travelling to certain places or accepting incoming travellers and tourists.

Despite this, COVID reports do often include careful disclaimers about the limited validity of their comparisons- even if the small print is then often ignored. ${ }^{39}$ Efforts are made to compare deaths and infections per capita, and not only in absolute terms, to use moving averages to get a sense of trends and, most difficult, to remind the reader that the numbers reported are highly dependent in the number of people being traced and tested for the virus. More interestingly, the importance of comparing like with like is also acknowledged in those graphs and tables found in the media that seek to 'control' for interfering variables so as to make the comparison fairer and more instructive. Thus figure 4 tries to build into its comparisons the added risk of young and old living together at home or, in figure 5, the factors of old age dependency ratio and population density.

Figure $4 \underline{\text { Intergenerational-ties-and-case-fatality-rates }}{ }^{40}$

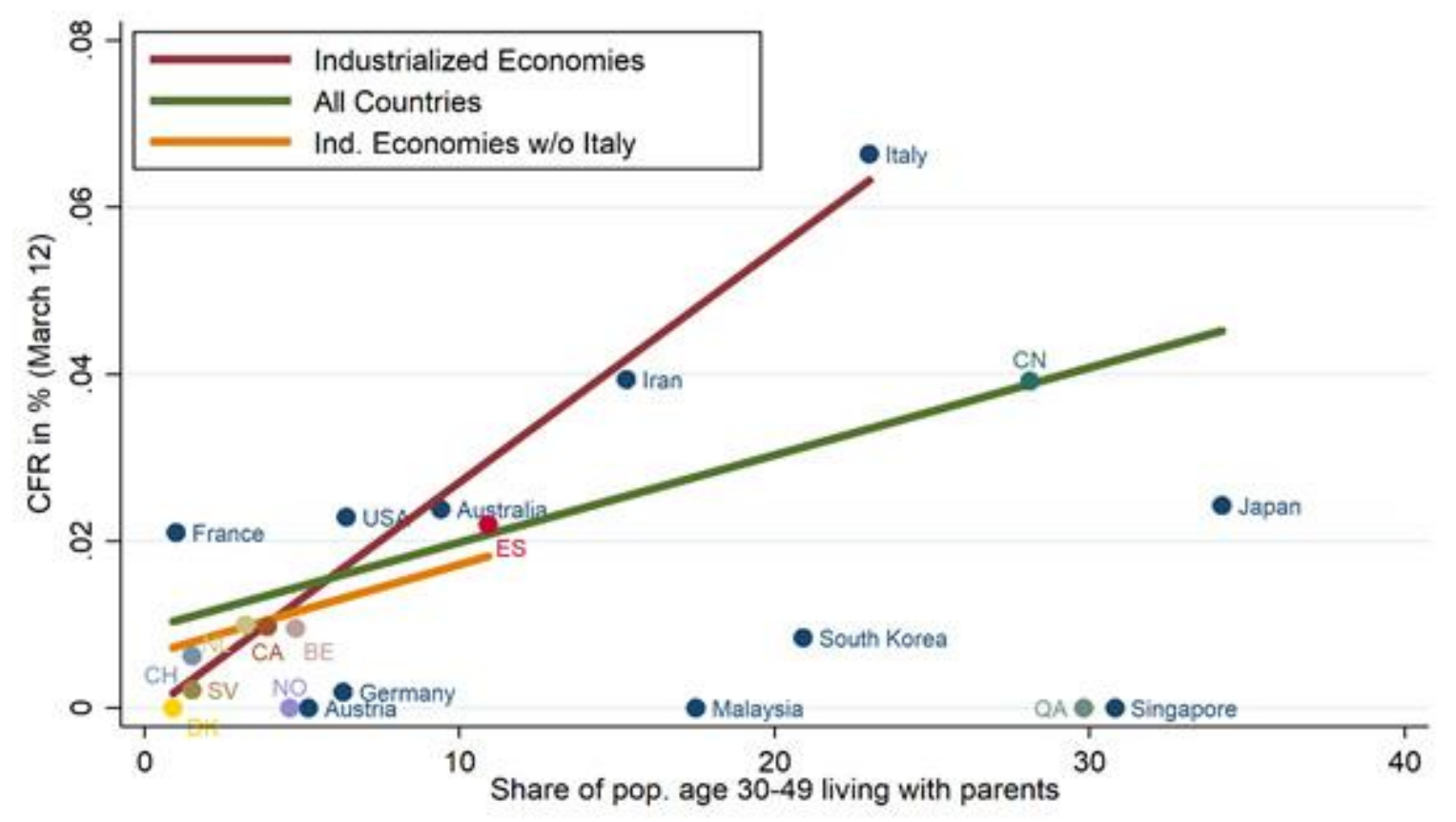

${ }^{39}$ Thus, the IMF tracker says 'The information included is not meant for comparison across members as responses vary depending on the nature of the shock and country-specific circumstances. Adding up the different measures-tax and spending, loans and guarantees, monetary instruments, and foreign exchange operations - might not provide an accurate estimate of the aggregate policy support. The tracker includes information that is publicly available or provided by the authorities to country teams and does not represent views of the IMF on the measures listed. https://www.imf.org/en/Topics/imf-and-COVID19/Policy-Responses-to-COVID-19.

The World Bank website warns us 'NOTE: The tracker focuses on discretionary actions and might not fully reflect the policies taken by countries in response to COVID-19, such as automatic insurance mechanisms and existing social safety nets which differ across countries in their breadth and scope'.

${ }^{40}$ See https://voxeu.org/article/intergenerational-ties-and-case-fatality-rates.

https://www.google.com/search?q=BBC+total+cases+per+100,000+people+by+week+up+to+18+August\&client=firefox-b$\mathrm{d} \&$ source $=$ lnms\&tbm=isch\&sa $=$ X\&ved=2ahUKEwjQi8iWg4LsAhUKkMMKHWYnC544ChD8BSgCegQICxAE\&biw= 1086\&bih=702\#imgrc=k-PtsRZWZYkMjM). 
Figure 5 Death and infection rates for COVID: Controlling for old age, dependency ratio and population density ${ }^{41}$

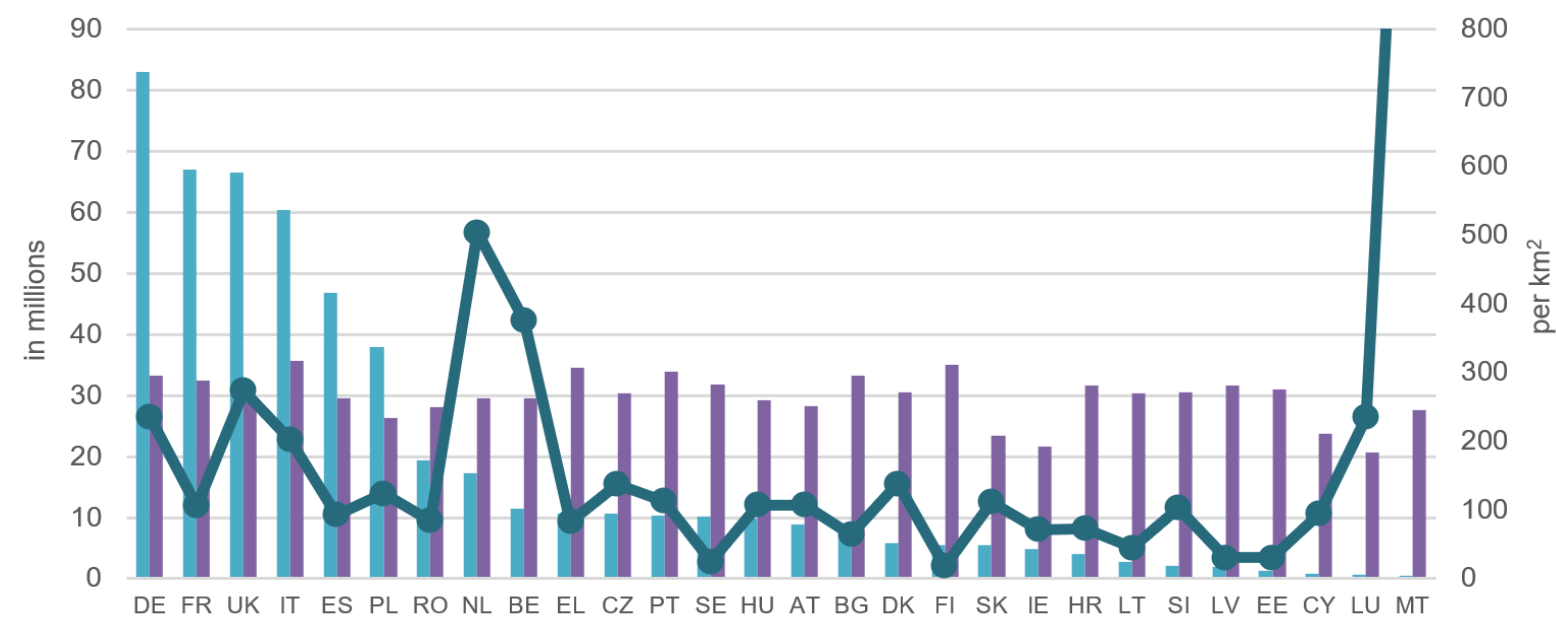

Population size in millions

Old-age-dependency ratio

Population density km2

But, if our main interest lies in identifying which places are doing better and are therefore safer, why bother to 'control' for differences? Presumably this is because we can only decide if given policies that have been adopted have been really successful (and therefore to be copied) if we are comparing like with like in terms of the difficulty of the challenge. But if that is the reason why do COVID ranking indicators refer to only a few of the many factors that I have noted that could potentially be relevant? Given the not unreasonable suggestion sometimes mooted that each country is so different that it needs to find its own way, ${ }^{42}$ what purchase would then be left for standardised indicators of performance?

Still more problematic is the way COVID indicators (like other global social indicators) conceal the possibility that countries may be trying to achieve different goals from those for which they are being evaluated. Rankings of countries' responses to COVID would be very different for example if the metric used was progress towards the goal of achieving herd immunity, ${ }^{43}$ or the costs imposed on the economy or on restrictions on political freedoms. A further problem facing the use of indicators here was finding a plausible metric for the trade-off between employment and health, especially as serious damage to the economy or reduction in public resources undoubtedly also has wider effects on health. ${ }^{44}$ The same

\footnotetext{
${ }^{41}$ See https://blogs.lse.ac.uk/europpblog/2020/05/19/comparing-european-reactions-to-COVID-19-why-policy-decisionsmust-be-informed-by-reliable-and-contextualised-evidence/.

42 "Each country's strategy to curb COVID-19 should be based on its specific situation and context and be both scientifically sound and culturally acceptable." "https://www.theguardian.com/world/2020/sep/25/what-lessons-can-europe-learn-fromsweden-COVID-19-experience.

${ }^{43}$ This approach was discredited because of the number of deaths that would have resulted, and the too great burden it would have placed on health systems. But the goal remains in the background, to be used as a yardstick regarding when a population is considered no longer at risk and for deciding how to distribute vaccines once they are developed. It may also be pursued by sub- groups of a population, as is alleged to be the case for some religious groups in Israel. See https://www.haaretz.com/israel-news/.premium-netanyahu-s-aim-to-extend-nationwide-lockdown-will-face-harsh-publicopposition-1.9211266.

${ }^{44}$ Some leaders openly gave priority to the economy. Brazil: President prioritises the health of the economy over the COVID19 crisis, rejecting recommended lockdown measures.
} 
applies to the reduction in political freedoms in the name of stopping the spread of the epidemic, ${ }^{45}$ a challenge to normal civil rights and democratic functioning that was muted in some mainstream newspapers, but regularly highlighted by media on the right with a more libertarian streak ${ }^{46}$ as well as by commentators on the left who were suspicious of what else will be done by governments in the name of emergency. The effort to reconcile such contending goals tended to produce incoherent rules, for example first encouraging people to get the economy restarted and then to retreat to the safety of their homes. ${ }^{47}$ Some leaders did try to answer criticisms of their relatively poor performance by claiming that other values were at stake. After the WHO praised Germany and Italy for their recent performance in dealing with the COVID virus, ${ }^{48}$ Prime Minister Boris Johnson explained to parliament (on the $24^{\text {th }}$ September 2020) that the UK had higher deaths rate than Germany and Italy because it gave a higher value to freedom. Italian president Sergio Mattarella replied immediately that Italy too believed in freedom but it also believed in taking the health threat seriously (Ouch!). ${ }^{49}$ A more effective and frequently used strategy for deflecting blame was to hold sections of the public responsible because of non- compliance with the latest version of the rules concerning social distancing.

But the best illustration of the difficulty of providing useful indicators where the goals of those assessed differ is offered by the Swedish case. ${ }^{50}$ Sweden (uniquely in Europe) chose to follow a less strict approach, in particular seeking to avoid imposing a lockdown. ${ }^{51}$ Some commentators misread the

https://www.business-humanrights.org/en/latest-news/brazil-president-prioritises-the-health-of-the-economy-over-theCOVID-19-crisis-rejecting-recommended-lockdown-measures/;

'Mr Bolsonaro has repeatedly said that 70 per cent of Brazil's population of $211 \mathrm{~m}$ would eventually be infected with coronavirus and "there's no running away from that' 'https://www.ft.com/content/065c783e-2402-4c0d-ad40$1 \mathrm{~b} 5 \mathrm{e} 38 \mathrm{ae} 96 \mathrm{~d} 4$.

On the other hand, damage to the economy does also have direct and indirect implications for life and death (and vice versa). https://www.express.co.uk/news/uk/1341671/breast-cancer-screening-delayed-coronavirus-pandemic-NHS.

${ }^{45} \mathrm{https}: / /$ www.bbc.com/news/world-54082192.

${ }^{46}$ Examples of this in the UK include the Daily Telegraph and the Daily Express; for Italy see for example Il Giornale.

47 The Official UK site giving advice on COVID 19 - uses criteria for imposing quarantine that are certainly not always consistent with health considerations.

'Which workers are exempt from quarantine? There are a number of people who are exempt, regardless of where they are flying from, including: Road haulage and freight workers. Seasonal agricultural workers if they self-isolate where they are working. UK residents who ordinarily travel overseas at least once a week for work'.

https://www.gov.uk/government/publications/coronavirus-COVID-19-travellers-exempt-from-uk-border-rules/coronavirusCOVID-19-travellers-exempt-from-uk-border-rules.

${ }^{48} \mathrm{https}$ ://www.wantedinrome.com/news/who-cites-italy-as-good-example-of-how-to-contain-COVID-19.html.

${ }^{49} \mathrm{https}: / /$ www.theguardian.com/world/2020/sep/24/italian-president-rebuts-johnsons-freedom-remarks-over-covid-19restrictions.

${ }^{50}$ The priority given to the economy in USA and Brazil was unlikely to attract admiration where the COVID casualty level was so high.

${ }^{51}$ But differences on the ground should not be exaggerated. It would be misleading to assume that Sweden had no policies concerning social distancing. It closed schools for the over-16s and banned gatherings of more than 50 people, but otherwise relied on Swedes' sense of civic responsibility to observe physical distancing and home working guidelines. Shops, restaurants and gyms remained open Sweden also made use of contact tracing.

According to Antoine Flahault, "Many people think that because Sweden did not lock down, the government did nothing," he said. "In fact, it took several key measures. But mainly, it managed to make citizens understand and participate in the fight against the virus, without coercion, mandatory laws or regulations. The effect was not very different." https://www.theguardian.com/world/2020/sep/25/what-lessons-can-europe-learn-from-sweden-COVID-19-experience. See also 'https://www.irishtimes.com/news/world/europe/swedes-losing-trust-in-authorities-handling-of-COVID-19-pollfinds-1.4289245. 
Swedish choice as one aimed at achieving herd immunity, ${ }^{52}$ or else as giving priority to the economy. ${ }^{53}$ But what authorities in Sweden were arguing was that public health should be viewed in the broadest sense, saying the kind of strict mandatory lockdowns imposed elsewhere were both unsustainable over the long run and could have serious secondary impacts including increased unemployment and mental health problems.$^{54}$ The policy was held to steadily even at the expense of a greater number of infections and deaths as compared to their Scandinavian neighbours. ${ }^{55}$ Importantly, the number of infections and deaths was no greater than in those European countries that did opt for lockdown. ${ }^{56}$ As numbers went up there was considerable internal debate and heart searching in Sweden involving politicians, experts and public opinion. It was also asserted that Sweden's choice did not benefit it in economic terms as it was badly affected almost as much as its Scandinavian neighbours ${ }^{57}$ But, despite the ambiguities of the Swedish case, careful cross-national measurements of the side-effects of policies aimed at controlling the spread of COVID have not yet become the main focus of the indicators consumed daily by the public. These are constructed so as to measure rates of infection, death and recovery as the only metrics of success.

\section{COVID indicators and commensuration}

If COVID indicators are not primarily concerned with comparing like with like, it this is likely to be because they are geared more to evaluating performance and bringing about commensuration in the responses to the disease.$^{58}$ But have they succeeded in encouraging standardisation as to what counts as a COVID infection, or in what needs to be measured in seeing how performance varies? Even if it is premature to attempt to provide a full assessment of the success of these indicators it can be important to note the different possible meanings of success, and, in particular, to appreciate the tension that exists when (given) indicators try both to 'represent' or change society. Some commentators argue that the more data about COVID is repackaged so as to be useful as indicators the less likely it is to serve as a reliable description of what it purports to describe ${ }^{59}$ There is thus a basic dilemma in making data useful without distorting it. Others have criticised an approach that assumes that indicators 'represent' reality. Even so-called 'false numbers' can play important social roles ${ }^{60}$ Merry's use of Foucault's term 'truth effects' suggests a deep ambivalence about how far it makes sense to criticize indicators for getting

\footnotetext{
${ }^{52}$ For Sweden's chief epidemiologist, Anders Tegnell, the goal was not herd immunity but slowing the spread of the virus. See now https://www.ft.com/content/5cc92d45-fbdb-43b7-9c66-26501693a371.

${ }^{53}$ Some right-leaning newspapers in the UK were sympathetic to the Swedish approach, as to all attempts to limit state intervention https://www.telegraph.co.uk/news/2020/07/27/spains-experience-shows-swedens-COVID-approach-couldhave-right/.

${ }^{54} \mathrm{https}$ //www.irishtimes.com/news/world/europe/swedes-losing-trust-in-authorities-handling-of-COVID-19-poll-finds1.4289245 .

55 https://www.bbc.com/news/world-europe-52704836\#_blank; https://www.quotidiano.net/esteri/coronavirus-mondo-oggi1.5430679 As of end June Sweden's 5,230 deaths translates to a toll per million inhabitants of 511, many times higher than the corresponding totals in neighbouring Denmark (104), Finland (59) and Norway (47), all of which imposed strict confinements - but lower than the 650 registered in the UK, Spain's 606 and Italy's 573.

56 The younger average age in Sweden and less density of population also gave Sweden some advantages.

57 This was partly explained by Sweden's dependence on suppliers and markets in places hit by COVID.

${ }^{58}$ As we argued earlier, there is also some overlap between comparison and commensuration. Definitions of what counts as a variable for the purpose of comparison (whether it be countries, ethnic groups, rates of infection etc.) all rely on explicit or implicit forms of commensuration. Think only of the classificatory work that is involved in claiming that BME individuals are more highly represented in COVID infections and deaths.

${ }^{59}$ Infantino, note 12.

${ }^{60}$ See Martha Lampland, 'False numbers as formalizing practices' (2010) Social Studies of Science 377-404.
} 
things wrong, to the extent that they create what they purport to measure. At least some of the contributors to her collected case-studies take a post-positivist approach,61and many see the point of the exercise of making indicators as creating rather than resolving controversy over the meaning of ostensibly shared values. ${ }^{62}$

But it is arguable that COVID indicators have had only very limited success even in these terms. To be clear, it is not that other global social indicators, such as the Pisa measures of educational levels, or the World Bank measures of Better Business opportunities, or Transparency International's claims about corruption levels worldwide, succeed because they get things 'right'. Nor am I suggesting that they are incontestable or uncontested. Far from it. But the contestation itself presupposes that such indicators are widely cited and that a certain international hierarchy of ranking is widely shared - and is therefore difficult to change without contestation. This is far from the case with COVID rankings. The Johns Hopkins university indicator for example was widely used but it collated existing data rather than building its own and it made no pretences to ranking. The DEEP KNOWLEDGE website, which did rank countries, issued only the one snapshot in May and then went quiet.

The instability of rankings obviously had a lot to do with what appeared to be the changing impact of the virus itself in different places over time. But even to establish such varying outcomes required some a priori standardisation of the definitions and practices used for defining COVID in each country. Yet this (to date) has not been achieved. For example, Belgium is notorious for using an expansive definition of dying with the virus as dying from the virus; in the UK the definition of death figures included only people who died within 28 days of testing positive for coronavirus, and other ways of measuring suggested that the number of deaths was higher. Both the WHO and the leading medical journal, The Lancet, pleaded for the introduction of similar criteria for all countries. Worse, once it became clear how often COVID can be present even without symptoms, the number of those infected came to be seen simply as a function of how much testing was being carried out- something that varied enormously between and within countries. ${ }^{63}$ The alternative criterion that increasingly came to be recommended was to rely on excess deaths in any one year as compared to the average of other years.

But data about excess deaths tells us nothing about the number of infections, and its reliability again depends on how and how well deaths are measured, including how far other differences in the number of deaths from other causes, for example from other health conditions, road accidents or crime, are entered into such calculations. In any event, this was not the usual source of the numbers collated by Johns Hopkins University or the World Bank, nor were excess deaths the starting point for the statistics reworked for purposes of explanation and policy making in the comparative tables and figures published by the daily newspapers reported. These continued to focus on the changing numbers of medically certified deaths and infections even after it (quickly) became clear that the number of deaths did not mean the same over time and across different places and that infection numbers depended on levels of testing.

The record is no better when it comes to underlying assumptions about the causes of COVID and how best to deal with it. To a large extent this is because the relevant data is recent and changing and its interpretation is affected by the spread of the disease, its mutations, the changing risks it represents, and variation in those being most affected. But the sense of all being in flux is also underlined by the extent to which COVID numbers are produced daily via dashboards rather than annual snapshots. This means that countries can change their relative position in a short time. Places such as Italy which fared badly

\footnotetext{
${ }^{61}$ Rene Urueña, 'Indicators and the law', in Merry et.al., 2015 note 1. For a recent approach along these lines see Andrew Lang, 'International lawyers and the study of expertise: representationalism and performativity' in Research Handbook on the Sociology of International Law (Moshe Hirsch and Andrew Lang eds. 2020), 122.

${ }^{62}$ But David Nelken, in 'Conclusion: Contesting social indicators' in Merry et. al. (2015) note 1, 317, questions whether this is compatible with the other purposes attributed to indicators.

${ }^{63}$ The WHO calculated that one in ten of the world's population may have been infected as of October 2020 whilst $70 \%$ of recorded cases came from only ten countries. https://www.bbc.com/news/world-54422023.
} 
in the so called first wave of the disease ${ }^{64}$ are amongst the most successful (so far) in handling the threatened second wave; others, such as Israel, that were stars in the first wave, are currently trapped in escalating efforts at lockdown to deal with the second wave. ${ }^{65}$ And the changing and often unpredictable and unpredicted news of the spread of COVID reinforced doubts about whether experts and politicians really know the answer. It is, above all, difficult to have stable rankings of places with best practices when there is no proven answer to the question of the best response to take to COVID. Of course, it is not that we have learned nothing. ${ }^{66}$ As far as the causes of the epidemic spreading, we are told of the heightened risks for care homes, for certain categories of victims, such as health workers, the old, BMI people, the poor, and those compelled to work and shop in dangerous conditions. Some Asian countries have shown the importance of reducing the period from the first appearance of symptoms to the isolation of the individual. ${ }^{67}$ There is a growing consensus that best practice includes making tests extensive and affordable, tracing and isolating, imposing social distancing early and keeping the public well informed and on side.$^{68}$ Closing borders, as done quickly in Australasia, can keep out those travellers who might bring with them infection.

Undoubtedly, COVID indicators did play an important part in an ongoing process of signalling danger and justifying - or attempting to justify -national and locally imposed curbs on behaviour. But some places did badly despite following recommended policies, as seen in the failure of stringent policies in France, or the level of excess death rates in Peru despite the long lockdown. ${ }^{69}$ And the cross-national differences in these curbs reinforced doubts about the appropriateness of each response and the question remains open whether and when such requirements were timely and effective. ${ }^{70}$ There was considerable uncertainty, confusion and contradiction about the exact ways to implement crucial prophylactic measures such as social distancing, handwashing and the wearing of masks. For example, it was said that people may become more complacent when wearing masks. ${ }^{71}$ They may end up re-using them, which is unhygienic, use masks sold on the black market, or wear homemade masks, which could be of inferior quality and essentially useless. Even where the experts now seem agreed, it is precisely using indicators to learn that unsettles their normative efficacy. People find it difficult to treat the latest decrees and accompanying set of rules as absolute - when only shortly before different advice was being given and diametrically opposite rules were in force. ${ }^{72}$

Consensus on best practice is more a precondition of successful use of indicators than an outcome of them. Disagreements between experts (and lack of clarity whether politicians were following 'the

\footnotetext{
${ }^{64}$ Roberto Volpi and Eugenio Serravalle, Coronavirus Covid-19: No! Non è andato tutto bene (2020).

${ }^{65}$ Prime Minister Benjamin Netanyahu's cabinet decided on Thursday to tighten Israel's coronavirus lockdown after he voiced alarm that a surge in infections was pushing the nation to "the edge of the abyss," the YNet news site said. Israel went back into lockdown on September 18. But over the past week, the number of daily new cases has reached nearly 7,000, severely straining the resources of some hospitals. https://www.globaltimes.cn/content/1201955.shtml

${ }^{66} \mathrm{https}$ ://campaignforsocialscience.org.uk/news/an-immune-system-for-the-body-politic-using-social-science-to-controlCOVID-19/

${ }^{67}$ https://www.bbc.com/news/world-asia-51970379

${ }^{68} \mathrm{Id}$.

${ }^{69} \mathrm{https}: / / w w w . b b c . c o m / n e w s / w o r l d-l a t i n-a m e r i c a-53150808$ -

${ }^{70}$ Doubts have been sown even about the effectiveness whether lockdowns imposed after the first wave of the virus. See the study by J.P. Morgan cited at https://www.dailymail.co.uk/news/article-8347635/Lockdowns-failed-alter-coursepandemic-JP-Morgan-study-claims.html. Of course, taking Peru as an example, this only testifies to the need to recognise that 'best practices' will not work the same way in different contexts. See https://www.bbc.com/news/world-latinamerica-53150808.

${ }^{71}$ https://www.asiaone.com/lifestyle/doctor-says-wearing-face-mask-can-increase-your-risk-coronavirus-infection-heres-why

${ }^{72}$ Changing advice over the need to wear masks was only the most obvious of these switches.
} 
science' or just using what suited them) weakening the credibility of COVID indicators. This was also a period where scientific expertise on matters of policy (as with climate change) was taken desperately seriously by some and harshly questioned by others. As important was the way the transnational level of policy making tended to be subordinated here to the national level. ${ }^{73}$ This was not a situation where governments necessarily felt the need to respond to the pressure of naming and shaming of influential transnational (or even USA-sponsored) indicators. Transnational authorities, such as the WHO, following a period of caution in handling earlier epidemics, tried to get traction for their warnings and recommendations. But they often went unheard. This was not helped by their own hesitation in declaring a pandemic, and their equivocation over the benefits of wearing masks. ${ }^{74}$ Their authority was also directly challenged by the USA who alleged that they had showed too much indulgence towards China and who threatened to withdraw funding. ${ }^{75}$ Thus, the lead in policy making to deal with COVID was usually taken by nation states, sometimes, as in countries such as the USA and Brazil, led by politicians who were quick to cast doubt on expertise. If some used global social indicators selectively so as to gain legitimacy for their policies, as important, some of the makers of indicators themselves sought endorsements from political leaders (see figure 6 from the DEEP KNOWLEDGE website).

Figure 6 The DEEP KNOWLEDGE Indicator and political endorsement. ${ }^{76}$

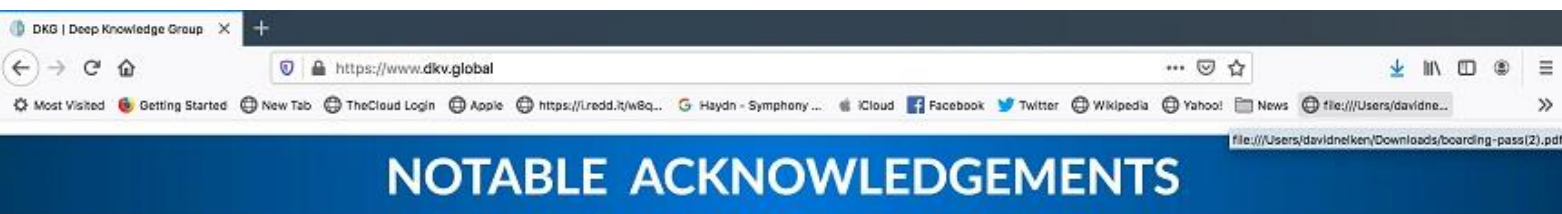

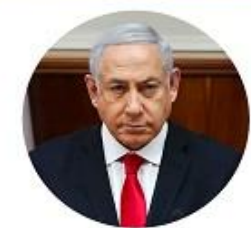

Benjamin Netanyahu Prime Minister of Isroel
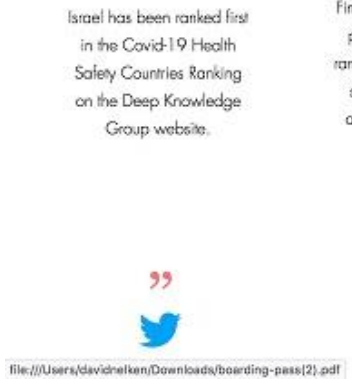

99

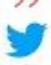

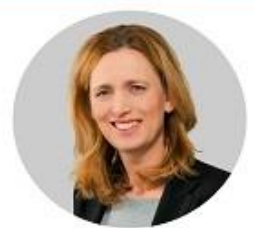

Karin Prien

German Minister for Education, Science and Culture

Gemrany is very for ahead in

the country comparison

Compored to the aher

courtries, Germany curently

hos the best socurity and

sobblily ranking in Europe and

is dso che of the leading

rations worktwide in terms of crisis monagement:

99

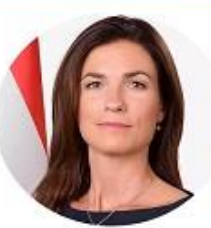

Judith Varga

Hungarian Minister of Justice

We are grateful tor all heatheare wowkers and first responders botting the coronovirus. Hungary will continue b focus all its efforts on protecting the lives of its cilizens and mitigating the codvetse health and economic impocts of the pandernic.

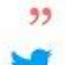

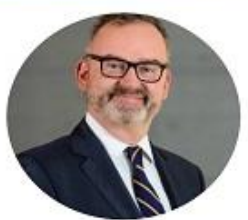

Fobrice Filliez Ambassador of Switzerland to Singapore Deep Knewledge Group's report, based on 130 parameters, ranks Switzerland \#1 due bo is econamy's rosilience \& caroful wors to relax lockdown withous sexificing public heath and safety.

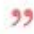

\footnotetext{
${ }^{73}$ On the continuing need for national endorsement of transnational standards even in successful efforts at governance see the discussion of normative 'settlement' in Terence. C. Halliday and Gregory Shaffer, Transnational Legal Orders (2015).

74 The WHO was somewhat more authoritative later on, for example in its directives regarding the six requirements that needed to be satisfied before exiting from lockdown.

75 https://www.bbc.com/news/world-us-canada-53327906

${ }^{76}$ See https://www.dkv.global/ (this self-advertisement is still on the website despite more recent developments contradicting earlier successes).
} 
A final consideration. Could it be that work on global social indicators has focussed too much on the similarities and not on the contrasts between different kinds of indicators and what they seek to measure ${ }^{77}$ Paradoxically, it may be more difficult to commensurate here than in the case of more established global social indicators precisely because, in some respects, there is less room for argument about the meaning of the data. Determining levels of corruption or of respect for the rule of law requires imposing definitions on given behaviours and disregarding competing perspectives. Cultural hegemony is all. But questions of death and infection are not so culturally nuanced. Thus, countries from the 'global north' such as the USA or Europe, where indicators are normally developed, continue to make their claims to superiority in other matters rated by global indicators. But their relative lack of success in dealing with COVID did not correlate with the received common sense of which countries usually stand higher in such rankings ${ }^{78}$ Moreover, the results of the COVID epidemic did not coincide with what had been predicted the previous year by a leading indicator (again organised by Johns Hopkins University) of which countries were supposedly best prepared to deal with this kind of health emergency (see figure 7). ${ }^{79}$

Figure 7 Countries best prepared?

\section{The Countries Best Prepared To Deal With A Pandemic}

Index scores by level of preparation to respond to an epidemic/pandemic*

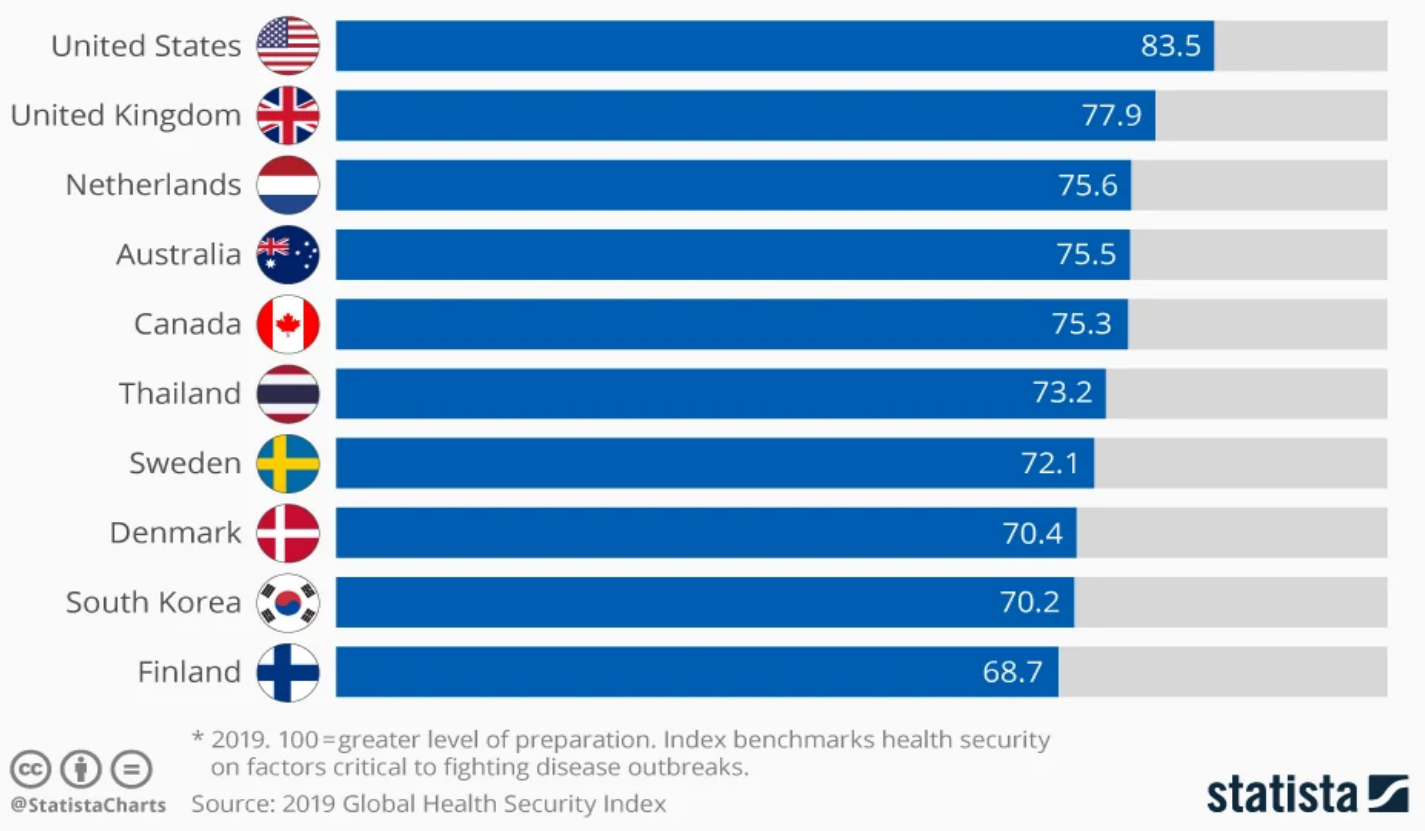

${ }^{77}$ For example, financial indicators that rank creditworthiness clearly affect what they measure (once the market reacts) but here both measuring and changing are treated as compatible.

${ }^{78}$ Although places such as Scandinavia (with the possible exception of Sweden), and South Korea, did handle COVID in conformity to expectations.

${ }^{79} \mathrm{https} / /$ www.weforum.org/agenda/2020/02/these-are-the-countries-best-prepared-for-health-emergencies/. Surprisingly, even after what we know - or think we know-about the effects of COVID, official indicators such as the EU's INFORMRISK INDEX still stress that it is poorer countries that are most at risk of collapsing health systems and consequent humanitarian crises. See haearehttps://drmkc.jrc.ec.europa.eu/inform-index/INFORM-Covid-19. But this indicator does, at least, add the qualifier, 'The main scope of the INFORM COVID-19 Risk Index is global and regional risk-informed resource allocation, i.e. where comparable understanding of countries' risk is important. It cannot predict the impacts of the pandemic in individual countries.' 
It remains unclear whether the vaccines now in preparation will provide a technical 'fix' that avoids having to examine the wider social structural reasons for the relative failure of better resourced countries in responding to the challenge posed by COVID. There are worries about whether too much is being expected of them especially in terms of prevention. It is also not obvious how far the shock of this experience will necessarily lead to larger social changes that will help countries that did less well this time be better prepared to deal with any new epidemic ${ }^{80}$ Insofar as the making of indicators also includes attempts to monitor such changes, despite all their problems these exercises will continue to merit attention.

\footnotetext{
${ }^{80}$ The lessons ultimately learned from the epidemic may also depend on which countries succeed in producing an effective vaccine and how far they take short cuts in safety measures in order to do so. Will China (or Russia) prevail, or will the USA and UK recover some of their lost prestige by coming up with an effective solution?
} 


\section{Health Data for Global Monitoring of the COVID-19 Pandemic - Historical Background and Preliminary Analysis}

Nathan Genicot*

The central place of numbers in public debate has been one of the striking features of the COVID-19 crisis. The news was, of course, already saturated with quantitative information, but rarely has so much attention been paid to curbs, models, or indicators such as the reproduction number $(\mathrm{R})$ or intensive care bed-occupancy rates. Since the beginning of the pandemic, various international indicators have flourished, and cross-country comparison has been in full swing. ${ }^{1}$

As has been well-documented by the literature, recent decades have witnessed a significant rise in the use of international indicators and rankings which have been described not only as mere purveyor of information, but also as technology of governance. ${ }^{2}$ In a way, the response to the COVID-19 pandemic largely confirms this trend. ${ }^{3}$ However, in order to better understand the role played by these tools in this context, it is critical to bear in mind the specific circumstances of public health. Indeed, the fact that health has been prioritised by most public authorities during this crisis is significant since public health and epidemiology are heavily based on statistics.

In this regard, this article aims to study the production and management of health data related to the coronavirus pandemic at the global level. Giving a brief historical overview, I first describe how the collection of relevant data for the fight against infectious diseases has been a concern since the very birth of epidemiology. Then, I highlight the two rationales - audit and surveillance - that underpin this concern. Lastly, I try to identify some key features that characterise the current pandemic with regards to health data, focusing notably on the role of the World Health Organization (WHO) and certain actors related to it. I hope, on the one hand, to show how historical insight may shed light on the present use of international health indicators, and, on the other, to underscore the new elements that this crisis has revealed.

\section{Statistics at the Birth of Epidemiology}

The history of public health and the history of statistics are closely intertwined. Historians agree that the $19^{\text {th }}$ century marked the real beginning of epidemiology as it is understood today. Along with poverty, unemployment and criminality, disease was one of the fields affected by the avalanche of numbersfamously described by Hacking ${ }^{4}$ - that occurred in the 1820s. During this period of important social reform and public interventions, medical science had been strongly impacted by the statistical practice of both states and insurance companies. ${ }^{5}$

\footnotetext{
* Nathan Genicot, Centre Perelman de Philosophie du Droit, Université Libre de Bruxelles (nathan.genicot@ulb.be).

${ }^{1}$ Indicators have been produced by international organisations, universities, newspapers, and companies.

${ }^{2}$ S E Merry, K Davis, and B Kingsbury (eds.), The Quiet Power of Indicators: Measuring Governance, Corruption, and Rule of Law (Cambridge University Press, 2015); A Cooley and J Snyder (eds.), Ranking the World: Grading States as a Tool of Global Governance (Cambridge University Press, 2015); B Frydman and A Van Waeyenberge (eds.), Gouverner par les standards et les indicateurs : de Hume aux rankings (Bruylant, 2013); K Davis, A Fisher, B Kingsbury, and S Engle Merry (eds.), Governance by Indicators: Global Power through Quantification and Rankings (Oxford University Press, 2012).

${ }^{3}$ B George, B Verschuere, E Wayenberg, and B Zaki, 'A Guide to Benchmarking COVID-19 Performance Data' (2020) 80 Public Administration Review 696-700.

${ }^{4}$ I Hacking, 'Biopower and the avalanche of printed numbers' (1982) 34 Humanities in Society 279.

5 T M Porter, 'Medical Quantification: Science, Regulation and the State' in G Jorland, A Opinel, G Weisz (eds.), Body Counts (Montreal: McGill-Queen's University Press, 2005), 394-402 at 399.
} 
In its early years, epidemiology was only concerned with infectious diseases, ${ }^{6}$ paying particular attention to environmental and social influences on health. The most prominent figure in this regard is undoubtedly William Farr, who served for 40 years as superintendent of statistics at the General Register Office of England and Wales. He conceived epidemiology in a very pragmatic way: his main goal was to understand epidemics by linking unhygienic conditions with illness in order to develop strategies against outbreaks. ${ }^{7}$ Having noticed that vital phenomena such as births, deaths and disease were affected by regularities and patterns, Farr quickly understood how critical it was to collect data on causes of death as completely and precisely as possible, and to establish precise and consistent classification of disease. ${ }^{8}$ The gathering of data, as we see, has always been at the core of public health practice. Farr went even further in comparing several rates (death, sickness, fertility, etc.) between cities and creating a "healthy district" rate which served as "a standard against which to measure the "insalubrity' of other districts". 9

At the international level, the issue of tackling epidemics had been a concern long before the creation of the WHO in 1948. A century earlier, Paris hosted the first international health conference aimed at controlling outbreaks while the Congrès international d'hygiène was organised regularly. ${ }^{10}$ Unsurprisingly, the mission of the Office international d'hygiène publique - one of the first international health organisations established in the 1900s — was notably to collect and diffuse epidemiological and statistical information from member countries in order to become a world observatory on epidemics. The creation of the Health Organisation as part of the League of Nations in 1923 confirmed the trend towards the internationalisation of health statistics. As Edgar Sydenstricker, who served as Chief of the Service of Epidemiological Intelligence and Public Health Statistics of this organisation, claimed: "Comparable vital statistics for all nations, and a worldwide exchange of current information on the prevalence of disease (...) are no longer academic ideals but have become necessities. They are essential to a sound development of international cooperation for prevention of disease". ${ }^{11}$ The need for comparable information was indeed a key issue, and the substantive differences between countries in the way data were collected and classified was a nightmare for international epidemiologists. Thus, extensive work was done to achieve greater uniformity across the procedures of member states. ${ }^{12}$

In the aftermath of the Second World War, the WHO emerged as part of the United Nations. The international public health experts who contributed to its birth shared the view that science was essential to the improvement of health conditions at the global level. ${ }^{13}$ Moreover, they believed that medical science should be disseminated internationally. ${ }^{14}$ Accordingly, they thought that the future WHO's Health Statistics Division should not only collect raw data on epidemics, but also gather and analyse all types of data related to health. Therefore, they considered that, alongside descriptive statistics, the use

\footnotetext{
${ }^{6}$ It wasn't until the 1940s that non-infectious diseases, such as degenerative chronic diseases, came to the attention of epidemiologists.

${ }^{7}$ A Hardy and M E Magnello, 'Statistical methods in epidemiology: Karl Pearson, Ronald Ross, Major Greenwood and Austin Bradford Hill, 1900-1945’ (2002) 47 Sozial- und Präventivmedizin 80 at 81.

${ }^{8}$ M. Donnelly, 'William Farr and Quantification in Nineteenth-Century English Public Health' in G. Jorland, A. Opinel, G. Weisz (eds.) Body Counts, (McGill-Queen's University Press, 2005), 251-65 at 257.

9 ibid at 260.

${ }^{10}$ C Paillette, 'Épidémies, santé et ordre mondial. Le rôle des organisations sanitaires internationales, 1903-1923' (2012) 2 Monde(s) 235.

${ }^{11}$ E Sydenstricker, 'The Outlook for International Vital Statistics' (1924) 14 American Journal of Public Health 832-38.

${ }^{12}$ N V Lothian, 'The Service of Epidemiological Intelligence and Public Health Statistics' (1924) 14 American Journal of Public Health 287-90.

${ }^{13}$ Y-T Lin, 'Making Standards to Quantify All Health Matters. The World Health Organization's Statistical Practices, 19461960' (2017) 11 Monde(s) 247-66 at 252.

14 ibid.
} 
of inferential statistics was needed in order to compare and assess the different public health interventions put in place around the world. ${ }^{15}$

\section{Data collection for audit and surveillance purposes}

Over the following decades, the WHO became increasingly involved in the enhancement of national public health officials' expertise. It launched projects in numerous countries to support the development of national statistical services and contributed to the organisation of training in health statistics in various universities and institutes. ${ }^{16}$ The introduction of computers was a key element in the improvement of health data processing, and the WHO strongly promoted the development of informatics. The WHO's emphasis on the implementation of proper coordinated health information systems can be described in the light of two rationales: audit and surveillance. These two logics should not be sharply separated (indeed, they can both be traced back to William Farr's work), but it seems fruitful to stress their respective specificity.

Let us first look at the audit dimension. From the 1980s onwards, international health governance underwent a series of structural changes, one of the most important being the positioning of the World Bank as a major actor in this field. Its development assistance policies started to include new issues, such as education, health and population control. Health was no longer seen as a consequence of economic growth and development, but rather as a means to achieve them. ${ }^{17}$ The $\mathrm{WHO}$, in contrast, lost some of its power, partly due to the diminution of its regular budget and its resulting greater dependence on certain important donors. ${ }^{18}$ The end of the 1990s also saw the massive development of public-private partnerships, in which companies, foundations, non-governmental organisations (NGOs) and international organisations were all participating. ${ }^{19}$ All these elements fostered the emergence of a culture of performance and audit: the idea that countries must be assessed by various medical indicators in order to determine which ones should receive funding, and that metrics should also be used to identify which public health interventions are the most cost-effective. Managerial techniques were based on private sector practices introduced by foundations such as the Bill and Melinda Gates Foundation or the Bloomberg Initiative. ${ }^{20}$ Even international organisations resorted to such practices, with the World Bank stating that "development performance should be evaluated on the basis of measurable results", in $1998 .^{21}$

\footnotetext{
${ }^{15} \operatorname{Lin}(\mathrm{n} 13)$ at 257.

${ }^{16}$ A Fisher, 'From Diagnosing Under-immunization to Evaluating Health Care Systems: Immunization Coverage Indicators as a Technology of Global Governance' in K E Davis, A Fisher, B. Kingsbury, S E. Merry (eds.), Governance by Indicators, (Oxford: Oxford University Press, 2012), 217-46 at 222; WHO, The third ten Years of the WHO. 1968-1977 (WHO, 2008) 279.

17 J P Ruger, 'The Changing Role of the World Bank in Global Health' (2005) 95 American Journal of Public Health 60-70.

${ }^{18}$ T M. Brown, M Cueto, and E Fee, "The World Health Organization and the transition from "international" to "global" public health' (2006) 96 American journal of public health 62-72.

19 J-P Gaudillière, 'Un nouvel ordre sanitaire international ? Performance, néolibéralisme et outils du gouvernement médicoéconomique’ (2016) 52 Écologie \& politique 107-24 at 112.

${ }^{20}$ On this matter, see D Reubi, 'Epidemiological accountability: philanthropists, global health and the audit of saving lives' (2018) 47 Economy and Society 83-110.

${ }^{21}$ The World Bank, Comprehensive Development Framework quoted in D Restrepo Amariles, The Rise of Transnational Legal Indicators. Empirical Accounts of Law in a Global Society, Doctoral dissertation (Université Libre de Bruxelles, 2014). For an overview of the abundant literature on this issue, see A Broome and J Quirk, 'Governing the world at a distance: the practice of global benchmarking' (2015) 41 Review of International Studies 819-41.
} 
In this shifting landscape, the WHO initiated a series of reforms in order to better position itself in the field of international health. The idea that global health threats were growing and that the WHO had to assume the role of coordinator on the world scene started to spread. Gro Harlem Brundtland, appointed Director-General in 1998, fully adopted the rhetoric of the World Bank, announcing that the WHO was to become a "department of consequence." 22 The publication of the World Health Report 2000-Health Systems: Improving Performance, wherein national health system performances are measured and ranked, is a perfect illustration of this evolution. ${ }^{23}$

Surveillance is the second dimension that is significant in understanding the evolving relationship of public health and statistics in the second half of the $20^{\text {th }}$ century. This notion was put forward in the USA during the 1950s and the 1960s by Alexander Langmuir, chief epidemiologist at the Center for Disease Control and Prevention. ${ }^{24}$ The term was previously used to describe the follow-up on contacts of persons affected by infectious diseases. Langmuir extended the scope of this idea to include the surveillance of the disease itself, involving the systematic collection, analysis and interpretation of data related to a particular disease. This comprised of not only case detection, but also studies that analysed the distribution and spread of infections and serological surveys. In addition, the developed notion of surveillance aimed to highlight that quarantine measures were not the only policy actions available to combat infectious disease. The emphasis was hence placed on the need for rapid transmission of data so as to allow proper public health action. In the 1960s, the WHO adopted this new approach to communicable diseases, replacing the concept of epidemiological intelligence with that of epidemiological surveillance. ${ }^{25}$

The last key period leading up to the arrival of the global public health system that we know today started in the 1990s. Prior to that time, industrialised countries tended to believe that infectious diseases were no longer a problem, at least not for them. However, the accelerating globalisation at the end of the century was seen as fostering the circulation of viruses, and therefore as requiring a better supranational structure for disease monitoring. ${ }^{26}$ One of the main concerns pertained to the poor communication of information about outbreaks by the states. Indeed, states were often reluctant to acknowledge the existence of an epidemic in their territory, concerned about the adverse consequences for their economy caused by such an announcement. In this regard, the surveillance system put in place by the 1969 International Health Regulation relied completely on the willingness (and indeed, the openness) of the member countries in conveying information about diseases within their borders. It also only dealt with three diseases: cholera, plague and yellow fever. The system was clearly outdated with respect to the issues of the time. ${ }^{27}$

By 1995, the WHO began to work on a substantive reform of its functioning which culminated in the adoption of the 2005 International Health Regulation (IHR) that is currently in force. ${ }^{28}$ Among other things, the IHR 2005 set up a comprehensive surveillance system and requires state parties to implement national surveillance structures which must assume a proactive role in the monitoring of all events that may constitute public health emergencies within their territories (Article 5) ${ }^{29}$ Alongside this country

\footnotetext{
${ }^{22}$ Brown, Cueto, and Fee (n 18) at 70.

${ }^{23}$ Gaudillière (n 19) at 120.

${ }^{24}$ L Weir and E Mykhalovskiy, 'The Geopolitics of Global Public Health Surveillance in the Twenty-First Century' in A. Bashford (ed.) Medicine at the Border: Disease, Globalization and Security 1850 to the Present (London: Palgrave Macmillan UK, 2007), 240-63.

${ }^{25}$ WHO, The second ten Years of the WHO. 1958-1967 (WHO, 1968) 95.

${ }^{26}$ Weir and Mykhalovskiy (n 24) 243.

${ }^{27}$ J Youde, 'Mediating Risk through the International Health Regulations and Bio-Political Surveillance' (2011) 59 Political Studies $813-30$ at 816.

${ }^{28}$ International Health Regulation 2005.

29 ibid, Art 5.
} 
notification system, the regulation also contains a major innovation. Namely, the possibility for the WHO to be informed of potential health emergencies by non-official sources of information (Article 9) such as sub-national agencies, NGOs, news or internet sources. ${ }^{30}$ Notably, the inclusion of this procedure in the IHR 2005 can be explained by the prior emergence of private companies, such as ProMed-mail or the Global Public Health Intelligence Network that specialised in the early detection of disease outbreaks through the screening of various informal sources. The idea was that the WHO could rely on the work of these actors in order to detect and declare health emergencies without state approval. The concept of syndromic surveillance was created to describe this constant and near real-time monitoring of unstructured data aimed at detecting early signs of outbreaks. ${ }^{31}$ Thanks to the power of algorithms and big data, these new techniques were supposed to track outbreaks in a more efficient way than classical epidemiological methods.

\section{The Global Management of Health Data during the COVID-19 Crisis}

In light of these developments, how can we describe the management of data and the production of international indicators during the COVID-19 pandemic? This crisis has incited a new level of use and reliance on digital technologies with regards to the collection of data and its subsequent visualisation and analysis.

For examples of the growth of technologies on data collection, one only has to think of all the contact tracing app initiatives which have emerged since the beginning of the health emergency. Their goal is indeed to gather the most precise information in order to allow decision-making on the basis of this information. Similarly, we can look at the COVID-19 Surveillance Digital Data Package launched within the District Health Information Software 2 (DHIS2). ${ }^{32}$ Created at the end of the 1990s, this platform claims to be the world's largest health management information system and has been implemented in dozens of low- and middle-income countries for the collection, analysis, visualisation and sharing of health data. The newly created COVID-19 package is specifically dedicated to the fight against the coronavirus and is already operational or in development in 50 countries. ${ }^{33}$ Its various functions include, among other things: the registering and tracking of suspected cases; the monitoring of patient outcomes; the screening of travellers coming from risk locations and, where necessary, their enrolment into a follow-up programme (as well as tools that facilitate the communication and analysis of all this information).

The possibilities offered by technologies also partly explain the great variety of actors who have created visualisation tools. Indeed, alongside the $\mathrm{WHO}^{34}$ to which I return below, dashboards and indicators have been developed not only by countries and regional organisations (such as the European Center for

\footnotetext{
${ }^{30}$ International Health Regulation (n 28) Art 9. See also Youde (n 27) at 821.

${ }^{31}$ S L Roberts and S Elbe, 'Catching the flu: Syndromic surveillance, algorithmic governmentality and global health security’ (2017) 48 Security Dialogue 46-62.

32 'DHIS2 Overview' (DHIS2) <https://www.dhis2.org/overview>. This software is developed by the Health Information Systems Programme which is part of the University of Oslo. See E Adu-Gyamfi, P Nielsen, and J Ivar Sæbø, 'The Dynamics of a Global Health Information Systems Research and Implementation Project' (2019) Proceedings of the 17th Scandinavian Conference on Health Informatics; G Lurton, 'Santé globale et mesure: Un nouveau paradigme pour de nouveaux acteurs' (2020) Cahiers du Comité pour l'histoire de l'Inserm [en ligne] 73-80.

33 'COVID-19 Surveillanace Digital Data Package' (DHIS2) <https://www.dhis2.org/COVID-19>.

34 'WHO Coronavirus Disease (COVID-19) Dashboard (WHO) <https://covid19. who.int/>.
} 
Disease Prevention and Control ${ }^{35}$ ), but also by universities (e.g. Johns Hopkins University ${ }^{36}$, Oxford's Our World in Data ${ }^{37}$ ), private groups (e.g. Worldometer ${ }^{38}$ ), and newspapers (e.g. BNO News $\left.{ }^{39}\right) \cdot{ }^{40} \mathrm{~A}$ number of these projects are highly influential. The Johns Hopkins Dashboard is, for instance, regularly cited by journalists or public authorities, and is the main source on which the World Bank's own dashboard, Understanding the COVID-19 pandemic through data, is based. ${ }^{41}$ This abundance of data visualisation tools would not have been possible without the greater accessibility of information and the progress of artificial intelligence that we are seeing today. Since most countries publish their own data online, it is relatively easy for all these indicators to refer to it. In addition, many indicators consult freely accessible national newspapers as a complementary source. However, artificial intelligence techniques are arguably also essential to the designing of such tools, as they facilitate the automated updating of this data.

In this landscape, the WHO might seem outdated as it is far from being the sole leading authority. The crisis has revealed to the public an array of powerful private groups, foundations, companies and networks active in the health field with links to the academic world and international organisations. This has resulted in the growing influence of the private sector on health metrics-from its production to its analysis and communication. However, one should not exaggerate the WHO's loss of influence. First, the organisation adopted a strategy of working with non-state actors in various fields for years. Rather than trying to be the sole actor, the WHO tries to position itself as the coordinator of global health governance by building relationships with various partners. The IHR 2005, as explained earlier, was designed to foster collaboration between the WHO and firms specialising in syndromic surveillance. The DHIS2 software mentioned above offers another good illustration of this kind of collaboration: a specific WHO package has been developed in order to "support adoption of WHO health data standards into national routine health management information systems" and is now implemented in 39 countries. ${ }^{42}$

In relation to the latter point, another important element for understanding the WHO's role as coordinator and collaborator during the pandemic relates to its work of classification and standardisation. As we know, an important aspect of statistics' power lies in their ability to transform reality through the establishment of categories. ${ }^{43}$ In the area of health, the International Classification of Diseases, in constant evolution for more than a century, impacts on many components of medical care, including administrative and financial. ${ }^{44}$ With regards to the COVID-19 crisis, the WHO has published a large number of technical guidance documents advising governments and health professionals on

\footnotetext{
35 'COVID-19 situation update worldwide' (European Centre for Disease Prevention and Control) <https://www.ecdc.europa.eu/en/geographical-distribution-2019-ncov-cases>.

36 'COVID-19 Dashboard by the Center for Systems Science' (Johns Hopkins University) $<$ https://coronavirus.jhu.edu/map.html >.

37 'Coronavirus Pandemic (COVID-19)' (Our World in Data) <https://ourworldindata.org/coronavirus>.

38 'COVID-19 Coronavirus Pandemic' (Worldometer) <https://www.worldometers.info/coronavirus/>.

39 'Tracking coronavirus: Map, data and timeline' (BNO News, Apr 2020) <https://bnonews.com/index.php/2020/04/thelatest-coronavirus-cases/>.

${ }^{40}$ See the contribution of Marta Infantino, Global Numbers in the Pandemics: The Spread of Indicators and How to Spot Them (in this Working Paper) for a comparative study of many of these indicators.

41 'Understanding the Coronavirus (COVID-19) pandemic through data' (World Bank) $<$ http://datatopics.worldbank.org/universal-health-coverage/coronavirus/>.

42 'DHIS Digital Data Packages for WHO' (DHIS2) <https://www.dhis2.org/who>.

43 "Enumeration demands kinds of things or people to count. Counting is hungry for categories. Many of the categories we now use to describe people are byproducts of the needs of enumeration." in Hacking (n 111) at 280.

${ }^{44}$ G C Bowker and S . Star, Sorting Things Out. Classification and Its Consequences (MIT Press, 1999).
} 
various issues, including, naturally, the collection and coding of data.$^{45}$ If we consider, for example, the crucial question of certifying death due to COVID-19, many problems may occur (comorbidities, no confirmed diagnostics, etc.). Guidelines indicating in which cases COVID-19 should be recorded as a cause of death are thus essential for any cross-country comparison and surveillance at supranational level. ${ }^{46}$ More generally, the WHO recommendations include: sampling strategies for patient testing; case definitions (suspected, probable, confirmed); delimitation of age groups; contact tracing; periodicity of reporting and so forth. These elements may appear innocuous, but they largely determine the content of the data published by the states, and consequently the information provided by the indicators mentioned above. Besides, these technical guidance documents are often implemented into software programs, thus fostering the process of standardisation. This is indeed the case for the DHIS2 COVID-19 package which claims to include "standard meta-data aligned with the WHO's technical guidance on COVID-19 surveillance, case definitions and implementation guidance to enable rapid deployment in countries". ${ }^{47}$

\section{Conclusion}

As we have seen, the hunger for data has always characterised the health field. However, in this respect, a key element that the crisis has revealed is the growing importance of the private sector and of publicprivate alliances in the production and processing of data. The landscape of international health statistics appears fragmented among various actors of different kinds. Nonetheless, all these actors share the belief that numerous and accurate data ensure objectivity, and are thus essential to the fight against the virus. These data not only allow the assessment of the efficacy and cost-effectiveness of public measures, but are also the prerequisite for epidemiological surveillance both at the micro level (e.g. a contact tracing app that warns people when they have encountered a person who is infected) and the macro level (e.g. an epidemiological study aimed at determining the level of immunity reached in a population). In this sense, although an initiative such as the Apple-Google partnership for COVID-19 contact tracing ${ }^{48}$ may seem to have little in common with the work of the WHO during the pandemic, it is important to understand that it also forms a part of the new global health surveillance regime. It clearly illustrates the fact that major information technology companies, that present themselves as essential partners of state, tend to occupy a central place in the field of health data. Hence, looking at the socio-technical infrastructure that supports the life cycles of global health data can be an interesting perspective for further analysis of the role played by international indicators during the pandemic.

\footnotetext{
45 'Country \& Technical Guidance - Coronavirus disease (COVID-19)' (WHO) <https://www.who.int/emergencies/diseases/novel-coronavirus-2019/technical-guidance-publications>.

${ }^{46}$ Nonetheless, significant measurement differences remain between countries.

47 'COVID-19 Surveillance Digital Data Package' (DHIS2) <https://www.dhis2.org/COVID-19>.

48 'Privacy-Preserving Contact Tracing' (Apple/Google) <https://covid19.apple.com/contacttracing>.
} 


\title{
Towards Computational Indicators: Internet of Things, Data Analytics and Encoding in COVID-19 Contact Tracing Apps
}

\author{
David Restrepo Amariles*
}

\section{Introduction}

COVID-19 has revealed the critical role data plays in the exercise of social control. Most prominently, the key policy objective during the peak of the pandemic was defined in statistical terms, i.e. to "flatten the curve" of infections. Governments enacted draconian measures affecting individuals' rights and civil liberties to achieve said objective. The characteristics of SARS-CoV-2 (the virus causing the COVID19 disease) and its effects on the health of individuals and the socio-economic conditions of communities prompted governments to venture beyond traditional methods of data collection and analysis to secure epidemiological surveillance. Ultimately, they drew upon the opportunities offered by the internet of things (IoT) and big data analytics. In this context, mobile and cell tower location data were used to analyse the movement of people during and after the lockdown period, while contact tracing apps (CTAs) were developed with the purpose of tracking, analysing and mitigating the spread of the virus in the population. ${ }^{1}$

This short article focuses on CTAs. It analyses the data life cycle in CTAs (i.e. data collection, collation and analysis) to show, firstly, (1) that output data is technology-charged, and secondly, (2) that they enable a new generation of computational indicators. In contrast to traditional indicators, computational indicators draw on a combination of large-scale and multifaceted data collection through connected objects and the Internet. This includes computational data analysis, and data representation through encoding, such as encryption and social graphs. Finally, this article highlights how the inherently computational dimension of CTAs may contribute to embed technology into the enforcement of the pandemic mitigation restrictions (PMRs) enacted by governments, such as lockdowns, quarantines, social distancing and testing.

The International Health Regulations (IHR) of the World Health Organization (WHO), a binding instrument under international law, defines surveillance in Article 1 as the "systematic ongoing collection, collation and analysis of data for public health purposes and the timely dissemination of public health information for assessment and public health response as necessary". ${ }^{2}$ SARS-CoV-2 challenges the traditional SIR model of epidemiological surveillance used for the collection and analysis of data that is based on a threefold epidemiological status-susceptible, infected, and recovered (SIR). The new SEIR model includes the exposed as a new epidemiological status to account for the fact that the SARS-CoV-2 spreads through asymptomatic carriers. ${ }^{3}$ As Winkler and I argue elsewhere ${ }^{4}$, the SEIR

\footnotetext{
* David Restrepo Amariles, HEC Paris (restrepo-amariles@hec.fr).

I would like to thank Jan Lukeš who provide valuable research assistance for this paper.

${ }^{1}$ See two examples in the UK, Conor Reynolds, 'BT Confirms that it's Providing Gov'T with Mobile Location Data' ( $C B R$, March 2020) <https://www.cbronline.com/news/bt-mobile-phone-location-data-lockdown> and France 'Les statistiques issues du réseau de téléphonies mobiles au service de la lutte contre la pandémie de Covid-19' (Inserm, March 2020) <https://presse.inserm.fr/les-statistiques-issues-du-reseau-de-telephonies-mobiles-au-service-de-la-lutte-contre-lapandemie-de-COVID-19/38831/>. See also the MIT Technology Review Covid Tracing Tracker showing that around 50 countries have adopted or are in the process of adopting CTAs, 'MIT Technology Review Covid Tracing Tracker' (Flourish, Aug 2020) <https://public.flourish.studio/visualisation/2241702/>.

${ }^{2}$ Art. 5, International Health Regulations 2005.

${ }^{3}$ Zhou Tang et al., 'Prediction of New Coronavirus Infection Based on a Modified SEIR Model' (2020) MEDRXIV.

${ }^{4}$ See Matteo Winkler and David Restrepo Amariles, Governing the Disparate Effects of COVID-19 for Vulnerable Groups (Forthcoming).
} 
model requires the collection and real time use of large amounts of data from individuals, health facilities and disease clusters to be effective. This has led some scholars to argue that COVID-19 epidemiological surveillance has eventually become a data science issue. ${ }^{5}$

This article is divided in three sections. Section I analyses CTAs in light of the first two phases of the data life cycle of epidemiological surveillance, namely, data collection and collation. It shows that as a result of the models and technologies underpinning CTAs, the output data is prescriptive and technology charged. Section II addresses into the third phase of the data life cycle (data analysis) and highlights the distinct features of computational indicators. In particular, it illustrates how encoding and data representation may ultimately affect the exercise of social control during the pandemic, for instance, through the use of social graphs and the enforcement of PMRs. Section III concludes.

\section{Section I: Technology-Charged Data in COVID-19 Contact Tracing Apps}

The use of CTAs gained traction among policymakers to respond to the new SEIR model and support strategies to exit from lockdowns. ${ }^{6}$ CTAs are designed to help health authorities expand the range of sources used to collect epidemiological data and limit the adverse social effects of the coronavirus. As Hinch et al. states, "[a] measure of success for digital contact tracing is the extent to which it reduces onwards transmission of the virus whilst simultaneously minimising the number of people in quarantine." and as a consequence, the data they produce are technology-charged.

\section{Data Collection through IoT}

In addition to collecting medical data directly from individuals (as in the case of manual tracing and hospital records), CTAs also rely on the IoT. They encode data out of the interrelation between computing devices (i.e. mobile phones), thereby serving as a proxy for human interaction. Encoding allows the selection of relevant information from raw data and its conversion into a representation that is suitable for subsequent computational applications. The result is output data that is technologycharged because it encapsulates information shaped by the built-in models and technologies. For instance, the information contained in encounter data registered by encounter IDs reflects a set of choices in terms of epidemiological model (e.g. 15 minutes exposure to create a data point), system design (e.g. choice between GPS location vs. Bluetooth handshake), and software (e.g. decentralised vs. centralised processing). Therefore, scrutinizing the backend processes through which this epidemiological data is collected and encoded is necessary to can cast light on how the choice of models and technologies embedded in CTAs shape social control and law enforcement during the pandemic.

\footnotetext{
${ }^{5}$ See Callaghan, 'COVID-19 Is a Data Science Issue', (2020) Patterns 1. See also Bo Xu et al., 'Epidemiological Data from the COVID-19 Outbreak, Real-Time Case Information' (2020) 7 Scientific Data 106.

${ }^{6}$ Luca Ferretti, Chris Wymant, Michelle Kendall, Lele Zhao, Anel Nurtay, Lucie Abeler-Dörner, Michael Parker, David Bonsall, Christophe Fraser, 'Quantifying SARS-CoV-2 transmission suggests epidemic control with digital contact tracing'(2020) 268(1492) Science. Also see Robert Hinch, Will Probert, Anel Nurtay, Michelle Kendall, Chris Wymant, Matthew Hall, Katrina Lythgoe, Ana Bulas Cruz, Lele Zhao, Andrea Stewart, Luca Ferretti, Michael Parker, Ares Meroueh, Bryn Mathias, Scott Stevenson, Daniel Montero, James Warren, Nicole K Mather, Anthony Finkelstein, Lucie Abeler-Dörne, David Bonsall, Christophe Fraser, 'Effective Configurations of a Digital Contact Tracing App: A report to NHSX' (2020) accessible at Github: https://github.com/BDI-pathogens/covid19_instant_tracing/blob/master/Report\%20-\%20Effective\%20Configurations\%20of\%20a\%20Digital\%20Contact\%20Tra cing\%20App.pdf

${ }^{7}$ Ibid, at 2 .
} 
CTAs collect data through the app itself and the operating system (OS) of the mobile device in which it is installed. The majority of tracing apps developed in response to COVID-19 were designed to use the so-called "Bluetooth handshake", a quick and energy-efficient exchange of data (e.g. timestamps and encounter IDs) through Bluetooth between two devices with the tracing app installed. This proximitytriggered approach enables tracing by recording encounters between infected and exposed individuals without needing constant access to the internet and the geolocation information of individuals.

\section{System Design and Privacy}

The design of the system affects both the type of data that is collected and users' rights, such as privacy and data protection. Take the case of encryption. When users install the app, their phone is given a unique ID that is used to generate untraceable encounter IDs every approximate 15 minutes (to prevent tracking in the streets). This encounter ID is transmitted to other users, together with timestamp and signal strength (a proxy for distance), and equivalent information is received by the user. Once an infection is confirmed and the user shares the data in their phone with authorities, the impact of differences in design on individuals' rights to privacy and data protection begin to become apparent. In general, there are two main approaches - centralised and decentralised data processing. ${ }^{8}$ This distinction will be described in more detail later, but the key difference is that decentralised solutions upload anonymous decryption keys and distribute them to all phones. Evaluation to assess whether an exposure has occurred is then triggered. Centralised solutions upload encounter data to a central server, and the server sends exposure notifications. Centralised versions are less privacy-preserving, allowing for social graph creation, i.e. graphs representing social relations between entities, and with high function creep potential.

However, certain CTAs do not use the Bluetooth handshake. They are designed to work based on GPS or other location data. Such apps are mostly regional (e.g. Care19 app in the US) ${ }^{9}$ or used in countries with low data protection and privacy standards (e.g. China). Google and Apple considered this design choices to be highly invasive and incompatible with the privacy-preserving design of their Application Programming Interface (API). Apple and Google's Exposure Notification (GAEN) API therefore incorporates a restriction on the collection of any kind of location data. ${ }^{10}$ Since both companies are the developers of the most common mobile phone operating systems (OS) worldwide, they have full control over the ability of app software to break such a rule. Therefore, as long as the rule is in place, governments cannot use the GAEN protocol to get location data. This led countries like France and the UK to publicly call for a softening of the privacy standards built into their API to allow for more flexibility in the design of the CTAs and the collection of data for their epidemiological surveillance strategies. ${ }^{11}$ Google an Apple replied negatively. ${ }^{12}$

\footnotetext{
${ }^{8}$ See Cristina Criddle and Leo Kelion, 'Coronavirus contact-tracing: World split between two types of app' (BBC, May 2020) <https://www.bbc.com/news/technology-52355028>.

${ }^{9}$ Stephen Nellis and Paresh Dave, 'Showdown looms between Silicon Valley, U.S. states over contact tracing apps' (Retuers, Apr 2020) <https://www.reuters.com/article/us-health-coronavirus-usa-apps/showdown-looms-between-silicon-valley-us-states-over-contact-tracing-apps-idUSKCN22702F>.

10 'Google COVID-19 Exposure Notifications Service Additional Terms' (May 2020), for copy see here $<\mathrm{https} / / /$ docs.google.com/viewer?url=https $\% 3 \mathrm{~A} \% 2 \mathrm{~F} \% 2 \mathrm{Fblog}$.google $\% 2 \mathrm{Fdocuments} \% 2 \mathrm{~F} 72 \% 2 \mathrm{FExposure}$ Notifications_ Service_Additional_Terms.pdf $>$.

${ }^{11}$ For France see : https://www.theguardian.com/world/2020/apr/21/france-apple-google-privacy-contact-tracing-coronavirus

${ }^{12} \mathrm{See}$ https://www.reuters.com/article/us-health-coronavirus-france-tech/france-accuses-apple-of-refusing-help-withstopcovid-appidUSKBN22H0LX?feedType=RSS\&feedName=technologyNews\&utm_source=feedburner\&utm_medium=feed\&utm_c ampaign=Feed $\% 3 \mathrm{~A}+$ reuters\%2FtechnologyNews+\%28Reuters+Technology+News $\% 29$
} 
MIT SafePaths ${ }^{13}$ is a good example of how software shapes the data CTAs produce and, en passant, the rights and obligations of its users under the PMRs. MIT SafePaths, a software produced at the MIT, is an open source technology that seeks to increase the accuracy of data collection of CTAs by adding geolocation information to the encounter data without revealing the precise location of the user. Encoding this location data would allow CTAs to filter false exposures, to better inform users about their exposures, to better trace exposures in mobile users when timestamps are not enough to track their interactions (e.g. drivers, deliverers, police officers, etc.), and to filter the number of daily unique IDs processed by every phone. ${ }^{14}$ In other words, it would enrich the information embedded in the output data of CTAs to determine whether a person is to be considered or not exposed with higher precision. This ultimately has a direct influence on their epidemiological status and on their obligations under the PMRs.

\section{Data collation}

Generally, CTAs work as a closed data system. They collate data produced out of an encounter. For instance, the data collated by CTAs implementing the Bluetooth handshake generally consists of some sort of encrypted package, containing exposure ID, date, time and signal strength. The data exchanged in most CTAs are changed regularly to prevent on-the-street tracking based on exposure ID and signal strength. While this improves data protection, it also prevents two phones from recognizing each other for longer durations. Thus, if multiple users are living in apartment buildings, their phones will constantly encounter each other, producing large quantities of useless data and draining power of their phones (unless users actively turn the app on and off). Such issue is actually part of a much bigger problem with location-less Bluetooth handshake solutions, that being lack of control - trolling attitudes such as misreporting and behaviours of users seeking attention might, and probably would, become problematic.

If CTAs adopt the software solution offered by MIT SafePaths, it would add quantized GPS location into the handshake. This is a rounded area of certain size evaluated based on citizen density. ${ }^{15}$ The authors claim that such data is low risk to individual privacy, but would encode very valuable information for contact tracing as it gives context to exposure notifications that is otherwise missing. ${ }^{16}$ An example can be situations when two users get an exposure notification based on handshake that happened while stuck on a highway without leaving a car. The location context would give the user enough information to evaluate the notification as harmless. Yet, for this solution to effectively preserve privacy it needs, among other things, to verify constantly that the "location quantum" size works effectively based on population density. Otherwise, CTAs could end up putting data protection and privacy rights behind a technical-wall and or inside a black box.

Despite CTAs working generally as a closed data system, data collation is not limited to the data collected directly through the app. They can integrate external data with potentially no limits. In fact, in

\footnotetext{
${ }^{13}$ MIT SafePaths, ‘Adding Location Context to Apple/Google Exposure Notification Bluetooth API: MIT SafePaths Encryption Proposals for GPS + Bluetooth' (Apr 2020) copy available here <https://docs.google.com/document/d/1uTjdUetEEtnwN-6_iw3HTZOdAd0kKsK7GR1YbdS10Ss/edit>.

${ }^{14}$ Current "basic" GAEN technology does process some data uneccesarily. For example, mobile phones that never left Paris do not need to process data from phones that never left Lyon, and so forth.

${ }^{15}$ MIT SafePaths (n 13).

${ }^{16}$ Alex Berke, Michiel Bakker, Praneeth Vepakomma, Kent Larson and Alex Sandy 'Assessing Disease Exposure Risk with Location Data: A Proposal for Cryptographic Preservation of Privacy' (2020) accessible here $<$ https://www.media.mit.edu/publications/assessing-disease-exposure-risk-with-location-histories-and-protectingprivacy-a-cryptographic-approach-in-response-to-a-global-pandemic/>.
} 
several countries (most notably in Korea ${ }^{17}$ CTAs can mine data from websites (such as social media), acquire data through APIs from other apps or databases (such as CCTV or credit cards), and even adjust the system design to integrate data that is already collected by the OS of phones (such as contact details or location data). This data could be added alongside data collected from traditional sources of epidemiological surveillance ${ }^{18}$ such as call centres, hospital records, emergency call registries, passenger information and national health indexes to generate aggregate indicators.

\section{Section II: Computational Indicators, Data Analysis and Social Graphs}

The varied and rich data collected and collated by CTAs can enable the production of a new generation of indicators with computational features. This objective has been explicitly acknowledged, for example, by the developers of COVI, an AI-supported app developed at the MILA Institute to fight COVID-19 in Canada. They say:

"The data, apart from the analytics information, will be used for improving the risk prediction and epidemiological models. It will also form the basis for generating aggregated, population-level data to be shared with government actors and other third parties, solely for purposes relating to efforts to understand or combat COVID-19." 19

In contrast to traditional indicators, that calculate scores through the aggregation of raw data and rank entities through hand-crafted weights, computation indicators rely on ICT, data analytics and artificial intelligence methods to collect, analyse and represent data. Fuli et al. note that traditional social indicators are characterized by three main features: labour intensive data collection, data insufficiency and expert-relied data fusion. ${ }^{20}$ These features contrast starkly with those of computational indicators.

Firstly, data collection is labour intensive as traditional indicators usually rely on user studies like questionnaires and surveys that are time-consuming and require significant human resources. In contrast, computational indicators draw on automated methods of data collection such as IoT and data mining, and can extract information from wider ranges of sources such as large relational databases, structured and unstructured data, and the internet. All these options are either already used or available to CTAs. But what information could computational indicators use, for instance, to rank the rule of law of countries compared to existing indicators such as the Rule of Law Index and the World Bank Governance Indicators? Through automatic extraction, they could explore large scale and unstructured information sources, such as parliamentary debates, newspapers, court and police records, and citizens' opinions from social media. In brief, computational indicators could provide a more accurate representation of reality and the entities they rank as they can draw on a potentially limitless pool of data, rather than on proxies or representative samples.

Secondly, traditional indicators provide insufficient data as they tend to account only for a limited number of the targeted entities. For example, Fuli et al. report that the QS World University Rankings cover only 800 out of the 2,553 universities in China. This is in part due to the difficulty of conducting

\footnotetext{
${ }^{17}$ Norton Rose Fulbright, 'Contact tracing apps: A new world for data privacy' (Norton Rose Fulbright, July 2020) available at <https://www.nortonrosefulbright.com/en-kr/knowledge/publications/d7a9a296/contact-tracing-apps-a-new-world-fordata-privacy $>$.

${ }^{18}$ See Hsinchun Chen, Daniel Zeng and Ping Yan, Infectious Disease Informatics: Syndromic Surveillance for Public Health and Bio-Defense (Springer, 2010) 33-44; Mohamed Buheji, 'Mitigating the Tsunami of COVID-19 through Sustainable Traceability' (2020) 10(21) Pub. Health Res, at 22.

${ }^{19}$ Hannah Alsdurf, Yoshua Bengio, Tristan Deleu, Prateek Gupta, Daphne Ippolito, Richard Janda, Max Jarvie, Tyler Kolody, Sekoul Krastev, Tegan Maharaj, Robert Obryk, Dan Pilat, Valérie Pisano, Benjamin Prud'homme, Meng Qu, Nasim Rahaman, Irina Rish, Jean-Franois Rousseau, Abhinav Sharma, Brooke Struck, Jian Tang, Martin Weiss, Yun William Yu, 'COVI White Paper' (arXiv, Cornell University, July 2020) < https://arxiv.org/abs/2005.08502>.

${ }^{20}$ Fuli Feng, Nie Liqiang, Wang Xiang, Hong Richang and Chua Tat-Seng, 'Computational social indicators: A case study of chinese university ranking' (2017) Proceedings of the 40th International ACM SIGIR Conference on Research and Development in Information Retrieval 455-464.
} 
large-scale data collection for each entity and processing large amounts of data. Computational indicators can instead rely on techniques such as natural language processing (NLP) to extract data from documents, IoT to collect data from objects, and big data analytics to draw insights from large datasets. This can allow computational indicators to cover a larger number of entities and people, for example, every mobile phone user around the world.

Finally, data aggregation and analysis in traditional indicators rely on categories crafted based on the opinion of experts, which can be resource-consuming and subject to controversy. Although computers cannot replace human expertise and judgement, they can implement novel methods to analyse data and rank it, or as the team of MILA puts it: "[t]he use of ML [machine learning] to integrate complex clues which would otherwise require human intuition mitigates the absence of direct human intervention into a fully automatic contact tracing app". ${ }^{21}$ Machine learning could thus be used to identify hidden patterns and to cluster data, while algorithms like PageRank and the graph-based multi-channel ranking scheme proposed by Fuli et al. ${ }^{22}$, can be used to rank entities.

\section{Data Analysis and Encoding}

CTAs highlight two additional characteristics of computational indicators: encoding and graph representations. Computational indicators draw on information contained in encodings, i.e. technologycharged data, rather than raw data. Encoded data is rich and multidimensional because it encapsulates different sorts of information gathered during data collection. As mentioned earlier, encounter IDs may contain information such as proximity, time and location, and could even include personal information if the application is granted access to the OS. This information would enable CTAs to generate, as proposed by the COVI application, some sort of contextual, real time and personalised indicators of risk exposure and infection. ${ }^{23}$

Yet, encoded information can only be read and analysed with a computer program that supports the specific type of encoding, depending on the app's software and system design. Take the two types of computing capabilities CTAs use to analyse data, namely, centralised (e.g. central servers) or decentralised (users' phones) solutions. The main distinction between centralised and decentralised CTAs is the ability of central authority access to encounter data when using a centralised approach. In centralised solutions there are no technological barriers that could reliably block someone with sufficient developer access and permission from the owner from accessing the data. This is because pairings of unique IDs, encounter IDs and phone numbers are known to the central server. Therefore, an inquisitive database admin could find out a personal identifier (phone number) of person who was infected and everyone they met.

In contrast, in decentralised systems like the GAEN protocol, the system design ensures there is no risk of identification of the person met. ${ }^{24}$ There still is the risk that the person uploading data is identified from server connections through IP addresses, but this is a smaller risk. Moreover, since every user of the app receives unique IDs (that change daily and are anonymous) of every other user, the knowledge of "who met who" is essentially inaccessible. ${ }^{25}$ Hence, the information obtained from the data encoded into the central servers is limited in decentralised systems. The metadata about server connections (e.g.

\footnotetext{
${ }^{21}$ Alsdurf et al (n 19), 12.

${ }^{22}$ Fuli et al. (n 20).

${ }^{23}$ Alsdurfet al (n 19) 12.

${ }^{24}$ Apple/Google 'Exposure Notificaion: Bluetooth Specification' (April 2020) accessible here <https://covid19-static.cdnapple.com/applications/covid19/current/static/contact-tracing/pdf/ExposureNotification-BluetoothSpecificationv1.2.pdf >.

25 ibid.
} 
the IP address of phone sending data) are supposed to be scrubbed clean and not stored. The only data being saved are therefore a set of unique IDs that are sent to every user daily. As a result, server operators do not have special information (compared to users) as long as they are honest about metadata erasing. This being said, centralised systems offer much more to the owner of the server. Since data about encounters is uploaded and servers track who met who, this allows the server owner to create representations of information, for instance, through social graphs or heatmaps.

\section{Data Analysis and Graph Representations}

An additional characteristic of computation indicators is the capacity to represent information through social graphs. The computational capabilities of centralised CTAs allow them to extract information from large amounts of data and represent it through social graphs, unveiling patterns and relations between entities that would otherwise be difficult to identify. Figure 1 below depicts an example of a scenario when persons $\mathrm{A}$ and $\mathrm{G}$ upload their exposure data (indicated as a dotted line) to a central exposure notification server. This is a scenario depicting a centralised system based on Bluetooth handshake without any location data.

Figure 1: Central Exposure Notification

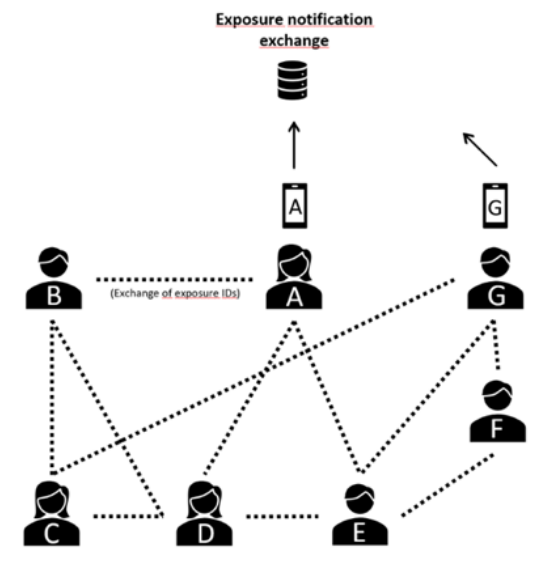

Figure 2: Insights Gathered by the Central Server

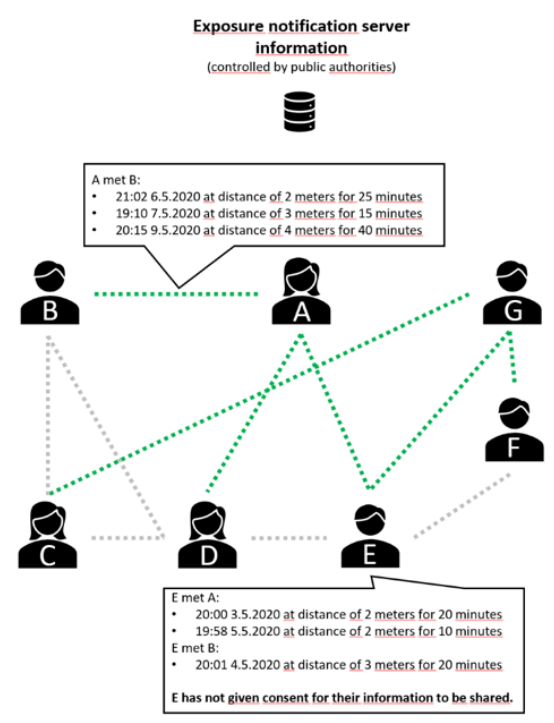


In contrast, Figure 2 shows the insights gathered by a central server based on scenario in Figure 1. Since metadata of exposure and exposure keys are sent, it means the server can track all users that met with A or $\mathrm{G}$, the timestamps and approximate durations of meetings, and a proxy for a distance (based on Bluetooth signal strength). Thus, the central server has information about person E, who uses the app, but has not given permission to upload their data. Yet, the central server can collect and track person $\mathrm{E}$ based on data provided by others (who met them). Moreover, if 4 people (B, D, E, G) upload their data, the whole network will be known by the server. Generalizing this idea means that users uploading their data "uncover" a disproportionate area on the social graph (i.e. a network of all handshakes happening) to the central server with some users never uploading anything themselves. The underlying issue is the access of the server to the identity of people not uploading the data and the ability to combine data sets from various uploaders (e.g. persons A and G).

Moreover, if CTA data is aggregated with mobile and tower location data, social graphs can provide completely unique insight into movements of populations, allowing identification at a very granular level of the trajectories of persons and their encounters. These graphs could be used for purposes beyond epidemiological surveillance, such as police investigations. They pose a serious threat to rights and freedoms of individuals, including privacy and data protection rights, but more importantly, can easily function creep into a tool of mass surveillance. ${ }^{26}$

\section{Section III: Conclusion}

Through analysis of CTAs, this paper shows the increasing role that technology and data-and specially their intertwinement - play in the exercise of social control. On the one hand, it shows CTAs' capabilities to collect, analyse and represent large amounts and varieties of data, produce output data that is technology-charged and enable a new generation of computational indicators (which can be personalised and contextualised in real time). On the other hand, it shows that the technologies underpinning CTAs have an impact on the rights and obligations of individuals. For example, when they are used to inform the implementation of the 3T strategy (test, treat and track) thereby allowing authorities to identify and prioritize who must get tested and treated. ${ }^{27}$ More importantly, CTAs are sometimes directly employed to enforce laws on individuals according to their specific epidemiological status. This includes the assignment of specific obligations like the disclosure of health-related personal information, as well as the imposition of physical restrictions, such as the prohibition to leave one's domicile or to access public transportation. ${ }^{28}$

These developments seem to suggest that CTAs fit and accelerate the movement towards a form of law into technologies, ${ }^{29}$ where legal prescriptions are collapsed into mathematical

\footnotetext{
${ }^{26}$ On this topic see Shoshana Zuboff, The Age of Surveillance Capitalism- The Fight for a Human Future at the New Frontier of Power: (Public Affairs 2019); Shoshana Zuboff, Big Other: surveillance capitalism and the prospects of an information civilization. J Inf Technol 30, 75-89 (2015)

${ }^{27}$ For an application of the T3 strategy in the context of malaria see C.W. Mbuli et al., 'Trends of Reported Outpatient Malaria Cases to Assess the Test, Treat and Track (T3) Policy in Kenya', (2016) East African Medical Journal at S7; Shiela Akanteele Agandaa, 'Implementation and Challenges of Test, Treat and Track (T3) Strategy for Malaria Case Management in Children under Five Years in the Bongo District, Ghana' (2016) 2(235) Clin Res Trials.

${ }^{28}$ See Buheji (n 18) at 23 .

${ }^{29}$ I use this concept in contrast with law in books - where legal prescriptions are defined by statutes and other formal legal sources, and law in action - where legal prescriptions are equated to the social rules effectively followed by individuals in a given context. See Roscoe Pound, 'Law in Books and Law in Action' (1910) 44 American Law Review 12, 30. Also see David Restrepo Amariles, 'Algorithmic Decision Systems: Automation and Machine Learning in the Public Administration', in W. Barfield (ed.), The Cambridge Handbook of the Law of Algorithms (CUP, 2020), at 273-300.
} 
models ${ }^{30}$ and computing devices and code.$^{31}$ This movement poses a serious risk to the rule of law that requires careful scrutiny. This is particularly the case when you consider that CTAs built an unprecedented ecosystem (e.g. Google and Apple, researchers, governments, and local and regional corporations) and infrastructure (e.g. OS, software applications, servers, languages, etc.) that could easily mission creep into a global tool of mass surveillance.

${ }^{30}$ David Restrepo Amariles, 'The Mathematical Turn: l'indicateur Rule of Law dans la politique de développement de la Banque Mondiale', in B. Frydman and A. Van Waeyenberge (eds.), Gouverner par les Standards et les Indicateurs: de Hume aux Rankings (Bruylant, 2014), at 193.

${ }^{31}$ See Samer Hassan and Primavera De Filippi, 'The Expansion of Algorithmic Governance: From Code is Law to Law is Code' (2017) The Journal of Field Actions, 88-90 ; David Restrepo Amariles, 'Le droit algorithmique: sur l'effacement de la distinction entre la règle et sa mise en œuvre' in F. G'sell (ed.), Law and Big Data (Dalloz, 2020); David Restrepo Amariles and Gregory Lewkowicz, 'De la donnée à la décision : comment réguler par les données et les algorithmes', in Les Big Data à Decouvert (CNRS éditions 2017) 80-82. 


\title{
Indicators, Security, and Sovereignty - During COVID-19 in the Global South
}

\author{
John Harrington*
}

\section{Introduction}

This paper considers the spread of COVID-19 as a telling moment or épreuve in contests over governance in Global South states. ${ }^{1}$ Two distinct governance modes are engaged in this crisis: 1) indicators/metrics; and 2) securitization. Indicators have been a vehicle for the governance (?) of states, particularly in the Global South, through the external imposition and internal self-application of standards and benchmarks and the comparative rankings which ensue therefrom. Securitization refers to the performative calling-into-being of emergencies in the face of existential threats. National sovereignty is at stake in both modes: limited, superintended, and redirected by indicators on the one hand; articulated as originary and untrammelled through securitizing moves on the other. Health has been a key focus for analysts of each. Stopping the spread of disease is cast by scholars as a pre-eminent task for 'the international community', with post-colonial, Global South states figured either as useful transmission belts, or as obstacles, recalcitrant and corrupt. ${ }^{2}$ Contrariwise, the nation is (still) taken by political leaders and many citizens as the primary object of the pandemic threat and the central agent in responding to it. We may hypothesize that COVID-19 is the occasion for an as yet undecided contest between de-spatialized health governmentality and the reassertion of territorial segmentation as the frame for an autochtonously defined national interest -a retreat, it is feared, from Post-Westphalian to Westphalian governance in global health. ${ }^{3}$ The lineaments of this struggle can be presented more clearly through a discrete focus on indicators and securitization and the interplay between them. In what follows, I first sketch an outline of each governance mode, remarking on the application of each to health promotion in the Global South. The purchase of this theoretical outline is then tested briefly through a focus on Kenya, and, in particular, its response to COVID-19 in the early months of the pandemic, between February and May 2020. Both modes were deployed in political and legal interventions during this period. It is clear that government ministers tended to adopt securitization language, while foreign and civil society actors drew on indicators and related benchmarks to support criticism of state action and inaction.

\section{Indicators and Metrics in Global Health}

I focus here, not so much on the production of indicators, but on their use. In this regard, socio-legal studies, such as the work of Sally Engle Merry, have clear affinities with the critique of metrics in global health developed by medical anthropologists such as Vincanne Adams. ${ }^{4}$ Both note the depoliticizing

\footnotetext{
* John Harrington, Cardiff University (harringtonj3@cardiff.ac.uk).

${ }^{1}$ See Luc Boltanski and Eve Chiapello, The New Spirit of Capitalism (Verso, 2017).

${ }^{2}$ Lawrence Gostin, Global Health Law (Harvard University Press, 2014); see also John Harrington, 'Locating the State in Global Health Law: A Nodal Governance Analysis', in A Kirkland and M-A Jacob (eds), Research Handbook on Law, Medicine and Society (Elgar, 2020) 190-206.

${ }^{3}$ David Fidler, 'The World Health Organization and Pandemic Politics. The Good, the Bad, and an Ugly Future for Global Health' (Council on Foreign Relations - Blog, 10 April 2020), <https://www.thinkglobalhealth.org/article/world-healthorganization-and-pandemic-politics>.

${ }^{4}$ Sally Engle Merry, The Seductions of Quantification: Measuring Human Rights, Gender Violence, and Sex Trafficking (University of Chicago Press, 2016), and Vincanne Adams (ed.), Metrics: What Counts in Global Health (Duke University Press, 2016). As well as the affinities discussed in the text, both authors adopt a normative-methodological stance in defence of qualitative, ethnographic research as an inclusive source of evidence to complement and counter the ascendant quantitative mode.
} 
intent behind indicators, which are to provide neutral representations, permitting objective judgment. ${ }^{5}$ Both point to a distinct theory or world view underpinning these technologies. Repeated use sustains these effects by 'hardening' indicators into common-sense, as they are taken up by more or less powerful actors in a given field, such as health policy. Equally, contestation may undermine their pragmatic effectiveness by laying bare the contingency of their production. ${ }^{6}$ The stability and power of indicators, or loss of the same, is thus achieved 'in action' as Siems and Nelken put it. ${ }^{7}$

In focusing on the Global South, we do well to take account of the 'globality critique' raised in this context by Morag Goodwin. ${ }^{8}$ Attention must be paid to the specific cultural and political contexts within which particular indicators see action. Such discrete 'rhetorical situations' certainly include international sites, like the World Health Organization (WHO) or the United Nations (UN) General Assembly, at which global health governance is produced and debated. ${ }^{9}$ But they also arise in regional, national and local fora, whether formal or informal, where measures are translated, transformed, and resisted. This should lead further to a genealogical concern with the colonial origins of 'indicator culture' ${ }^{10}$ Europe's colonies and the independent states which succeeded them have been defined, privatively, as uncivilized, insanitary and underdeveloped. ${ }^{11}$ Indicators mark that backwardness, as well as the progress of territories and peoples away from it, ranking them over time and relative to each other. ${ }^{12}$

This is not an undifferentiated history of tutelage. Until the end of the 1970s, Global South states asserted strong sovereignty against former colonial powers and monopoly capital through demands for a New International Economic Order. In the present context, they were accorded a leading role in realizing the WHO/ UNICEF Declaration of Alma Ata on Health for All. ${ }^{13}$ Adams characterizes that phase as one of 'inter-national health'. ${ }^{14}$ The dream of a strong health state endures, as we will see in the next section. ${ }^{15}$ But its realization was sharply curbed in the 1980s as a result of economic shocks, structural adjustment, and the collapse of the bipolar Cold War order. States were disciplined first by technologies of economic governance and then, more widely, through the elaboration of detailed health and other social targets (e.g. on child nutrition and immunization), and their enforcement via aid conditionalities. ${ }^{16}$

Metrics met and meet a concern with health outcomes as well as inputs, and with the causal connection between them. ${ }^{17}$ They enable the framing of accountability in quantitative and value-for-money terms,

\footnotetext{
${ }^{5}$ Kevin Davis, Benedict Kingsbury, and Sally Engle Merry, 'Indicators as a Technology of Governance' (2012) 46 Law \& Society Review 76.

${ }^{6}$ For a fine example, see Adeola Oni-Orisan, 'The Obligation to Count: The Politics of Monitoring Maternal Mortality in Nigeria,' in Adams (ed), Metrics 82-104.

${ }^{7}$ Mathias Siems and David Nelken, 'Global Social Indicators and the Concept of Legitimacy' (2017) 13 International Journal of Law in Context 436-44.

${ }^{8}$ Morag Goodwin, 'The Poverty of Numbers: Reflections on the Legitimacy of Global Development Indicators,' (2017) International Journal of Law in Context 485-49.

${ }^{9}$ See Sally Engle Merry, Human Rights and Gender Violence (University of Chicago Press, 2006); Loyd F. Bitzer 'The Rhetorical Situation', (1968) 1 Philosophy and Rhetoric 1-14.

${ }^{10}$ Merry (n 4) 9-20.

${ }^{11}$ Arturo Escobar, Encountering Development: The Making and Unmaking of the Third World (Princeton University Press, 1995).

${ }^{12}$ See generally Davis et al (n 5).

${ }^{13}$ See Nistan Chorev, The World Health Organization Between North and South (Cornell University Press, 2012).

${ }^{14}$ Vincanne Adams, 'Introduction' in Adams (ed) (n 4) at 6.

${ }^{15}$ Paul Wenzel Geissler (ed) Para-States and Medical Science: Making African Global Health (Duke University Press, 2015).

${ }^{16}$ Celine Tan, Governance Through Development: Poverty Reduction Strategies, International Law and the Disciplining of World States (Routledge, 2011).

${ }^{17}$ See Mathias Siems, Mapping the causal relationships between indicators in the COVID-19 crisis (in this Working Paper).
} 
thus enabling an ongoing commercial and philanthropic takeover of aid delivery in this field. ${ }^{18} \mathrm{UN}$ bodies have followed, with indicators giving concrete and measurable detail to states' right to health obligations under the International Covenant on Economic Social and Cultural Rights, for example. ${ }^{19}$ Similarly, the WHO's International Health Regulations were comprehensively revised in 2005, moving away from their minimalist, state-led approach to disease control. ${ }^{20}$ National authorities lost their exclusive power to notify the WHO of disease outbreaks (i.e. official concealment can now be outflanked by scientists and NGOs). They are also required to maintain institutional capacity to detect epidemics and to put in place statutory measures to enable a proportionate response, or what has been called 'public health emergency legal preparedness'. ${ }^{21}$ States' compliance with the latter set of obligations is tracked and ranked most notably by the Global Health Security Index prepared by the Johns Hopkins Center for Health Security, the Nuclear Threat Initiative and the Economist Intelligence Unit. $^{22}$

The most recent era, that in which COVID-19 appeared, is one of 'global health', marked by a normative and institutional reorientation of the state apparatus (e.g. constitutionalization of human rights, creation of parastatals to collect data and implement feedback) and an empowering of other domestic and foreign actors (e.g. the judiciary, civil society, donor agencies) to police states' performance. ${ }^{23}$ The depoliticizing effect here involves an occlusion of the neo-imperial reach of this regime behind techniques of counting and ranking. The underlying world view is an alloy of humanitarianism, new public management and an older developmentalism. ${ }^{24}$ To return to Adams, indicators and metrics instantiate a 'new kind of sovereign' beyond the nation, whereby the state is interpellated as the subject responsible for the promotion of its citizens' health and called to account at multiple instances. ${ }^{25}$

\section{Securitization and Infectious Disease}

A rival view of health sovereignty is suggested by the Copenhagen School of Security Studies (CS). ${ }^{26}$ At the centre of that analytic are moments of 'securitization' which achieve the suspension of normal politics in time of emergency and its replacement by special measures. A successful securitizing move involves the identification of an existential threat to a significant referent object in a form consistent with relevant linguistic conventions. Such moves are illocutionary in that they are per se performative of the shift from normal to special. ${ }^{27}$ The suspension of normal politics in this way represents a

\footnotetext{
${ }^{18}$ Susan Erikson 'Metrics and Market Logics of Global Health' in Adams (ed) (n 4) 147-162.

${ }^{19}$ Merry (n 4).

${ }^{20}$ David Fidler D and Lawrence Gostin 'The New International Health Regulations: An Historic Development for International Law and Public Health' (2006) 93 Journal of Law, Medicine and Ethics 85-94.

${ }^{21}$ Thérèse Murphy and Noel Whitty 'Is Human Rights Prepared? Risks, Rights and Public Health Emergencies' (2009) 17 Medical Law Review 219-244.

22 '2019 Global Health Security Index' (GHS Index) <https://www.ghsindex.org/>. See further, Elizabeth Cameron, Jennifer Nuzzo, and Jessica A. Bell, Global Health Security Index: Building Collective Action and Accountability (Nuclear Threat Initiative, October 2019).

${ }^{23}$ Vincanne Adams, 'Introduction', in Adams (ed) (n 4) 31

${ }^{24}$ Andrew Lakoff, 'Toward a Genealogy of Global Health Security' in Bruce Magnusson and Zahi Zalloua, Contagion: Health, Fear and Sovereignty (University of Washington Press, 2012) 44-70.

25 ibid at 45. See also Michael Hardt and Antonio Negri, Empire (Harvard University Press 2000).

${ }^{26}$ Barry Buzan, Ole Waever, and Jap de Wilde, Security: A New Framework for Analysis (Lynne Reiner, 1998).

${ }^{27}$ John Langshaw Austin, How To Do Things with Words (Harvard University Press, 2005).
} 
primordial exercise of sovereignty consistent with Hobbesian and Schmittian views of the state. ${ }^{28}$ This is not to say that all rules and guarantees are automatically suspended on foot of a securitizing move, but that they could be, and that the sovereign is definitively the locus of the decision to do so.

Subsequent writers have extended the category of 'referent objects' capable of being securitized beyond territorial integrity and military security, to include population health. ${ }^{29}$ Pandemics can clearly be represented as existential threats to health, but also, to economic and political stability. ${ }^{30}$ The relevant formalities for the securitizing move may be found in law, e.g., permissible derogations from human rights in national constitutions, or at international level the WHO's power to declare a 'Public Health Emergency of International Concern' ${ }^{31}$ But these legal forms do not exhaust the political possibilities.

Other work has challenged and revised significant elements of the CS model in ways relevant to the current discussion. By limiting securitization to well defined and self-contained speech acts, it overlooks the role of audience engagement in the success or failure of any given move. The latter, thus, depends on a more wide-ranging persuasive (or 'perlocutionary') effort. ${ }^{32}$ In the case of pandemics, that often involves evoking an atmosphere of dread and horror. ${ }^{33}$ Specific colonial histories and post-colonial concerns may add resonance too. For example, Indonesia's decision to withhold virus samples from the WHO during the $2006 \mathrm{H} 5 \mathrm{~N} 1$ outbreak followed on a securitization of national resources and the threat to them from expropriation by foreign vaccine producers, summarized as an assertion of "viral sovereignty'. ${ }^{34}$ Securitization, then, is better viewed as a process than a moment, and as a continuum rather than a binary outcome. Speech and text matters, but so too do images and actions, which may prefigure or contribute to verbal securitization moves, as where police enforce a lockdown in advance of a presidential declaration. ${ }^{35}$

The normatively Eurocentric nature of securitization theory also leads it to presume a unified nation with uncontested interests, capable of being existentially threatened, and to posit a sharp distinction between normal and special politics. ${ }^{36}$ Experience in the Global South has been more varied. Postcolonial states and their interests are less coherent than the model suggests, not least due to the impositions of global governmentality discussed in the previous section. Moreover, colonial and independence regimes have long subsisted with the help of wide executive discretion and open-ended emergency legislation creating (semi-)permanent states of exception. ${ }^{37}$ The line between the normal and special is fluid. To return to Goodwin's 'globality critique', noted above, the form and outcome of a securitizing move can, thus, only be grasped by paying careful attention to context.

\footnotetext{
${ }^{28}$ Michael Williams, ‘Words, Images, Enemies: Securitization and International Politics' (2003) 47 International Studies Quarterly 511-553.

${ }^{29}$ Colin McInnes and Simon Rushton, 'HIV/AIDS and Securitization Theory' (2012) 19 European Journal of International Relations115-138.

${ }^{30}$ Melissa Curley M and Jonathan Herington, 'The Securitisation of Avian Influenza: International Discourses and Domestic Politics in Asia,' (2017) 37 Review of International Studies 141-166.

${ }^{31}$ Gostin (n 2).

32 Thierry Balzacq, 'The Three Faces of Securitization: Political Agency, Audience and Context,' 11 (2005) European Journal of International Relations 171-201; Chaïm Perelman, L'empire Rhetorique: Rhétorique et Argumentation (Librairie Philosophique J. Vrin, 2000).

${ }^{33}$ Jessica Stern, 'Dreaded Risks and the Control of Biological Weapons' (2002-2003) 27 International Security 89-123.

${ }^{34}$ Shahar Hameiri ‘Avian influenza, “viral sovereignty”, and the Politics of Health Security in Indonesia,' (2014) 27 The Pacific Review 333-356.

${ }^{35}$ Claire Wilkinson 'The Copenhagen School on tour in Kyrgyzstan: Is Securitization Theory Useable Outside Europe?' (2007) 38 Security Dialogue 5-25.

36 Juha Vuori 'Illocutionary Logic and Strands of Securitization: Applying the Theory of Securitization to the Study of NonDemocratic Political Orders' (2008) 14 European Journal of International Relations 65-99.

${ }^{37}$ A.W. Brian Simpson, Human Rights and the End of Empire: Britain and the Genesis of the European Convention (Oxford University Press, 2004).
} 


\section{COVID-19 in Kenya: Indicators and Securitization}

Timeline - February to May 2020

Measures taken in Kenya in anticipation of, and in response to the spread of COVID-19 are familiar from elsewhere in Africa. On the $13^{\text {th }}$ March, the first case was confirmed in a 27 -year old woman who returned to Kenya from the United States via London. ${ }^{38}$ The following day, the government banned all public events. ${ }^{39}$ By the $15^{\text {th }}$ March, three more cases had been discovered and President Uhuru Kenyatta unveiled a range of measures to combat the spread of the virus, encouraging people to work from home and to practice hygienic measures. ${ }^{40}$ On the $22^{\text {nd }}$ March the government stopped all international flights. ${ }^{41}$ Three days later a $7 \mathrm{pm}$ to $5 \mathrm{am}$ curfew was announced..$^{42}$ Although a range of fiscal measures to help mitigate the economic impact of these steps was also announced, they did little to offset the impediments posed to Kenyans working in the informal sector, particularly women and those living in slum settlements. ${ }^{43}$ Police enforced the curfew indiscriminately and with considerable violence, causing serious injuries to many with at least one fatality. ${ }^{44}$ This triggered protests from local and international human rights organizations, and the launch of a constitutional challenge in the Nairobi High Court. ${ }^{45}$ In April, travel in and out of Kenya's two largest cities Nairobi and Mombasa was restricted and the Cabinet Secretary for Health made it mandatory to wear face masks in public. ${ }^{46}$ Despite these measures, which remain in force, the number of coronavirus cases continued to rise through the period discussed. By the end of May 2020, Kenya had a total of 1,962 confirmed cases with 64 people recorded as having died from the virus. ${ }^{47}$

\footnotetext{
${ }^{38}$ Elizabeth Merab, 'Kenya Confirms First Coronavirus Case' (Daily Nation, 24 March 2020), $<$ https://www.nation.co.ke/news/Kenya-confirms-first-coronavirus-case/1056-5489268-28tq11/index.html>.

39 'Kenya Bans Public Events After First Case of Coronavirus' (Al Jazeera, 13 March 2020) $<$ https://www.aljazeera.com/news/2020/03/kenya-bans-public-events-case-coronavirus-200313101019200.html>.

40 'Kenya Coronavirus Cases Rise to Four' (Kenyan Ministry of Health, 17 March 2020) <https://www.health.go.ke/kenyacoronavirus-cases-rise-to-four-cs-health/>.

${ }^{41}$ Carolyne Tanui, 'Kenya Bans All international Passenger Flights as Coronavirus Cases Rise to 15' (Capital News, 22 March 2020) <https://www.capitalfm.co.ke/news/2020/03/kenya-bans-all-international-passenger-flights-as-coronacases-rise-to-15/>.

${ }^{42}$ Brian Okoth 'Tax Relief, CRB-Listing Suspension: Here are All Directives to Issued by Pres. Kenyatta to Ensure You Have More Money in Your Pocket’ (K24, 25 March 2020) <https://www.k24tv.co.ke/news/tax-relief-crb-listingsuspension-here-are-all-directives-issued-by-pres-kenyatta-to-ensure-you-have-more-money-in-your-pocket18275/?utm_source=website\&utm_medium=coronavirus\&utm_campaign=coronavirus\&utm_term=coronavirus $>$.

43 ibid.

${ }^{44}$ Otsieno Namwaya, 'Kenya Police Abuses Could Undermine Coronavirus Fight' (Human Rights Watch - Dispatches, 31 March 2020) <https://www.hrw.org/news/2020/03/31/kenya-police-abuses-could-undermine-coronavirus-fight>

${ }^{45}$ Mary Wambui 'Family Distraught After Teenager Allegedly Shot By Police Dies' (Daily Nation, 13 May 2020) $<$ https://www.nation.co.ke/news/Boy13-allegedly-shot-by-police-dies-/1056-5509816-c80fb8z/index.html>.

46 'COVID-19: Kenya Bans Travel in and Out of Nairobi, Other Areas' (Al Jazeera, 6 April 2020) $<$ https://www.aljazeera.com/news/2020/04/COVID-19-kenya-bans-travel-nairobi-areas-200406163601579.html>; Vincent Achuka 'You Face Arrest for Not Wearing a Face Mask in Public' (Daily Nation, 13 May 2020), $<$ https://www.nation.co.ke/news/You-face-arrest-you-for-not-wearing-face-mask-in-public/1056-5524258fekeqlz/index.html>.

${ }^{47}$ /Coronavirus Disease (COVID-19) Situation Report - 133' (World Health Organization, June 2020), $<$ https://www.who.int/docs/default-source/coronaviruse/situation-reports/20200601-COVID-19-sitrep133.pdf?sfvrsn=9a56f2ac_4>.
} 


\section{Indicators in Use}

Within Kenya, there was considerable criticism of these measures for their lack of a rational basis and design articulated using the technologies and idiom of global governmentality set out above. For example, two Kenyan epidemiologists complained respectively about the Government's lack of transparency in relation to data sharing protocols, which would allow the disease to be tracked, and its failure to specify 'a scientifically determined threshold on when lockdown measures could be relaxed' ${ }^{48}$ However, indicators and metrics specifically, played a relatively small role in internal discussion of the response to COVID-19. Most prominent in the earliest phase of the pandemic was an index of preparedness and vulnerability among African countries published in The Lancet on $20^{\text {th }}$ February by Gilbert et al. ${ }^{49}$ This paper modelled potential impact based on multivariate analysis of existing indicators, primarily the WHO's International Health Regulations Monitoring and Evaluation Framework which is itself a composite of both self-assessment, annual reporting data, external evaluations, after action reviews, and simulation exercises. ${ }^{50}$ It also drew on the Infectious Disease Vulnerability Index, which helped to account for 'indirect factors that might compromise the control of emerging epidemics, such as demographic, environmental, socioeconomic, and political conditions' ${ }^{51}$ These data were mapped alongside the volume of air travel in the country to estimate the risk of importation.

The Gilbert index was picked up by commentators in the Global North as an early call for action to support African health systems, but also to highlight the potentially catastrophic results of the virus spreading to the continent. A further paper in The Lancet used it to highlight the need to 'act collectively and fast', arguing that the authors had provided a valuable tool to help countries 'prioritise and allocate resources' ${ }^{52}$ This theme was given more sensationalist expression in media headlines and stories, which relied on the index to claim that 'the outbreak could become uncontrollable if it reaches densely populated African mega-cities' 53 and that a 'potential calamity' awaited without 'increased [external] resources and surveillance of vulnerable African nations.' 54

Kenya was ranked as a 'medium risk' country on the Gilbert index owing to its 'variable capacity' to deal with the pandemic and its 'high vulnerability'. ${ }^{55}$ This categorization gained salience with the controversy over a flight from China that landed at Nairobi airport carrying 239 passengers in late February 2020 before border restrictions were introduced. A video of the flight posted on social media

\footnotetext{
${ }^{48}$ Mark Nanyingi, 'Predicting COVID-19: What Applying a Model in Kenya Would Look Like' (The Conversation, 30 March 2020) <https://theconversation.com/predicting-COVID-19-what-applying-a-model-in-kenya-would-look-like134675>; Nelly Yatich, 'COVID-19 Response,' (unpublished research paper, 2020) accessible here $<$ https://www.scribd.com/document/454964698/COVID-19-Response>.

${ }^{49}$ Marius Gilbert, Giulia Pullano, Francesco Pinotti, Eugenio Valdano, Chiara Poletto, Pierre-Yves Boëlle, Eric D’Ortenzio, Yazdan Yazdanpanah, Serge Paul Eholie, Mathias Altmann, Bernardo Gutierrez, MoritzKraemer, Vittoria Colizza 'Preparedness and Vulnerability of African Countries Against Importations of COVID-19: A Modelling Study' (2020) 395 The Lancet $871-77$.

50 ibid at 871 .

51 Gilbert et al (n 49) at 873.

52 John N. Nkengasong and Wessam Mankoula 'Looming threat of COVID-19 Infection in Africa: Act Collectively, and Fast,' (2020) 395 The Lancet 841-842; April Zhu, 'Which African Countries Are most Vulnerable to the Coronavirus?' (The New Humanitarian, 24 February 2020) <https://www.thenewhumanitarian.org/news/2020/02/24/CoronavirusAfrica-risk-virus-Covid19-WHO-Lancet-study $>$.

53 Sarah Newey 'Warning for African Countries as Coronavirus Cases Mount Worldwide' (The Telegraph, 19 February 2020) <https://www.telegraph.co.uk/global-health/science-and-disease/warning-african-countries-coronavirus-casesmount-worldwide/>.

54 Adrian Humphreys 'Health Officials Brace for Spread to Africa as Modelling Study Reveals Most Vulnerable Countries' (National Post, 19 February 2020) <https://nationalpost.com/health/health-officials-brace-for-coronavirus-spread-toafrica-as-modelling-study-reveals-most-vulnerable-countries $>$.

55 Gilbert et al (n 49).
} 
triggered outcry, though the Government insisted that flights were safe and that international guidelines had been adhered to. ${ }^{56}$ Intervening in the debate, prominent journalist Patrick Gathara relied on Gilbert et al's paper to criticize the government's preparations. 'While Kenya had a moderate risk of importing the virus from China', he wrote, 'it had amongst the lowest scores on the continent for the capacity to handle an outbreak. ${ }^{57}$ The authorities needed to increase public information and to prepare people and the health care system for the effects of the pandemic. At that point already, Gathara argued that to stop flights into Kenya was a distraction, suggesting that the virus would come to the country eventually and it was better to prepare for it. By contrast the Daily Nation alluded to a University of Southampton study, which they claimed, ranked Nairobi as 'sixth among African cities whose populations are at high risk of being infected with COVID-19' while 'government bureaucrats continue[d] to allow in travellers from 18 high-risk cities in mainland China'. ${ }^{58}$ Ultimately the Law Society of Kenya successfully petitioned the High Court to force the government to suspend flights from China, basing its claim on the then current WHO list of 'hotspot' countries. ${ }^{59}$ The Gilbert index was also picked up on Twitter by Kenyans critical of government inaction. ${ }^{60}$ Beyond these instances we have found little evidence that indicators were deployed either by the Government or its critics.

\section{Securitizing Moves}

By contrast, with the relatively low frequency of indicators and metrics in domestic debate, a review of political speeches, legal interventions, and relevant media from this period shows the prominence of securitization discourse in the sense used by the Copenhagen School. The President thus referred repeatedly and dramatically to the 'extraordinary' and 'emergency nature' of COVID-19 claiming that 'our national interest [has never] been threatened to this extent before. ${ }^{\prime} 1$ 'Our families', he declared,

\footnotetext{
${ }^{56}$ Dauti Kahura, 'Harsh Economic Times, Political Uncertainty... and Now Corona' (The Elephant, 3 April 2020) $<$ https://www.theelephant.info/features/2020/04/03/harsh-economic-times-political-uncertaintyand-now-corona/>; Nasibo Kabale, 'Coronavirus: Kenya to Expect More Flights from China' (The East African, 27 February 2020) $<$ https://www.theeastafrican.co.ke/scienceandhealth/flights-from-China-to-Kenya/3073694-5471320u1whfvz/index.html>.

${ }^{57}$ Patrick Gathara 'Kenya Needs to Stop Panicking and Start Preparing for Coronavirus' (Al Jazeera, 2 March 2020), $<$ https://www.aljazeera.com/indepth/opinion/kenya-stop-panicking-start-preparing-coronavirus200302110915576.html>.

58 'Coronavirus Scare: Nairobi Ranked Sixth Amongst Africa’s Riskiest Cities' (Daily Nation, 28 February 2020), $<$ https://www.nation.co.ke/kenya/news/coronavirus-nairobi-ranked-sixth-among-africa-s-riskiest-cities-254712>. Though not referenced in the piece this is the likely source: Shengjie Lai, Isaac I. Bogoch, Alexander Watts, Kamran Khan, Andrew Tatem 'Preliminary Risk Analysis of 2019 Novel Coronavirus Spread Within and Beyond China' (University of Southampton, 25 January 2020) <https://www.worldpop.org/resources/docs/china/WorldPop-coronavirus-spread-riskanalysis-v2.pdf>.

59 'Coronavirus Disease Update 12' (World Health Organisation Information Network for Epidemics, 28 February 2020), $<$ https://www.who.int/docs/default-source/coronaviruse/risk-comms-updates/update-12-epi-wincovid19.pdf?sfvrsn=77b3264d_2>.

${ }^{60}$ See for example, Tweet from @DrOngwae (February 27 2020) <https://twitter.com/DrOngwae/status/1232999982569074688>; Tweet from @erickokioma (February 29 2020) <https://twitter.com/erickokioma/status/1233717495699300354>; Tweet from @ MasoloMabonga (February 29 2020)

<https://twitter.com/MasoloMabonga/status/1233640955934334979> and Tweet from @KOT_Loyals (February 26 2020) <https://twitter.com/KOT_Loyals/status/1232532275214069760>/

${ }^{61}$ Uhuru Kenyatta 'Uhuru's Speech in Full As More COVID-19 Measures Announced,' (Daily Nation, 27 March 2020), $<$ https://www.nation.co.ke/kenya/news/uhuru-s-speech-in-full-as-more-COVID-19-measures-announced-281796>; Uhuru Kenyatta, 'Presidential Address on Enhanced Measures in Response to the COVID-19 Pandemic,' (Kenyan Ministry of Foreign Affairs, 6 April 2020) <http:/www.mfa.go.ke/wp-content/uploads/2020/04/presidential-addressenhanced-measures-in-response-to-the-COVID-19-pandemic-6th-April-2020.pdf>.
} 
'our schools, our way of life, the way we worship, our economy, our businesses, our workers, every single Kenyan stands threatened by this invisible, relentless enemy.' The struggle against the virus was a 'war' in which the Kenyan people were called to fight. ${ }^{62}$ In this vein, steps to secure the border 'against security threats', and the imposition of lockdown measures in refugee camps, served to associate COVID-19 with the ongoing threat of terrorist incursion from Somalia. ${ }^{63}$ Evoking previous pandemics, such as sleeping sickness in colonial East Africa, and his own role as commander-in-chief, Kenyatta pledged to 'do everything in [his] power to ensure that we, as a nation, shall not suffer such terrifying outcomes'. The ambition to suspend normal politics, which is the result of successful securitization, was suggested, ironically, by the government's refusal to declare a state of emergency formally under Article 52 of Kenya's 'reform' Constitution of 2010, which would have subjected these measures to procedural and human rights constraints. Rather, use was made throughout of Presidential decrees, without statutory basis, to announce disease control measures, and of the broadly framed Public Order Act, rather than the dedicated Public Health Act, as the basis for enforcing them. ${ }^{64}$ The latter step was upheld by the Nairobi High Court on the basis that 'panic and fear' might lead to extensive disorder requiring more than health-based measures in response. ${ }^{65}$ The authoritarian tone was amplified in media commentary, which noted that China's speedy reaction had been enabled by 'a decisional process ... unencumbered by layers of bureaucracy and government ... powers to enforce its measures from the top down' ${ }^{66}$

The President's speeches implied that the audience for the Government's securitising move was the whole citizenry. Code-switching between English (global, colonial) and Kiswahili (national vernacular and official language), he prophesied, that 'Our nation shall prevail, the aspirations of our destiny shall stand. Together we shall be victorious. Pamoja tutashinda. We can and we shall defeat the Coronavirus Pandemic'. ${ }^{67}$ This familiar mode of constituting an affirmative identity shared between speaker and hearers was undercut by the more coercive and accusatory rhetoric of the Cabinet Secretary for Health, Mutahi Kagwe. ${ }^{68}$ Emphasizing the need for discipline, he focused on violations of sanitary rules on public transport, for example, expressing 'disappointment with Boda Boda [motorbike taxi] operators who, despite our repeated advice, are carrying more than one passenger at a time... this is not the time for cat and mouse games. If it gets to that level of disobedience, we will have no choice but to deploy stiffer measures against you. ${ }^{69}$ He condemned 'young people who deliberately break curfew regulations

\footnotetext{
62 ibid Kenyatta 'Presidential Address on Enhanced Measures in Response to the COVID-19 Pandemic'.

${ }^{63}$ Oscar Gakuo Mwangi, 'The "Somalinisation" of Terrorism and Counterterrorism in Kenya: The Case of Refoulement,' (2019) 12 Critical Studies on Terrorism 298-316.

${ }^{64}$ This decision was upheld; 'Advisory Note on Ensuring a Rights-Based Response to Curb the Spread of COVID-19' (Aninas Community Networks for Development, 2020) $<$ https://icjkenya.org/attachments/article/312/Advisory\%20Note\%20on\%20Ensuring\%20a\%20Rights\%20Based\%20Response $\% 20$ t o\%20Curb\%20the\%20Spread\%20of\%20COVID-19\%2028-3-2020.pdf>.

${ }^{65}$ Law Society of Kenya v Hillary Mutyambai et al. Petition 120 of 2020 (Covid 025), High Court of Kenya at Nairobi (Constitutional and Human Rights Division) (Per Korir J at para 113), accessed online at $<$ http://kenyalaw.org/caselaw/cases/view/193192/>.

${ }^{66}$ Alexander Chagema 'Pandemic Has Exposed Leaders' Shortcomings' (The Standard, 19 March 2020), $<$ https://www.standardmedia.co.ke/article/2001364855/COVID-19-has-exposed-leaders-shortcomings>; Leonard Khafafa 'To Beat COVID-19, We Must Learn From China' (The Standards, 18 march 2020), $<$ https://www.standardmedia.co.ke/business/article/2001364621/to-beat-COVID-19-we-must-learn-from-china>.

${ }^{67}$ Uhuru Kenyatta 'Presidential Address on the State Interventions to Cushion Kenyans Against Economic Effects of COVID-19 Pandemic' (President of the Republic of Kenya, 25 March 2020), $<$ https://www.president.go.ke/2020/03/25/presidential-address-on-the-state-interventions-to-cushion-kenyans-againsteconomic-effects-of-COVID-19-pandemic-on-25th-march-2020/ >.

${ }^{68}$ Nancy Agutu, 'Kenyans are Indisciplined, Difficult in Fight Against Coronavirus-Kagwe' (The Star, 24 March 2020), $<$ https://www.the-star.co.ke/news/2020-03-24-kenyans-are-indiscipline-difficult-in-fight-against-coronavirus-kagwe/>.

${ }^{69}$ Mutahi Kagwe, 'National Emergency Response Committee on Coronavirus' (Kenyan Department of Health, 18 April 2020), <https:/www.health.go.ke/wp-content/uploads/2020/04/CamScanner-04-18-2020-15.24.47.pdf>.
} 
due to the false belief that they cannot catch this disease' ${ }^{70}$ Kagwe urged citizens to 'point out those in our midst who are not observing the measures, thereby putting our nation at great risk', a group described in media commentary as 'traitors' who belonged 'in the lowest circle of Hell with Judas Iscariot'. ${ }^{71}$ This impetus to exclude and condemn enemies of the people was bolstered by the (in fact wholly counterproductive) use of quarantine, originally intended for new arrivals from abroad, as a punishment for Kenyans violating disease-control measures. ${ }^{72}$

\section{COVID-19 and the Ideology of Order}

The foregoing bears out several features noted in critiques of securitization theory, especially as it applies in Global South contexts. First, we observe that the securitizing move is the result of an iterative process over a period of months, rather than a one-off speech act. Successive interventions complement each other by emphasizing different elements of the Copenhagen School formula. Law matters in this, but more by way of non-steps (i.e. failure to make a constitutional declaration) and formal technical choices (i.e. as between types of legislation, and in favour of decrees), than through the direct assumption of powers. In addition, we saw that coercive action did not flow mutely from antecedent verbal moves. Rather it also preceded statements, contributing of itself to their securitizing effect by creating an atmosphere of emergency. None of this happened in a historical vacuum. Presidential and ministerial statements explicitly or implicitly evoked lieux mémoires of Kenyan history, e.g. colonial depredations, the war against the Somali minority and related terrorist threat. More insidiously, the mode of address alternated between a bland inclusivity and an authoritarian call to discipline. Reinforced by police and state paramilitary deployments, these evocations reproduced the 'ideology of order' which has oriented the practice and self-image of the Kenyan state since its inception, according to E.S. Atieno Odhiambo. ${ }^{73}$ Anxious about territorial fragmentation and ethnic conflict elites have insisted 'at all times that sovereignty, national unity and national security are sacred and inviolate. ${ }^{74}$ As Makau Mutua argued, this is an essentially Hobbesian vision of the state as prior to and above normative entanglements, centralised and self-sufficient. ${ }^{75}$ Serious attempts have, of course, been made to tame the Kenyan Leviathan, e.g. by entrenching fundamental rights and subordinating the legal order to global governmentality regimes, as discussed above. But the ideology of order and related coercive routines

\footnotetext{
${ }^{70}$ Mutahi Kagwe, 'National Emergency Committee on Coronavirus' (Kenyan Ministry of Health, 21 April 2020), $<$ https://www.health.go.ke/wp-content/uploads/2020/04/CamScanner-04-21-2020-16.10.55.pdf<.

${ }^{71}$ Muthai Kagwe, 'National Emergency Response Committee on Coronavirus: Update on Coronavirus in the Country and Response Measures as at 7th April,' (Kenyan Department of Health, 21 April 2020) <https://www.health.go.ke/wpcontent/uploads/2020/04/FINAL-UPDATE-7TH-APRIL-2020.pdf>; Kingori Choto, 'Kenyans, A Great Nation is Built By Disciplined Citizens,' (Captial News, 1 April 2020) <https://www.capitalfm.co.ke/news/2020/04/kenyans-a-greatnation-is-built-by-disciplined-citizens/>; see also Adahere Cavince, 'Let's Adhere to Government Guidelines to Beat Pandemic,' (The Standard, 12 April 2020) <https://www.standardmedia.co.ke/article/2001367760/let-s-adhere-togovernment-directives-to-beat-pandemic $>$.

72 'Kenya: Quarantine Conditions Undermine Rights' (Human Rights Watch, 28 May 2020), $<$ https://www.hrw.org/news/2020/05/28/kenya-quarantine-conditions-undermine-rights $>$.

${ }^{73}$ E.S. Atieno-Odhiambo 'Democracy and the Ideology of Order in Kenya' in Michael G Schatzberg, The Political Economy of Kenya (Praeger, 1987)177-201.

74 ibid.

${ }^{75}$ Makau Mutua, Kenya's Quest for Democracy: Taming Leviathan (Foundation Publishers, 2008).
} 
remain to hand as a reflex response in times of political breakdown (e.g. disputed elections), ${ }^{76}$ security crises (e.g. terrorist attacks) ${ }^{77}$ and, now, pandemic outbreak.

\section{Conclusion}

In conclusion, a qualification is required. The greater and lesser prominence of 'securitization' and 'indicator culture' respectively in Kenya in the early months of the COVID-19 pandemic suggests a moment in which the governmentality network of global health was eclipsed by the more forthright exercise of national sovereignty as regards disease control. However, this is only a tentative conclusion. Further investigation is required covering the subsequent career of the (unfortunately) ongoing pandemic. Attention also needs to be paid to continued vigour (or not) of other elements in the ensemble of globalized health governance, including litigation based on UN human rights norms, for example. It is certainly too early to draw definitive conclusions about 'the return of the nation state'. Particularly risky here would be any extrapolation from the self-sufficient posture adopted in Washington or Beijing to the case of Global South states which remain dependent on overseas aid for much of their health budgets, and on the normative output of the WHO and other bodies for the organizational substance of their public health systems. Finally, further investigation is required on the extent to which indicators partake of both global governmentality and securitization. We saw above that Kenyan commentators used indicators to criticize and (it was hoped) constrain the unscientific action and inaction of the authorities. But indicators were equally used by foreign observers to make catastrophic predictions regarding the spread of COVID-19 in Africa as a whole. This runs together the mode of government by numbers with a longer established idiom of the continent as an exceptional space of infection. ${ }^{78}$ The latter evokes dread and tends to counsel defensive self-isolation on the part of Northern states.

\footnotetext{
${ }^{76}$ John Harrington and Ambreena Manji 'Restoring Leviathan? The Kenyan Supreme Court, Constitutional Transformation, and the Presidential Election of 2013,' (2015) 9 Journal of Eastern African Studies 175-192.

${ }^{77}$ John Harrington, ‘\#weareone: Blood Donation, Terrorism and Dreams of Inclusion in Kenya,’ (2020) 90 Africa 112.

${ }^{78}$ See A Hirsch, 'Why are Africa's Coronavirus Successes being Overlooked?' (The Guardian 21 May 2020). <https://www.theguardian.com/commentisfree/2020/may/21/africa-coronavirus-successes-innovation-europe-us>.
} 


\section{Mapping the Causal Relationships Between Indicators in the COVID-19 Crisis}

Mathias Siems*

\section{Introduction}

Many academic disciplines aim to identify causal relationships. This is the case for the natural sciences but frequently also the social sciences. For example, is has been said that ethnography has the 'ability to uncover causal mechanisms and trace processes'. ${ }^{1}$ Yet, more commonly, it is quantitative research using inferential statistics that aims to provide robust proof of causal relationships. In this regard, indicators of social phenomena play a key role in providing researchers with the necessary data that can be used in econometric research. In addition, indicators can have more direct causal ambition, as some of them have the explicit aim to influence behaviour. For example, this is the case for the various governance and law-related indicators issued by international organisations such as the World Bank. ${ }^{2}$ Research by Davis et al. calls this the 'governance effect of indicators' ${ }^{3}$ and this potentially widereaching impact of indicators has also been discussed under the perspective of the legitimacy of indicators. ${ }^{4}$

With regards to the COVID-19 crisis, the causal relationship between indicators may be rather straightforward. According to George et al's article 'A Guide to Benchmarking COVID-19 Performance Data', there is a simple causal link between two sets of indicators. On the one side, we have 'policy and strategy indicators', 'capacity indicators' and 'environment indicators' which, on the other side, have an impact on 'output and outcome indicators', specifically 'testing for COVID-19' and 'COVID-19 deaths'. Figure 1 illustrates this position.

Figure 1: George et al's position on indicators in the COVID-19 crisis

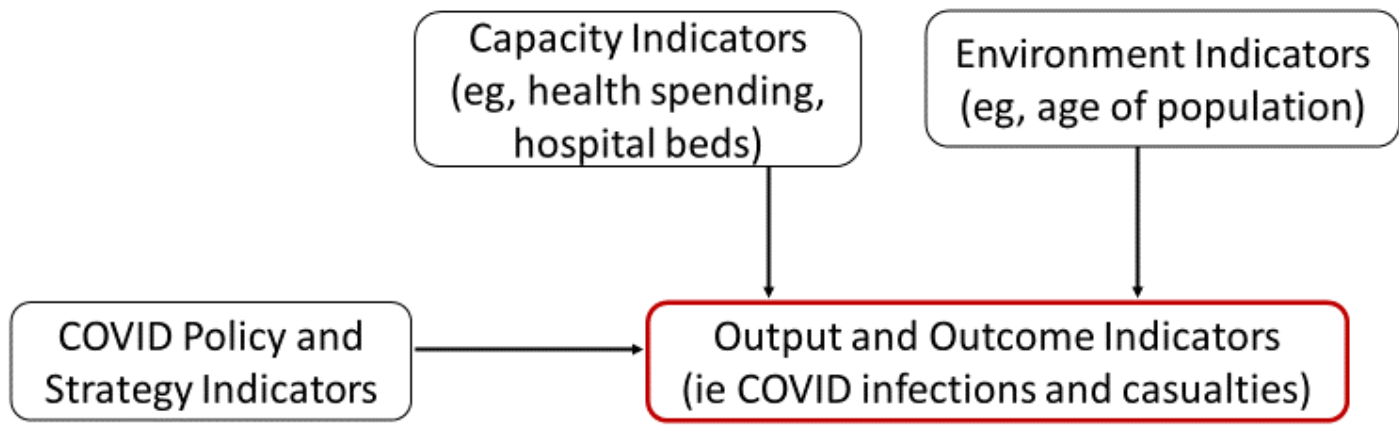

\footnotetext{
* Mathias Siems, European University Institute and Durham University (mathias.siems@eui.eu).

${ }^{1}$ Gabriel Abend, Caitlin Petre and Michael Sauder, 'Styles of Causal Thought: An Empirical Investigation' (2013) 119 American Journal of Sociology 602 at 606.

${ }^{2}$ Eg, the 'Worldwide Governance Indicators' $(W G I)<$ https://info.worldbank.org/governance/wgi/>, and the Doing Business Reports (Doing Business) <https://www.doingbusiness.org/>.

${ }^{3}$ Kevin Davis, Benedict Kingsbury and Sally Engle Merry, 'Indicators as a Technology of Global Governance' (2012) 46 Law and Society Review 71.

4 'Global Social Indicators: Constructing Transnational Legitimacy', Special Issue of the International Journal of Law in Context, vol. 13, issue 4 (pp. 433-573), 2017 (edited by David Nelken and Mathias Siems).

${ }^{5}$ Bert George, Bram Verschuere, Ellen Wayenberg and Bishoy Louis Zaki, 'A Guide to Benchmarking COVID-19 Performance Data' (2020) Public Administration Review 696 at 698.
} 
It is the aim of this contribution to challenge this simple narrative and suggest a more complex relationship between the various indicators in the COVID-19 crisis. It will do so by way of presenting a more complex stylised chart that incorporates the possibility of feedback mechanisms. Naturally, such a chart cannot consider all possible considerations that can play a role in reality. Thus, while the following aims to go beyond the causal relationship suggested by George et al, it does accept their general idea that it is fruitful to think about causal relationships between indicators in the COVID crisis.

\section{Mapping COVID-Indicators}

Figure 2: Possible causal relationships between indicators in the COVID-19 crisis

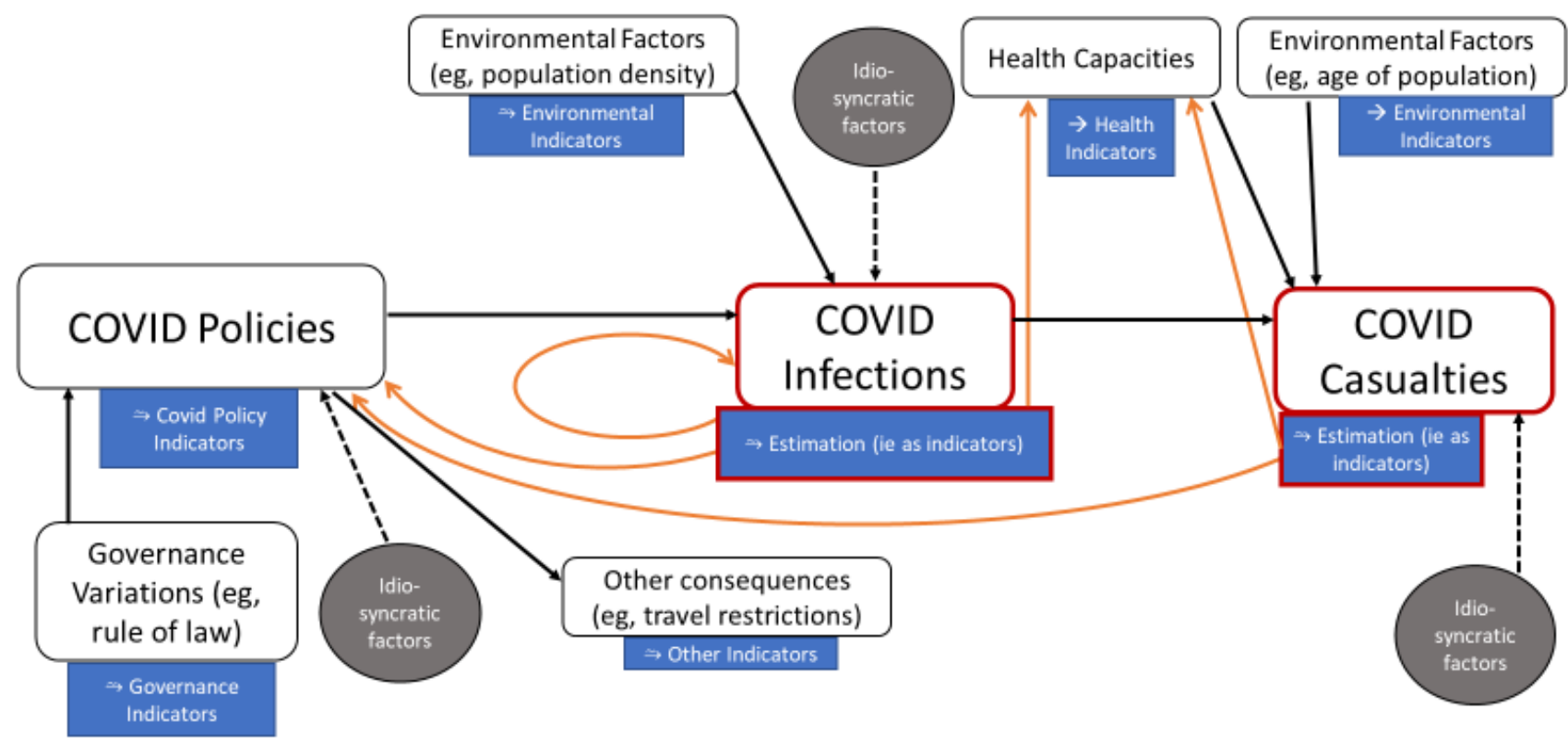

The 'main narrative' of Figure 2 incorporates the position by George et al, notably the causal link between COVID policies and infections/casualties. With respect to indicators on health capacities ${ }^{6}$ and environmental factors (e.g. population density or age of population), ${ }^{7}$ the chart distinguishes between the impact on COVID infections and on COVID casualties. ${ }^{8}$ Stating that there are such links is not meant to imply that there is always a causal relationship between the relevant factors. For example, there was no causality between COVID policies and infections for the first COVID cases. At the same time, it is of course possible that certain factors, such as health capacity, do not have an impact on the number of COVID deaths.

Going beyond George et al., the following suggests further key issues that are of relevance for the causal relationships between indicators in the COVID-19 crisis: variations of governance and idiosyncratic factors, the distinction between the indicator and the object, as well as possible feedback mechanisms.

\footnotetext{
${ }^{6}$ See also Nirmal Kandel, Stella Chungong, Abbas Omaar and Jun Xing, 'Health Security Capacities in the Context of COVID-19 Outbreak: An Analysis of International Health Regulations Annual Report Data from 182 Countries' (2020) 395 The Lancet 1047.

${ }^{7}$ George et al (n 5) at 699.

${ }^{8}$ Thus, in this chart and the following text, 'COVID' refers to both the virus 'SARS CoV-2' and the disease 'COVID-19'.
} 
The role of variations of governance and idiosyncratic factors

The chart presented in Figure 2 shows that COVID policies can reflect variations of governance. For example, it has been discussed how far autocratic political systems - or, more generally, countries with a low rating in rule of law indicators - may be able to impose and implement harsher COVID lockdown measures. ${ }^{9}$ Beyond the aspired reduction of COVID infections, it is also clear that COVID policies have further implications on society. Those can be knock-on effects, for example, how lockdown policies affect the ability to travel and crime rates. ${ }^{10}$ They can also be of a deliberate nature, for example, policies that provide financial support and relief to business and citizens. ${ }^{11}$

The chart also suggests that idiosyncratic factors can play a role for both policies and infections/casualties. With respect to COVID policies, for example, a recent newspaper article states that a single local council official who imposed the first lockdown may have prevented a major COVID outbreak at the beginning of the pandemic in Germany. ${ }^{12}$ As regards COVID infections and casualties, idiosyncratic factors mean that these numbers should not simply be seen as a result of governments having 'failed' or 'succeeded' in their COVID policies and provision of health capacities. ${ }^{13}$ For example, in the Italian region of Lombardy, it was perhaps simply bad luck that a football game of Atalanta Bergamo coincided with the first COVID cases and thus led to a fast and wide spread of the virus in this region (and in Bergamo in particular). ${ }^{14}$ While an indicator of major sports events could fall under the heading of 'environment factors', this would not capture the fact that this particular event happened at this particular date. Moreover, it is the nature of the virus that even the behaviour of one single person can matter if this person sets in course a chain of infections that leads to its spread in the population.

The distinction between the indicator and the object

The text so far (as well as the paper by George et al) has not yet distinguished between the indicator ${ }^{15}$ and the object the indicator is meant to represent. Yet, this distinction is crucial in order to fully understand the role of indicators in the COVID crisis. Therefore, Figure 1 always distinguishes between

${ }^{9}$ Ugo Mattei, Liu Guanghua and Emanuele Ariano ‘The Chinese Advantage in Emergency Law' (2020) Global Jurist $<$ https://www.degruyter.com/view/journals/gj/ahead-of-print/article-10.1515-gj-2020-0032/article-10.1515-gj-20200032.xml>.

${ }^{10}$ For the former see for example, 'International Travel Restrictions in the Response to the COVID-19 Outbreak' available at <https://public.tableau.com/profile/nccr.on.the.move\#!/vizhome/Covid-19outbreak_15843550159920/Lists>. For the latter, see for example George Mohler et al., 'Impact of Social Distancing During COVID-19 Pandemic on Crime in Los Angeles and Indianapolis' (2020) 16 Journal of Criminal Justice 101692.

${ }^{11}$ See for example, Giliberto Capano, Michael Howlett, Darryl SL Jarvis , M Ramesh and Nihit Goyal, 'Mobilizing Policy (In)Capacity to Fight COVID-19: Understanding Variations in State Responses' (2020) 39 Policy and Society 285.

12 'The local council official who stopped coronavirus in Germany' (The Telegraph, 29 July 2020), <https://www.telegraph.co.uk/news/2020/07/29/local-council-official-stopped-coronavirus-germany/>.

${ }^{13}$ As sometimes done by the media. See for example, 'As governments fumbled their coronavirus response, these four got it right. Here's how' (CNN, 16 April 2020) <https://edition.cnn.com/2020/04/16/world/coronavirus-response-lessonslearned-intl/index.html>. For a different approach, namely a cross-country survey, see 'US and UK are bottom of the pile in rankings of governments' handling of coronavirus pandemic' (CNN, 27 August 2020), <https://edition.cnn.com/2020/08/27/world/global-coronavirus-attitudes-pew-intl/index.html>.

14 'How Atalanta's feel-good Champions League story became a "biological bomb" for coronavirus in Italy, Spain' (ESPN, 3 April 2020) <https://www.espn.com/soccer/italian-serie-a/story/4081211/how-atalantas-feel-good-champions-leaguestory-became-a-biological-bomb-for-coronavirus-in-italyspain>.

${ }^{15}$ For these purposes, this contribution applies a wide notion of indicators. Yet, it is also possible to identify a canon of characteristics, see Marta Infantino, Global Numbers in the Pandemics: The Spread of Indicators and How to Spot Them (in this Working Paper). 
both categories, indicating with ' $\Rightarrow$ ' that the relationship is only an approximate one. How far it is 'close', depends on the quality of the indicator and the context in which it is applied. For example, indicators that aim to measure COVID policies ${ }^{16}$ may work for countries that have enacted conventional measures (lockdowns, face-mask requirements etc) which are well enforced. However, this may not be the case for countries with more idiosyncratic rules, or where the law in the books and the law in practice diverge. ${ }^{17}$ Additionally, there are many different ways COVID infection data can be presented (e.g., as absolute numbers, per capita numbers, reproduction number, test positivity rate, infections with symptoms, infections requiring hospitalisation), and even with respect to COVID fatality data, it has been controversial to determine how persons with multiple health conditions are accounted for, and whether 'excess deaths' data is a more objective measurement. ${ }^{18}$

Given the degree of subjectivity that is involved in any construction of indicators, it is important that COVID indicators (too) are as clear and transparent as possible. This raises concerns, for example, for the COVID 'Safety Assessments' published by the private venture capital company Deep Knowledge Ventures as it includes undisclosed 'proprietary metrics'. ${ }^{19}$ As far as it can be determined, their ranking also combines diverse elements related to the number of infections, government policy, health capacity and so forth, which makes it difficult to see what such ranking of countries really tell us.

\section{Possible feedback mechanisms}

The distinction between indicator and object is also important because it enables us to understand the feedback mechanism of the chart (orange lines in Figure 2). Notably, it is possible that there is also a reverse causal relationship, given that COVID infections and casualties also affect COVID policies through the indicators of those infections and casualties. Governments may have better access to information than newspapers that report on the actual numbers. Yet, it is clear that, given the many asymptomatic infections, it is impossible to know the true total number of COVID infections. Thus, governments are bound to act on the imperfect numbers that exist. This is the case for governments that act honestly, while it is also evident that some governments have tried to count infections or casualties in a way that serves their own purposes. ${ }^{20}$ In addition, there is a feedback mechanism to health capacities and here, too, one would hope that governments use the best estimates possible in order to decide on future measures. ${ }^{21}$

Finally, the chart indicates that there can be a direct feedback mechanism between the indicators of COVID infections and the true number of infections. As the former numbers are published in newspapers, on websites, by governments themselves or through other means, the public are aware of them. In fact, data from Germany shows that citizens estimate the risk of becoming severely ill as even

\footnotetext{
${ }^{16}$ The most prominent one is Oxford's Stringency Index, available at <https://www.bsg.ox.ac.uk/research/researchprojects/coronavirus-government-response-tracker>.

${ }^{17}$ In this regard, these indicators share the problems of other overly generic and legalist indicators, for example, the World Bank's Doing Business Reports (n 2).

${ }^{18}$ See for example, Aurelia Colombi Ciacchi, 'The covid-19 Crisis: A Challenge for Numeric Comparative Law and Governance' (2020) 7 European Journal of Comparative Law and Governance 109; 'Coronavirus: Why are international comparisons difficult?' (BBC, 17 June 2020) <https://www.bbc.com/news/52311014>.

${ }^{19}$ The Deep Knowledge Group's 'COVID-19 Regional Safety Assessment' available at <https://www.dkv.global/covid>.

${ }^{20}$ See for example, 'Serbia Under-Reported COVID-19 Deaths and Infections, Data Shows' (Balkan Insight, 22 June 2020), <https://balkaninsight.com/2020/06/22/serbia-under-reported-covid-19-deaths-and-infections-data-shows/>.

${ }^{21}$ For a similar position see Linda Hantrais, 'Comparing European reactions to Covid-19: Why policy decisions must be informed by reliable and contextualised evidence' (LSE Blog, 19 May 2020), <https://blogs.lse.ac.uk/europpblog/2020/05/19/comparing-european-reactions-to-covid-19-why-policy-decisions-mustbe-informed-by-reliable-and-contextualised-evidence/>.
} 
higher than the actual risk. ${ }^{22}$ Thus, it also seems likely that the public will take this information into account when considering their own behaviour - for instance, in terms of applying forms of 'social distancing'. This governance effect of indicators ${ }^{23}$ can also be used to inform government policy, for example, to improve acceptance and compliance with restrictions on mobility (or even to decide whether softer forms of restrictions may be sufficient ${ }^{24}$ ).

\section{Conclusion}

It may be asked whether the mapping of causal relationships in this contribution could be used as a basis for empirical quantitative work. It is a limitation of this contribution that it has addresses the various elements at a general level. Intuitively, Figure 2 may refer to the state/country level, as states determine many COVID-related policies. Moreover, indicators (and data) are typically counted at the national level. However, the COVID crisis is also a case study that shows how very local events can have a global impact. Additionally, it demonstrates that, even within the same country, very different dynamics come into play in different local areas and regions. It also seems likely that not only infections cross borders, but that government policies too are influenced by developments in other countries. ${ }^{25}$ Thus, even if one considered only the state level, it would be a statistical problem that the units are not independent of each other. ${ }^{26}$ All of this does not mean that empirical work is not feasible. Nonetheless, it would need to go beyond the current level of empirical research of the policy responses to the COVID crisis.

${ }^{22}$ Ralph Hertwig et al, 'Wie gefährlich ist COVID-19? Die subjektive Risikoeinschätzung einer lebensbedrohlichen COVID19-Erkrankung im Frühjahr und Frühsommer 2020 in Deutschland (July 2020) <https://www.soep-cov.de/Berichte/>. The WHO also conducts surveys on risk perceptions, see 'WHO tool for behavioural insights on COVID-19' (WHO) <https://www.euro.who.int/en/health-topics/health-emergencies/coronavirus-covid-19/technical-guidance/who-tool-forbehavioural-insights-on-covid-19>.

${ }^{23}$ Davis et al (n 4) at 699.

${ }^{24}$ This seems to be the position of the Swedish government; cf 'Social distancing and markedly reduced travel in Sweden' (Government Offices of Sweden, 18 June 2020), https://www.government.se/articles/2020/06/social-distancing-andmarkedly-reduced-travel-in-sweden/.

${ }^{25}$ See for example, Cindy Cheng et al, 'COVID-19 Government Response Event Dataset (CoronaNet v.1.0)' (2020) 4 Nature Human Behaviour 756; Magnus Lundgren et al, 'Emergency Powers in Response to COVID-19: Policy Diffusion, Democracy, and Preparedness', Faculty of Law, Stockholm University Research Paper No. 78 (2 July 2020), available at $<$ https://ssrn.com/abstract=3641384>.

${ }^{26}$ Thus, this is a variant of 'Galton's problem'; cf generally Raoul Naroll, 'Galton's Problem: The Logic of Cross Cultural Analysis' (1965) 32 Social Research 428. 
